\title{
Metabolic rewiring of the failing heart
}

Citation for published version (APA):

Kuhn, A-R. (2021). Metabolic rewiring of the failing heart: unravelling cause and effect. [Doctoral Thesis, Maastricht University]. Ridderprint. https://doi.org/10.26481/dis.20211118ak

Document status and date:

Published: 01/01/2021

DOI:

10.26481/dis.20211118ak

Document Version:

Publisher's PDF, also known as Version of record

\section{Please check the document version of this publication:}

- A submitted manuscript is the version of the article upon submission and before peer-review. There can be important differences between the submitted version and the official published version of record.

People interested in the research are advised to contact the author for the final version of the publication, or visit the DOI to the publisher's website.

- The final author version and the galley proof are versions of the publication after peer review.

- The final published version features the final layout of the paper including the volume, issue and page numbers.

Link to publication

\footnotetext{
General rights rights.

- You may freely distribute the URL identifying the publication in the public portal. please follow below link for the End User Agreement:

www.umlib.nl/taverne-license

Take down policy

If you believe that this document breaches copyright please contact us at:

repository@maastrichtuniversity.nl

providing details and we will investigate your claim.
}

Copyright and moral rights for the publications made accessible in the public portal are retained by the authors and/or other copyright owners and it is a condition of accessing publications that users recognise and abide by the legal requirements associated with these

- Users may download and print one copy of any publication from the public portal for the purpose of private study or research.

- You may not further distribute the material or use it for any profit-making activity or commercial gain

If the publication is distributed under the terms of Article $25 \mathrm{fa}$ of the Dutch Copyright Act, indicated by the "Taverne" license above, 


\section{METABOLIC REWIRING OF THE FAILING HEART \\ - UNRAVELING CAUSE AND EFFECT}

Annika-Ricarda Kuhn 


\section{COLOFON}

Cover design: Csilla Kuhn

Layout: Csilla Kuhn \& Annika-Ricarda Kuhn

Printing: Ridderprint | www.ridderprint.nl

ISBN: 978-94-6416-798-6

\section{Copyright $\odot 2021$ by Annika-Ricarda Kuhn.}

All rights reserved. Any unauthorized reprint or use of this material is prohibited. No part of this thesis may be reproduced, stored or transmitted in any form or by any means, without written permission of the author or, when appropriate, of the publishers of the publications. 


\title{
Metabolic rewiring of the failing heart - unraveling cause and effect
}

\author{
DISSERTATION \\ to obtain the degree of Doctor at Maastricht University, \\ on the authority of the Rector Magnificus Prof. dr. Rianne M. Letschert \\ in accordance with the decision of the Board of Deans, \\ to be defended in public on
}

Thursday 18 November 2021 at 14.00 hours (CEST)

by

Annika-Ricarda Kuhn

born on 30 March 1993

in Lutherstadt-Wittenberg, Germany 


\section{Supervisor}

Prof. dr. Blanche Schroen

\section{Co-supervisor}

Dr. Marc van Bilsen

\section{Assessment Committee}

Prof. dr. Leon Schurgers (Chair)

Dr. Ebba Brakenhielm (University of Rouen, France)

Prof. dr. Christoph Maack (University of Würzburg, Germany)

Prof. dr. Judith Sluimer

Dr. Sander Verheule

Financial support by the Dutch Heart Foundation for the publication of this thesis is gratefully acknowledged. 
There isn't a way things should be. There's just what happens, and what we do.

- Terry Pratchett 



\section{CONTENTS}

Chapter 1 General Introduction 9

Chapter 2 Metabolic Rewiring as modulator of cardiac failure: Lessons 19 from cancer research

Chapter 3 A directed network analysis of the cardiome identifies molecular pathways contributing to the development of $\mathrm{HFpEF}$

Chapter 4 Dysfunctional mitochondrial metabolism is a hallmark of HFpEF

Chapter 5 Metabolic cues modulate cardiac fibroblast phenotype and 163 function

Chapter 6 AntagomiR-103/107 treatment affects cardiac function and 203 metabolism

Chapter 7 General Discussion

Addendum Summary| Samenvatting | Zusammenfassung

Impact

Acknowledgements

About the author 
chapter

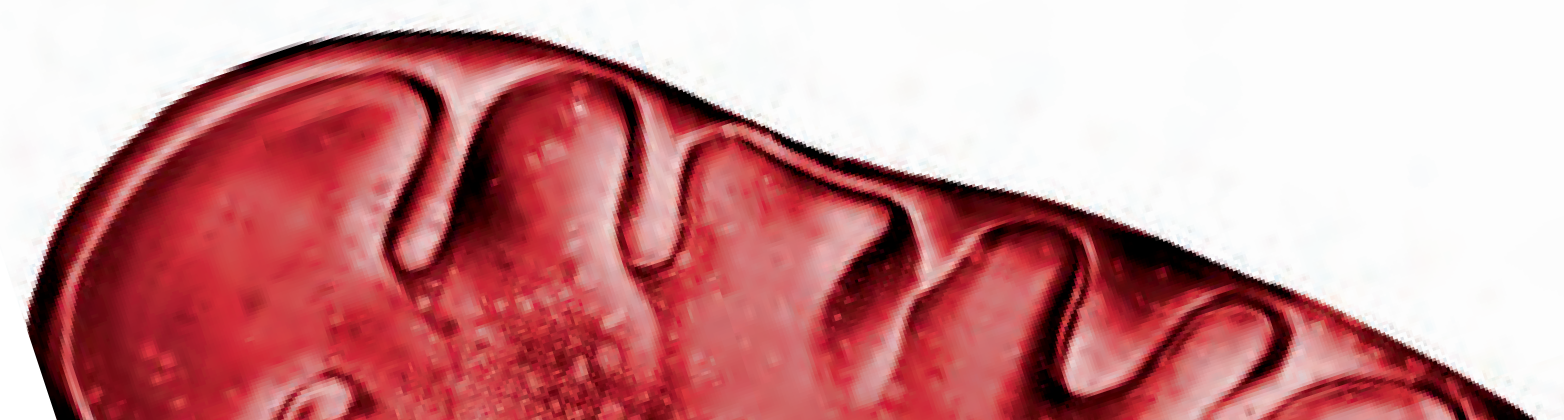




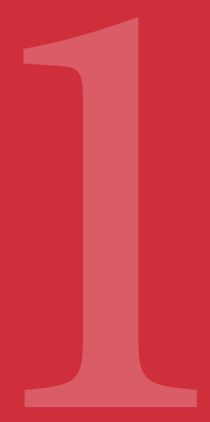

General Introduction 


\section{Pathophysiology of heart failure}

HFpEF from a clinical perspective: Cardiovascular disease remains a principal cause of morbidity and mortality, accounting for $31 \%$ of annual deaths globally. ${ }^{1}$ The prevalence of heart failure keeps rising, primarily due to an expanding, ageing population. ${ }^{2}$ Although previously less common than heart failure with reduced ejection fraction (HFrEF), heart failure with preserved ejection fraction (HFpEF) now accounts for almost half of all HF cases and will be the predominant form of HF within the next decade. ${ }^{3}$ In HFpEF, left ventricular relaxation or filling are impaired, leading to diastolic dysfunction concurrent with unchanged systolic function, hence displaying a preserved ejection fraction. HFpEF is a heterogenous syndrome frequently observed in concurrence with comorbidities associated with the metabolic syndrome (MetS), such as type-2-diabetes, obesity, hyperlipidemia and hypertension, accompanied by systemic metabolic alterations and low-grade chronic inflammation. ${ }^{4,5}$ As a result of our western-style diet and increasingly sedentary lifestyle, the prevalence of MetS has similarly been on the rise, currently afflicting $12-19 \%$ of the Dutch population. ${ }^{6}$ MetSassociated HFpEF development is therefore likely to increase even further in prevalence, underlining the urgent need for successful prevention and treatment strategies in this subset of HFpEF patients.

Treatment strategies currently available for HFpEF are primarily based on those successfully utilized in HFrEF, but unfortunately do not substantially reduce HFpEF mortality. ${ }^{7,8}$ Further elucidation of the pathophysiological mechanisms at play in HFpEF is therefore key in the development of therapies aimed at prevention or treatment of the disease.

HFpEF from a pathophysiological perspective: From a pathophysiological point of view the diastolic dysfunction that marks HFpEF can be caused by impaired relaxation or increased stiffness of the myocardium. In turn, increased passive stiffness of the myocardium can involve changes either outside or inside the cardiomyocyte. In the first case there is increased extracellular matrix deposition by cardiac fibroblasts, leading to interstitial fibrosis. In the second case, stiffness of the cardiomyocytes themselves is increased, primarily due to changes in the protein titin. Titin is a giant protein, one molecule spanning the length of an entire sarcomere, that is believed to have 'spring-like' properties, thereby acting as an important determinant of cardiomyocyte stiffness. ${ }^{9}$

An attractive hypothesis that has dominated this field for a long time, links the MetS-related systemic changes with increased cardiomyocyte stiffness. It states that systemic low-grade inflammation evokes generalized microvascular dysfunction, also involving the cardiac microvasculature. The cardiac endothelial dysfunction leads to increased oxidative stress and impaired NO signaling, ultimately affecting cardiomyocyte stiffness due to modification of titin. ${ }^{10}$ However attractive, the evidence in support of this molecular pathophysiological mechanism is still incomplete. In the meantime, variations on the original hypothesis have emerged and alternative hypotheses have been postulated, which also implicated disturbances in cardiac energy metabolism as a contributing factor in the development of $\mathrm{HFpEF}$. It has been postulated that the insulin resistance associated with MetS will directly 
affect cardiac energy metabolism ${ }^{11}$, that cardiac microvascular dysfunction may lead to a mismatch in cardiac oxygen supply and demand ${ }^{12}$, and that the increased oxidative stress stems from disturbances in cardiomyocyte mitochondrial metabolism ${ }^{13}$ rather than endothelial dysfunction.

\section{Animal models to fill the knowledge gap of metabolic rewiring in HFpEF}

Historically, HFpEF has been investigated primarily in terms of cardiac hypertrophy and diastolic dysfunction. The significance of alterations in cardiac energy and substrate metabolism in HFpEF pathophysiology, although commonly associated with the development of cardiac hypertrophy and failure, is still debated. ${ }^{14-17}$ The main aim of this thesis is to address this knowledge gap and document the role of (disturbances in) cardiac energetics in HFpEF pathophysiology. Given the scarce access to human cardiac tissue - there is no ethically acceptable reason to obtain cardiac biopsies on a sufficient scale from HFpEF patients - and insufficient complexity of cellular models, such endeavors still require animal models. The systemic effects and multiorgan involvement owed by different comorbidities in HFpEF patients, in particular involving MetS, underline the importance of fitting animal models to match the clinical complexity as much as possible. To this end rodent models of HFpEF have been developed and validated, for instance by combining a high-fat diet and L-NAME supplementation, thereby inducing obesity and insulin resistance (high-fat diet) and hypertension (L-NAME) ${ }^{18}$ In this thesis, we made use of the ZSF1-Obese rat, a genetic model of MetS-induced HFpEF. ZSF1-Obese rats are an F1 hybrid offspring of Spontaneously Hypertensive Heart Failure $\left(\mathrm{SHHF},+/ \mathrm{fa}^{\mathrm{cp}}\right)$ and Zucker Diabetic Fatty (ZDF, +/fa) rats, inheriting two distinct leptin receptor mutations (fa and fa ${ }^{\mathrm{cp}}$ ). Both the ZSF1-Lean and ZSF1Obese rats inherit the gene for hypertension (SHR-Mcc). However, only ZSF1-Obese rats suffer from obesity, hyperlipidemia, hypertension and diabetes, the typical comorbidities associated with MetS, and have been extensively documented to develop diastolic dysfunction and a reduced exercise capacity, the typical clinical hallmarks of HFpEF. ${ }^{19,} 20$

\section{Cardiac metabolism in health and disease}

Mitochondrial oxidation of fatty acids (60-90\%), glucose and lactate (totaling 10-40\%) primarily supplies the chemical energy, in form of Adenosine-5'-triphosphate (ATP), needed for the rhythmic contraction and relaxation of the healthy heart. The proportion of these substrates to cardiac ATP production alters dynamically, with increased circulating fatty acid levels reducing glucose and lactate use and vice versa. ${ }^{21}$ Accordingly, the healthy heart is an omnivorous organ, adjusting its substrate use depending on supply via the circulation. This metabolic flexibility gets compromised in heart failure. In HFrEF, cardiac glucose utilization is typically increased and the capability for mitochondrial oxidization of fatty acids becomes limited. ${ }^{17}$ This increased glucose uptake might at first glance appear as a beneficial, energy efficient response, since glucose oxidation generates more ATP per oxygen atom than that of fatty 
acids. However, the coupling of glucose uptake and glucose oxidation in heart failure is diminished and glucose is partially converted into lactate, reducing the ultimate ATP yield. ${ }^{22}$ In contrast, in the diabetic heart, cardiac substrate availability and utilization is limited in a different fashion: Due to insulin resistance, cardiac uptake of glucose is restricted and the cardiac metabolism is predisposed towards enhanced reliance on fatty acid utilization. ${ }^{23}$ Unlike glucose, the generation of ATP via the metabolism of fatty acids is fully dependent on the availability of oxygen. As a result, the cardiometabolic landscape during MetS-associated HFpEF is different from that associated with HFrEF, and the consequences of these differences are yet to be fully understood.

\section{Control of cellular processes by metabolic pathways - implications for therapy}

In cancer cells, high rates of aerobic glycolysis provide extra intermediates for anabolic processes, generating building blocks for DNA synthesis among others, and ultimately allowing proliferation and malignant growth of the tumor. ${ }^{24}$ This is just one example of how the principal metabolic pathways can affect cells beyond energy supply and demand. Thus, through modifications in the employment of principal metabolic pathways, not only substrate use and ATP generation are affected, but also cellular function and phenotype can be considerably adjusted. It is well conceivable that similar mechanisms play a role in HF development. Remodeling of the heart is dependent on phenotypical changes of several cardiac cell types, the most well-known being cardiomyocytes undergoing hypertrophic growth, and fibroblasts proliferating and transdifferentiating to myofibroblasts to promote fibrotic remodeling. Indeed, hypertrophic growth of cardiomyocytes is associated with increased glucose uptake as well as a switch from fatty acid oxidation to glycolysis and, in turn, this metabolic remodeling is associated with changes in important cardiomyocyte processes including ionic and redox homeostasis, unfolded protein response and autophagy. ${ }^{25}$ Presumably, such bidirectional effects also take place in cell types other than cardiomyocytes upon alterations of the cardiometabolic environment. However, little is known on how metabolic rewiring in the HFpEF heart contributes to diastolic dysfunction; which cells and cellular processes are affected by this process and in which way? In view of this complexity, it also makes it challenging to predict the potential impact of any metabolic therapeutic interventions on cardiac function.

\section{Post-transcriptional regulation of metabolic processes by microRNAs}

MicroRNAs (miRNAs) provide another level at which critical processes in disease development, including cardiac contraction and metabolism, are controlled. MicroRNAs are small non-coding RNA molecules that have attracted massive attention for their therapeutic potential. They act as posttranscriptional modulators and regulate major cell functions, including cellular metabolic pathways. ${ }^{26}$ Multiple miRNAs have been implicated in HF development as well as obesity and type-2-diabetes, as recently reviewed by our group and others. ${ }^{27-29}$ Modulatory strategies for miRNAs confer considerable therapeutic potential and 
are subject of different clinical trials in the treatment of cardiovascular and metabolic diseases. ${ }^{30}$ An example of this is miR-103/107: These paralog miRNAs were documented to regulate insulin sensitivity and their antagomiR-mediated inhibition improved insulin sensitivity and glucose tolerance in obese mice ${ }^{31}$, leading to clinical investigations into their therapeutic potential in patients with type-2-diabetes and fatty liver disease (NCT02826525).

\section{Scope and outline of the thesis}

Given the increasing recognition of the importance of metabolic changes in heart failure development, the main goal of this thesis was to map and identify metabolic alterations to uncover underlying mechanisms governing disease progression.

In chapter 2, we extensively review the role of cardiac metabolic rewiring in heart failure pathogenesis. For this, deriving inspiration from recent advancements in cancer research, we look beyond the effect of metabolic changes on energy balance. In this review, we provide an overview of the alterations in the principal metabolic pathways in context of their impact on phenotype and function of different cardiac cell types and discuss in what way these processes may contribute to heart failure development.

To identify putative critical processes and genes involved in the development of HFpEF, in chapter 3 we developed a novel cardiome-directed bioinformatic network analysis and applied this to RNA-Seq data from hearts of ZSF1-Obese and ZSF1-Lean rats.

To build upon these results and further investigate metabolic derangements in HFpEF, we assessed global circulating and cardiac metabolite alterations via transcriptomics, metabolomics and MALDI-Mass Spectrometry Imaging (MSI) in the ZSF1-Obese model of MetS-induced HFpEF in chapter 4.

Given the central role of cardiac fibrosis in determining cardiac stiffness and the largely unknown contribution of metabolic rewiring to fibroblast phenotype and functions, we studied the influence of metabolic alterations on fibroblast activation and transdifferentiation in chapter 5. Thereto, we modulated glycolysis in vitro and assessed the effect of these interventions on cardiac fibroblast phenotype and function. Additionally, to document cardiac pathology-driven changes in metabolite content of fibroblasts, the fibroblast-rich infarct zone of rat hearts was subjected to MALDI-MSI over the course of acute and subacute phases of infarct healing, which are associated with fibroblast activation and transdifferentiation.

In chapter 6 we assessed the impact of inhibitory strategies for miR-103/107, which previously have been shown to regulate insulin sensitivity and systemic glucose metabolism, on cardiac function and phenotype in mice. In an in vitro setting we explored metabolic effects 
of miR-103/107 inhibition in cardiomyocytes by assessing substrate uptake, metabolic fluxes, as well as by live-cell imaging of mitochondrial function.

Finally, chapter 7 summarizes the research of this thesis and implications of the experimental results are discussed in a broader context, including limitations of the studies and opportunities for future research. 


\section{References}

1. Mortality GBD, Causes of Death C. Global, regional, and national life expectancy, allcause mortality, and cause-specific mortality for 249 causes of death, 1980-2015: a systematic analysis for the Global Burden of Disease Study 2015. Lancet 2016;388:14591544.

2. Ponikowski P, Anker SD, AlHabib KF, Cowie MR, Force TL, Hu S, Jaarsma T, Krum H, Rastogi V, Rohde LE, Samal UC, Shimokawa H, Budi Siswanto B, Sliwa K, Filippatos G. Heart failure: preventing disease and death worldwide. ESC Heart Fail 2014;1:4-25.

3. Dunlay SM, Roger VL, Redfield MM. Epidemiology of heart failure with preserved ejection fraction. Nat Rev Cardiol 2017;14:591-602.

4. Savji N, Meijers WC, Bartz TM, Bhambhani V, Cushman M, Nayor M, Kizer JR, Sarma A, Blaha MJ, Gansevoort RT, Gardin JM, Hillege HL, Ji F, Kop WJ, Lau ES, Lee DS, Sadreyev R, van Gilst WH, Wang TJ, Zanni MV, Vasan RS, Allen NB, Psaty BM, van der Harst P, Levy D, Larson M, Shah SJ, de Boer RA, Gottdiener JS, Ho JE. The Association of Obesity and Cardiometabolic Traits With Incident HFpEF and HFrEF. JACC: Heart Failure 2018;6:701-709.

5. Grundy SM. Metabolic syndrome pandemic. Arterioscler Thromb Vasc Biol 2008;28:629636.

6. Slagter $\mathrm{SN}$, van Waateringe $\mathrm{RP}$, van Beek $A P$, van der Klauw MM, Wolffenbuttel BHR, van Vliet-Ostaptchouk JV. Sex, BMI and age differences in metabolic syndrome: the Dutch Lifelines Cohort Study. Endocrine Connections 2017;6:278-288.

7. Ponikowski $\mathrm{P}$, Voors AA, Anker SD, Bueno H, Cleland JGF, Coats AJS, Falk V, GonzálezJuanatey JR, Harjola V-P, Jankowska EA, Jessup $M$, Linde C, Nihoyannopoulos P, Parissis JT, Pieske B, Riley JP, Rosano GMC, Ruilope LM, Ruschitzka F, Rutten FH, van der Meer P, Group ESD. 2016 ESC Guidelines for the diagnosis and treatment of acute and chronic heart failure: The Task Force for the diagnosis and treatment of acute and chronic heart failure of the European Society of Cardiology (ESC)Developed with the special contribution of the Heart Failure Association (HFA) of the ESC. European Heart Journal 2016;37:21292200.

8. Tschope C, Van Linthout S, Kherad B. Heart Failure with Preserved Ejection Fraction and Future Pharmacological Strategies: a Glance in the Crystal Ball. Curr Cardiol Rep 2017:19:70.

9. Granzier HL, Labeit S. The Giant Protein Titin. Circulation Research 2004;94:284-295.

10. Paulus WJ, Tschope C. A Novel Paradigm for Heart Failure With Preserved Ejection Fraction Comorbidities Drive Myocardial Dysfunction and Remodeling Through Coronary Microvascular Endothelial Inflammation. Journal of the American College of Cardiology 2013;62:263-271.

11. Abel ED, O'Shea KM, Ramasamy R. Insulin resistance: metabolic mechanisms and consequences in the heart. Arteriosclerosis, thrombosis, and vascular biology 2012;32:2068-2076.

12. Cuijpers I, Simmonds SJ, van Bilsen M, Czarnowska E, González Miqueo A, Heymans S, Kuhn AR, Mulder P, Ratajska A, Jones EAV, Brakenhielm E. Microvascular and lymphatic dysfunction in HFpEF and its associated comorbidities. Basic Research in Cardiology 2020;115:39.

13. Miranda-Silva D, Lima T, Rodrigues $P$, LeiteMoreira A, Falcão-Pires I. Mechanisms underlying the pathophysiology of heart failure with preserved ejection fraction: the tip of the iceberg. Heart Fail Rev 2021.

14. van Bilsen M, van Nieuwenhoven FA, van der Vusse GJ. Metabolic remodelling of the failing heart: beneficial or detrimental? Cardiovasc Res 2009;81:420-428.

15. van Bilsen M, Smeets PJ, Gilde AJ, van der Vusse GJ. Metabolic remodelling of the failing heart: the cardiac burn-out syndrome? Cardiovasc Res 2004;61:218-226.

16. Doenst T, Nguyen TD, Abel ED. Cardiac metabolism in heart failure: implications beyond ATP production. Circulation research 2013;113:709-724.

17. Karwi QG, Uddin GM, Ho KL, Lopaschuk GD. Loss of Metabolic Flexibility in the Failing Heart. Front Cardiovasc Med 2018;5:68.

18. Schiattarella GG, Altamirano F, Tong D, French KM, Villalobos E, Kim SY, Luo X, Jiang N, May HI, Wang ZV, Hill TM, Mammen PPA, Huang J, Lee DI, Hahn VS, Sharma K, Kass DA, Lavandero S, Gillette TG, Hill JA. Nitrosative stress drives heart failure with preserved ejection fraction. Nature 2019;568:351-356.

19. Hamdani N, Franssen C, Lourenço A, Falcão-Pires I, Fontoura D, Leite S, Plettig L, López B, Ottenheijm CA, Becher PM, González A, Tschöpe C, Díez J, Linke WA, Leite-Moreira AF, Paulus WJ. Myocardial titin 
hypophosphorylation importantly contributes to heart failure with preserved ejection fraction in a rat metabolic risk model. Circ Heart Fail 2013;6:1239-1249.

20. Valero-Munoz M, Backman W, Sam F. Murine Models of Heart Failure with Preserved Ejection Fraction: a "Fishing Expedition". JACC Basic Transl Sci 2017;2:770-789.

21. Hue L, Taegtmeyer $\mathrm{H}$. The Randle cycle revisited: a new head for an old hat. $A m \mathrm{~J}$ Physiol Endocrinol Metab 2009;297:E578591.

22. Fillmore N, Levasseur JL, Fukushima A, Wagg CS, Wang W, Dyck JRB, Lopaschuk GD. Uncoupling of glycolysis from glucose oxidation accompanies the development of heart failure with preserved ejection fraction. Mol Med 2018;24:3.

23. Lehrke M, Marx N. Diabetes Mellitus and Heart Failure. Am J Cardiol 2017;120:S37S47.

24. DeBerardinis RJ, Chandel NS. Fundamentals of cancer metabolism. Sci Adv 2016;2:e1600200.

25. Tran DH, Wang ZV. Glucose Metabolism in Cardiac Hypertrophy and Heart Failure. J Am Heart Assoc 2019;8:e012673.

26. Vienberg S, Geiger J, Madsen S, Dalgaard LT. MicroRNAs in metabolism. Acta Physiol (Oxf) 2017;219:346-361.
27. Rech M, Barandiaran Aizpurua A, van Empel $V$, van Bilsen $M$, Schroen $B$. Pathophysiological understanding of HFpEF: microRNAs as part of the puzzle. Cardiovasc Res 2018;114:782-793.

28. van Rooij E, Sutherland LB, Liu N, Williams $A H$, McAnally J, Gerard RD, Richardson JA, Olson EN. A signature pattern of stressresponsive microRNAs that can evoke cardiac hypertrophy and heart failure. Proc Natl Acad Sci U S A 2006;103:18255-18260.

29. Wang L, Sinnott-Armstrong N, Wagschal A, Wark AR, Camporez JP, Perry RJ, Ji F, Sohn Y, Oh J, Wu S, Chery J, Moud BN, Saadat A, Dankel SN, Mellgren G, Tallapragada DSP, Strobel SM, Lee MJ, Tewhey R, Sabeti PC Schaefer A, Petri A, Kauppinen S, Chung RT, Soukas A, Avruch J, Fried SK, Hauner H, Sadreyev RI, Shulman GI, Claussnitzer M, Naar AM. A MicroRNA Linking Human Positive Selection and Metabolic Disorders. Cell 2020;183:684-701 e614.

30. Chakraborty C, Sharma AR, Sharma G, Lee SS. Therapeutic advances of miRNAs: A preclinical and clinical update. $J A d v$ Res 2021;28:127-138.

31. Trajkovski M, Hausser J, Soutschek J, Bhat B, Akin A, Zavolan M, Heim MH, Stoffel M. MicroRNAs 103 and 107 regulate insulin sensitivity. Nature 2011;474:649-653. 


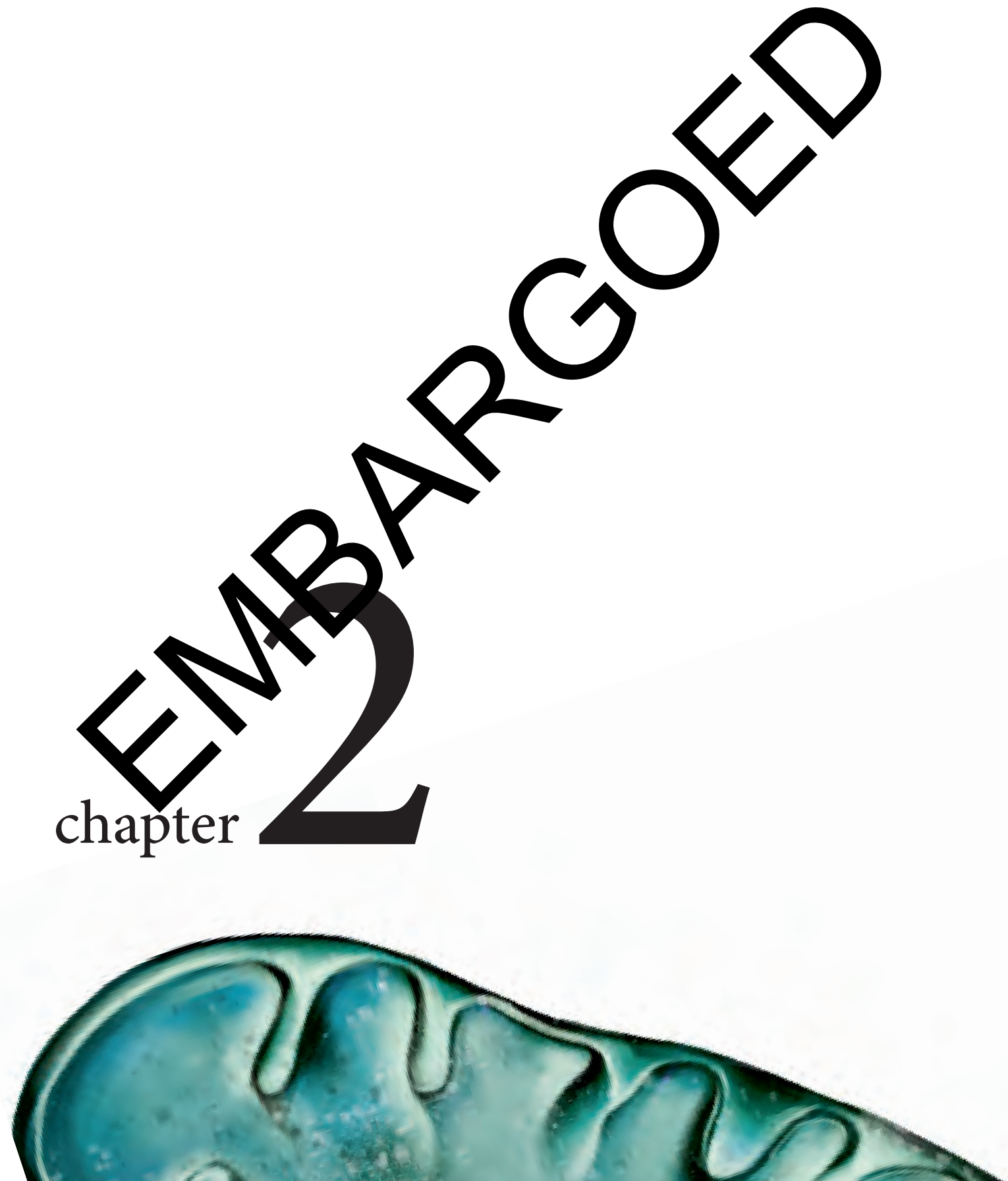


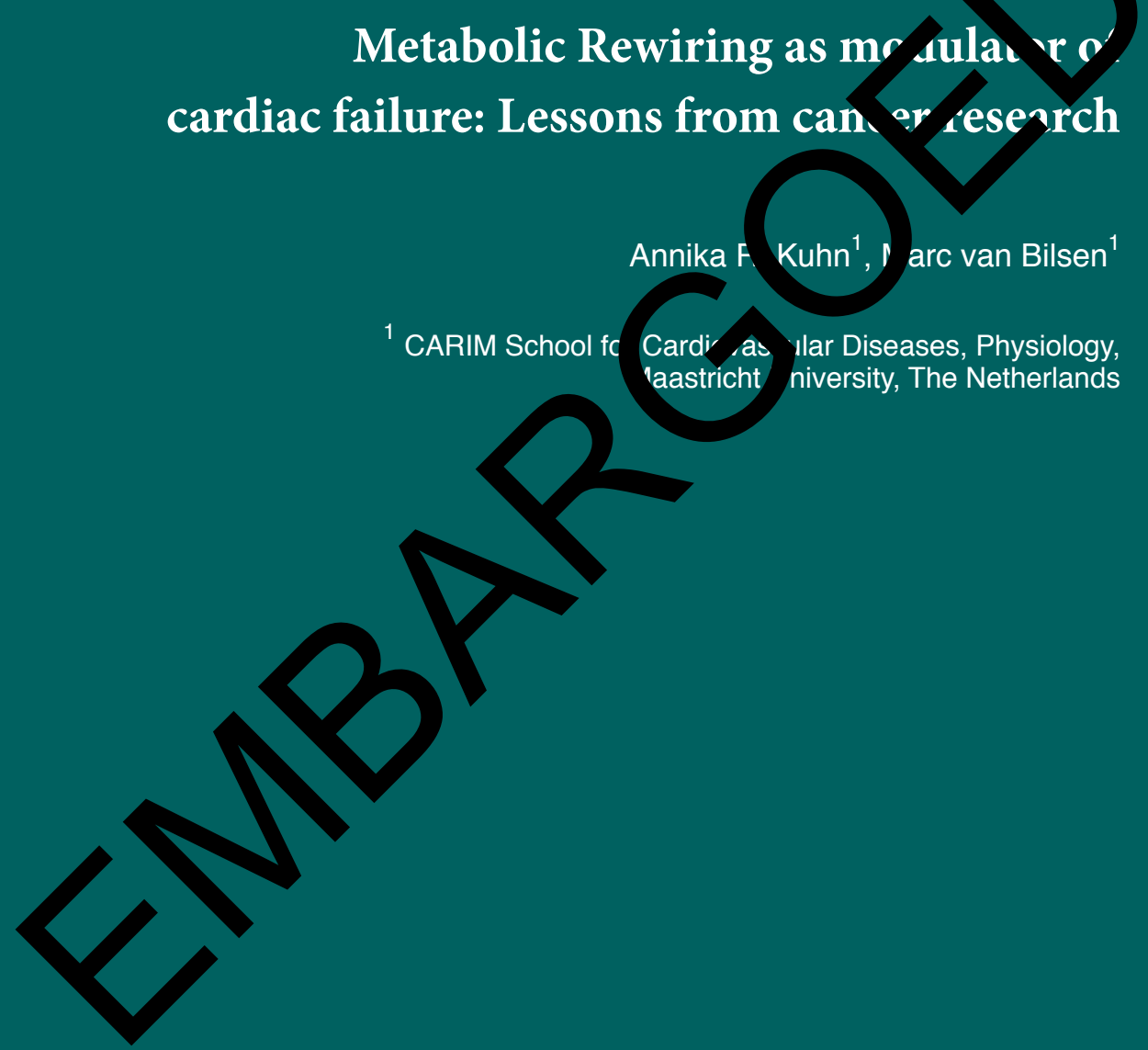



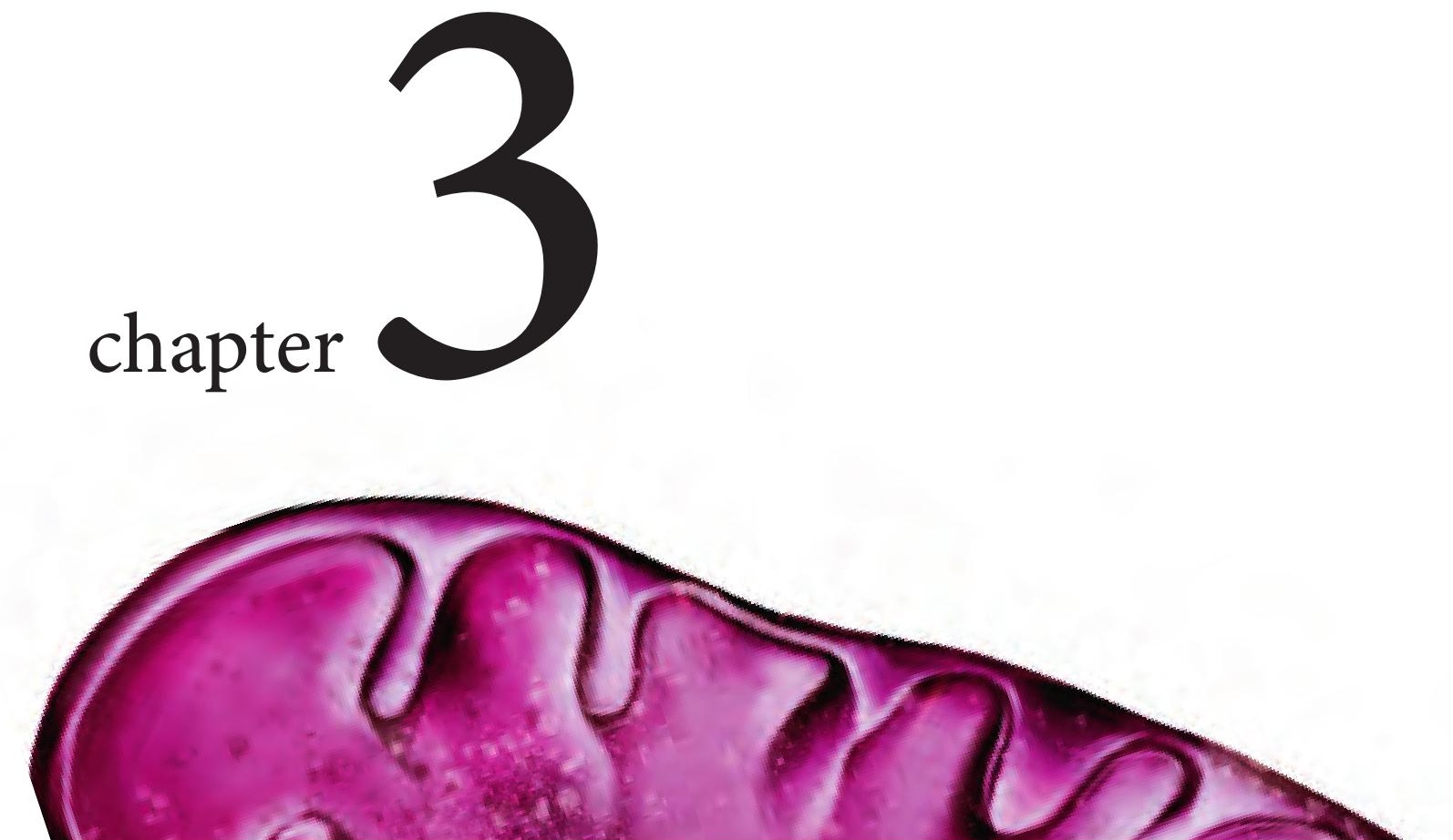


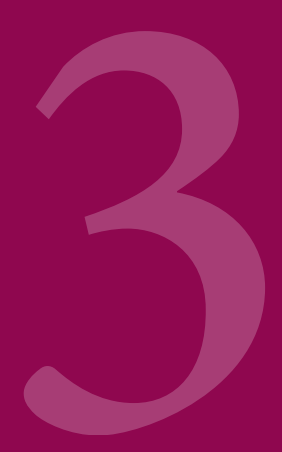

\section{A directed network analysis of the cardiome identifies molecular pathways contributing to the development of HFpEF}

Georg Summer ${ }^{1,2}$, Annika R. Kuhn ${ }^{3}$, Chantal Munts ${ }^{3}$, Daniela Miranda-Silva ${ }^{4}$, Adelino F. Leite Moreira ${ }^{4}$, André P Lourenço ${ }^{4}$, Stephane Heymans ${ }^{1,5,6}$, Inês Falcão-Pires ${ }^{4}$, Marc van Bilsen ${ }^{3}$

${ }^{1}$ CARIM School for Cardiovascular Diseases, Cardiology, Maastricht University, The Netherlands

2 TNO, Microbiology \& Systems Biology, Zeist, The Netherlands

${ }^{3}$ CARIM School for Cardiovascular Diseases, Physiology, Maastricht University, The Netherlands

${ }^{4}$ Unidade de Investigação Cardiovascular, Departamento de Cirurgia e Fisiologia, Faculdade de Medicina,Universidade do Porto, Portugal

${ }^{5}$ Department of Cardiovascular Sciences, KU Leuven, Belgium

${ }^{6}$ The Netherlands Heart Institute, NI-HI, Utrecht, The Netherlands 


\begin{abstract}
Aims: The metabolic syndrome and associated comorbidities, like diabetes, hypertension and obesity, have been implicated in the development of heart failure with preserved ejection fraction (HFpEF). The molecular mechanisms underlying the development of HFpEF remain to be elucidated. We developed a cardiome-directed network analysis and applied this to high throughput cardiac RNA-sequencing data from a well-established rat model of HFpEF, the obese and hypertensive ZSF1 rat. With this novel system biology approach, we explored the mechanisms underlying HFpEF.
\end{abstract}

Methods and Results: Unlike ZSF1-Lean, ZSF1-Obese and ZSF1-Obese rats fed with a high-fat diet (HFD) developed diastolic dysfunction and reduced exercise capacity. The number of differentially expressed genes amounted to 1591 and 1961 for the ZSF1-Obese vs. Lean and ZSF1-Obese+HFD vs. Lean comparison, respectively. For the cardiomedirected network analysis (CDNA) eleven biological processes related to cardiac disease were selected and used as input for the STRING protein-protein interaction database. The resulting STRING network comprised 3.460 genes and 186.653 edges. Subsequently differentially expressed genes were projected onto this network. The connectivity between the core processes within the network was assessed and important bottleneck and hub genes were identified based on their network topology. Classical gene enrichment analysis highlighted many processes related to mitochondrial oxidative metabolism. The CDNA indicated high interconnectivity between five core processes: endothelial function, inflammation, apoptosis/autophagy, sarcomere/cytoskeleton and extracellular matrix. The transcription factors Myc and Peroxisome Proliferator-Activated Receptor- $\alpha$ (Ppara) were identified as important bottlenecks in the overall network topology, with Ppara acting as important link between cardiac metabolism, inflammation and endothelial function.

Conclusions: This study presents a novel systems biology approach, directly applicable to other cardiac disease-related transcriptome data sets. The CDNA approach enabled the identification of critical processes and genes, including Myc and Ppara, that are putatively involved in the development of HFpEF. 


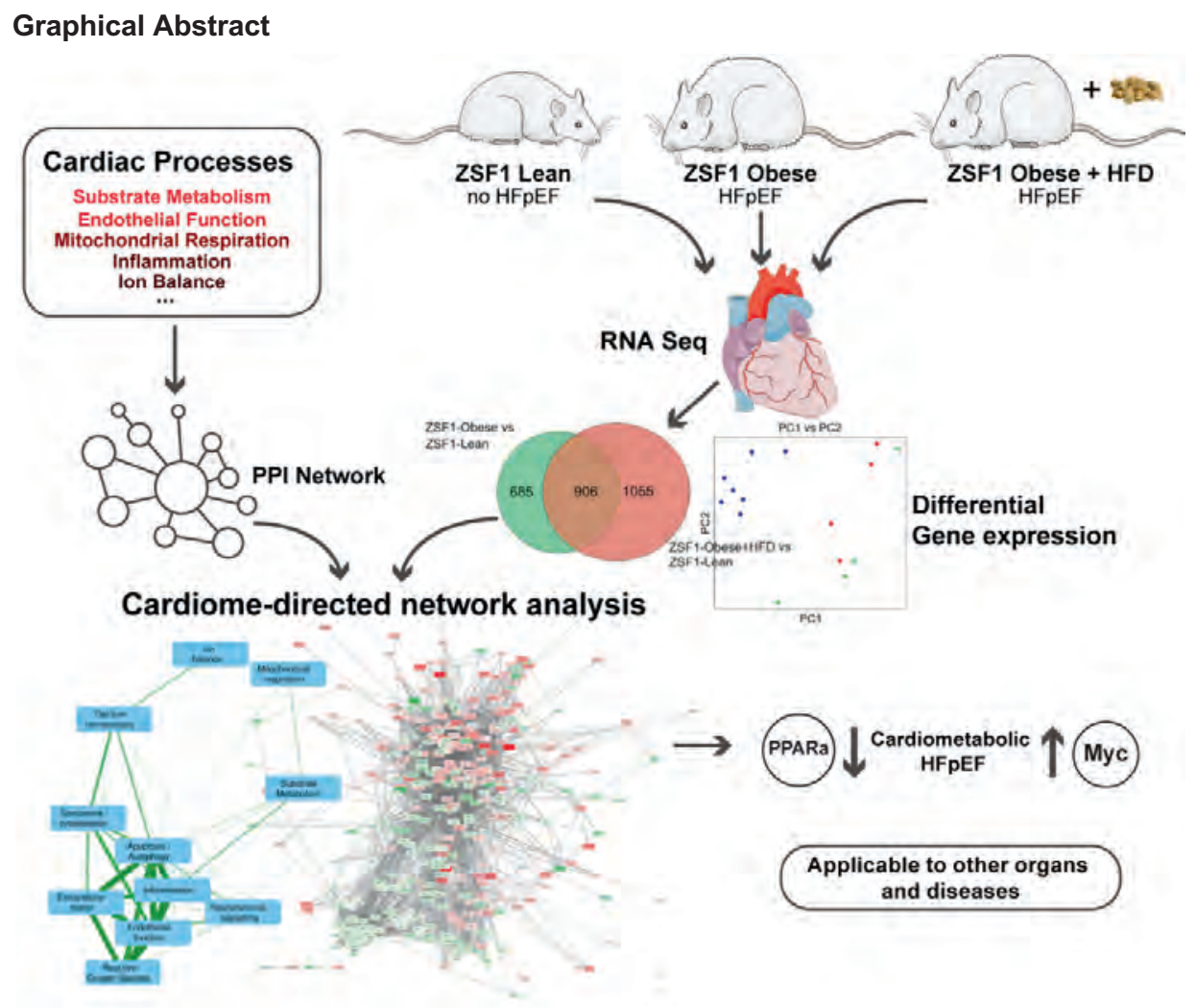

\section{Keywords}

heart failure, metabolic syndrome, transcriptomics, systems biology, mitochondrial metabolism 


\section{Introduction}

Nearly $50 \%$ of all heart failure (HF) patients suffer from heart failure with preserved ejection fraction (HFpEF). HFpEF is characterized by left ventricular (LV) diastolic dysfunction resulting due to impaired LV relaxation and/or filling. This form of HF is frequently seen in patients suffering from co-morbidities that are associated with the metabolic syndrome, namely obesity, hyperlipidaemia, diabetes mellitus and hypertension. ${ }^{1}$ This association tentatively suggests that systemic metabolic derangements predispose to the development of HFpEF. Thus diastolic dysfunction as such has been attributed to disturbances in myocardial relaxation, calcium homeostasis abnormalities ${ }^{2}$, as well as to increased passive stiffness either within ${ }^{3}$ or outside the cardiomyocyte. ${ }^{4}$ These changes are secondary to the changes in systemic metabolism and the chronic low-grade inflammation that accompany the metabolic syndrome. ${ }^{5}$ One of the prevailing current hypotheses is that the low-grade systemic inflammation leads to coronary microvascular dysfunction, which eventually impacts cardiomyocyte stiffness. ${ }^{6}$ However, the pathogenesis of HFpEF remains enigmatic and is subject of intense investigation.

The application of system biology approaches to 'omics' data has been proven useful in the identification of biological pathways and genes involved in disease processes. ${ }^{7,8}$ The aim of the present study was to develop a novel, cardiome-directed network analysis approach to analyse genome-wide transcriptome data in order to gain insight into the molecular mechanisms underlying HFpEF. Thereto, we performed RNA sequencing on cardiac tissue of ZSF1 rats, an extensively characterized preclinical model of metabolic risk-mediated HFpEF. ${ }^{9-12}$ ZSF1-Obese rats are the F1 hybrid offspring of Zucker Diabetic Fatty (ZDF) rats and Spontaneously Hypertensive Heart Failure (SHHF) rats ${ }^{13}$, each having a distinct leptin receptor mutation. ZSF1-Obese rats, carrying both leptin receptor mutations, are characterized by morbid obesity, diabetes mellitus and hypertension and have been shown to develop diastolic dysfunction and HFpEF. ${ }^{9}$ In contrast, ZSF1-Lean rats only suffer from hypertension and do not develop diastolic dysfunction. A subgroup of ZSF1-Obese rats received a high-fat diet (HFD) to assess if an additional metabolic challenge would exacerbate HFpEF progression. Changes in systemic metabolism and cardiac geometry and function were monitored.

To interrogate these transcriptome data sets we developed a novel network analysis approach, specifically tailored for cardiome data sets, to identify transcripts and biological processes that are putatively involved in the development of HFpEF. To this end, eleven processes that have previously been linked to cardiac pathogenesis were predefined and selected for further analysis. The publicly accessible protein-protein interaction (PPI) database STRING ${ }^{14}$ was used to construct a cardiac PPI network linked to these eleven processes. This network formed the basis to identify cellular processes and transcripts putatively involved in the development of HFpEF. 


\section{Methods}

\subsection{Animals}

All the procedures in this work followed the recommendation of the Guide for the Care and Use of Laboratory Animals, published by the US National Institutes of Health (NIH Publication No. 85-23, Revised 2011). Experiments were performed according to the Portuguese law for animal welfare and to the Guide for the Care and Use of Laboratory Animals published by the National Institutes of Health (NIH Publication 85-23, Revised 2011) and were certified by the Portuguese Veterinary Governmental Authorities, (0421/000/000/2013) approved by the Portuguese Foundation for Science and Technology and by the ethical committee of the institution. Only trained researchers, certified with a Laboratory Animal Science course according to the Federation of European Laboratory Animal Science Associations, performed animal handling and procedures.

Male ZSF1-Lean $(n=18)$ and ZSF1-Obese $(n=34)$ rats, 9 weeks of age, were purchased from Charles River (Barcelona, Spain). The rats were fed with a Purina diet (\#5008) at libitum and caged in pairs in individually ventilated chambers with a 12-h light/dark cycle at $22^{\circ} \mathrm{C}$ room temperature. A subgroup of ZSF1-Obese rats $(n=18)$ was fed a Western-type high-fat and high-carbohydrate diet (HFD) containing 48\% lard (\#D12468, Research diet Inc.). The phenotypic evaluation was conducted between 18 and 20 weeks of age in subgroups of rats as described in detail before ${ }^{9}$ and consisted of blood tests, metabolic cage studies for systemic metabolic analysis and echocardiography (under 3-4\% sevoflurane anaesthesia) for cardiac functional characterization. PV-loop analysis was deliberately not performed on animals used for RNA-Seq analysis as previous findings (unpublished data) indicated that the hemodynamic stress associated with $\mathrm{PV}$-loop analysis affects the cardiac transcriptome. $\mathrm{VO}_{2}$ peak effort and endurance were tested as previously described. ${ }^{11}$ The animals were euthanised at their $20^{\text {th }}$ week of age under inhaled anaesthesia (sevoflurane $8 \%$, deep anaesthesia was confirmed by a firm pinch on or between the toes) by quickly excising the hearts. These were immediately weighed, and samples from the LV free wall were collected and frozen in liquid nitrogen for subsequent RNA-Seq and qPCR analysis.

\subsection{Library Preparation, RNA-Seq and qPCR analysis}

Total RNA was isolated from LV tissue using the mirVana kit (Life Technologies \#AM1560) according to the manufacturer's instructions. Tissue was homogenized in $600 \mu \mathrm{l}$ lysis/binding buffer using a motorized rotor-stator.

For RNA-seq analysis total RNA was eluted from the columns in $50 \mu$ pre-heated DNase/RNase free water and checked for purity and quality (260/280 ratio $>1.90 ; 260 / 230$ ratio $>1.90) .1 .5 \mu \mathrm{g}$ of total RNA from ZSF1-Lean $(n=7)$, ZSF1-Obese $(n=4)$ and ZSF1Obese+HFD ( $n=4$ ) was sent to Nucleomics Core (Leuven, Belgium) for RNA sequencing. The RNA sequencing libraries were prepared using the Illumina TrueSeq Kit according to the manufacturer's protocol and sequenced on an Illumina NextSeq platform. Between 30 and 35 million single end reads were produced from each tissue sample. Obtained reads were trimmed for quality using Fast $\mathrm{X}^{15}$ and adapters using cutadapt. ${ }^{16}$ Tophat ${ }^{17}$ was used to map 
the reads against the Rattus norvegicus (rnor5.0) genome, cufflinks ${ }^{18}$ to annotate genomic features (Rattus norvegicus. Rnor 5.0.79.gtf) and htseq-count to summarize the expression of genes. ${ }^{19}$ Genes with less than 1 count-per-million over all samples were removed and considered not expressed for subsequent analysis. Differential expression between all experimental groups was assessed using EdgeR. ${ }^{20}$ Differential expression was considered statistically significant if the false discovery rate (FDR) was less than 0.05 .

For qPCR analysis cDNA was generated with the Iscript cDNA synthesis kit (\#170889105; Bio-Rad Laboratories) using an input of $250 \mathrm{ng}$ RNA. Gene expression analysis was performed on the CFX96 Touch real-time PCR detection system (Bio-Rad) using SYBRGreen Supermix (\#1708886; Bio-Rad). Target genes were normalized with the reference gene Cyclophilin-A by using the comparative threshold cycle $(\mathrm{Ct})$ method $2^{\Delta \mathrm{Ct}}$. Primer sequences are provided in Supplemental Table S1.

\subsection{Gene Ontology and pathway enrichment}

Differentially expressed genes were investigated for Gene Ontology (GO) and Pathway enrichment using the DAVID web service. ${ }^{21} \mathrm{GO}$ terms and pathways were considered significantly enriched if their EASE score was $<0.1$. The EASE Score is a modified Fisher Exact P-Value, commonly used for gene-enrichment analysis.

\subsection{Network building}

The STRING protein-protein interaction (PPI) database was used as the basis for the cardiome-directed network analysis (CDNA). PPIs from STRING version 10 for Mus musculus were extracted and included in the network. Mus musculus was preferred over rattus norvegicus because the network provides more PPIs and a larger coverage of the genome, increasing the size of the network by 1.8-fold. Next to interactions, the genes in the network were marked to indicate if they are expressed and differentially regulated in the two comparisons of the dataset (Obese vs Lean and Obese+HFD vs Lean).

\subsection{Network analysis, extraction and visualization}

The STRING PPI network was stored in a Neo4j database [https://neo4j.com/]. The eleven core networks were built based on biological processes implicated in cardiac disease. Based on expert knowledge, review of the literature, and testing in STRING, per process 1-3 proteins were selected to adequately represent the cardiac core processes (Table 1). These proteins were used as "baits" to construct a core PPI network reflecting an entire core process by adding their first neighbours. 
Table 1. Genes used to construct cardiac process-related networks in STRING.

Process

Sarcomere / cytoskeleton

Calcium homeostasis

Ion balance

Substrate Metabolism

Mitochondrial respiration

Extracellular matrix (ECM)

Endothelial function

Inflammation

Reactive Oxygen Species (ROS)

Apoptosis / Autophagy

Neurohumoral Signalling

\section{Bait genes}

Ttn, Vcl
Mcu, Atp2a2
Scn5a, Kcnq1
Hk2, Hadhb
Cycs
Thbs4, Mmp2
Flt1, Icam1
Myd88, Rela, Ccl2
Nfe2l2, Ncf1
Becn1, Bcl2
Gnas, Gnaq, Gnai1

For the consecutive analysis, a PPI confidence score of 0.4 was used in line with the default cut-off of the STRING website itself.

The individual core networks were extracted using the Neo4j query language Cypher. CyNeo4j $\mathrm{j}^{22}$ and Cytoscape ${ }^{23}$ were used to visualize the networks. Node and edge statistics were calculated using the NetworkAnalyzer plugin in Cytoscape. Hub genes and bottleneck genes were identified and ranked according to degree and their betweenness centrality, respectively.

\subsection{Connectivity of core processes}

To interrogate the interplay between core process in the network the number of differentially regulated genes that are common to the core processes were first determined. Next, the number of shared genes was corrected for by the size of each individual process. This normalization ensures that small processes that share a large number of their genes contribute strongly, whereas large processes with a few genes contribute less. The resulting ratios are summed to define the relatedness of two processes.

\subsection{Statistics}

Morphological, metabolic and echocardiographic numerical values are provided as mean \pm SEM. Statistical differences were analysed using One-way ANOVA with Bonferroni post hoc testing. Results were considered statistically significant at $P<0.05$. 


\section{Results}

\subsection{ZSF1-Obese rats show diastolic dysfunction}

The morphometric, metabolic and cardiac characteristics of the three experimental groups, ZSF1-Lean rats, ZSF1-Obese rats on a normal diet and ZSF-Obese rats on a high-fat diet (HFD), are shown in Figure 1 and Supplementary Table S2. In both obese groups, plasma glucose levels, glucose tolerance and insulin resistance were significantly increased compared to the control group, denoting development of type II diabetes mellitus. This was associated with a marked deterioration in $\mathrm{VO}_{2}$ upon peak effort and endurance testing, indicating that these rats developed HF-related symptoms.
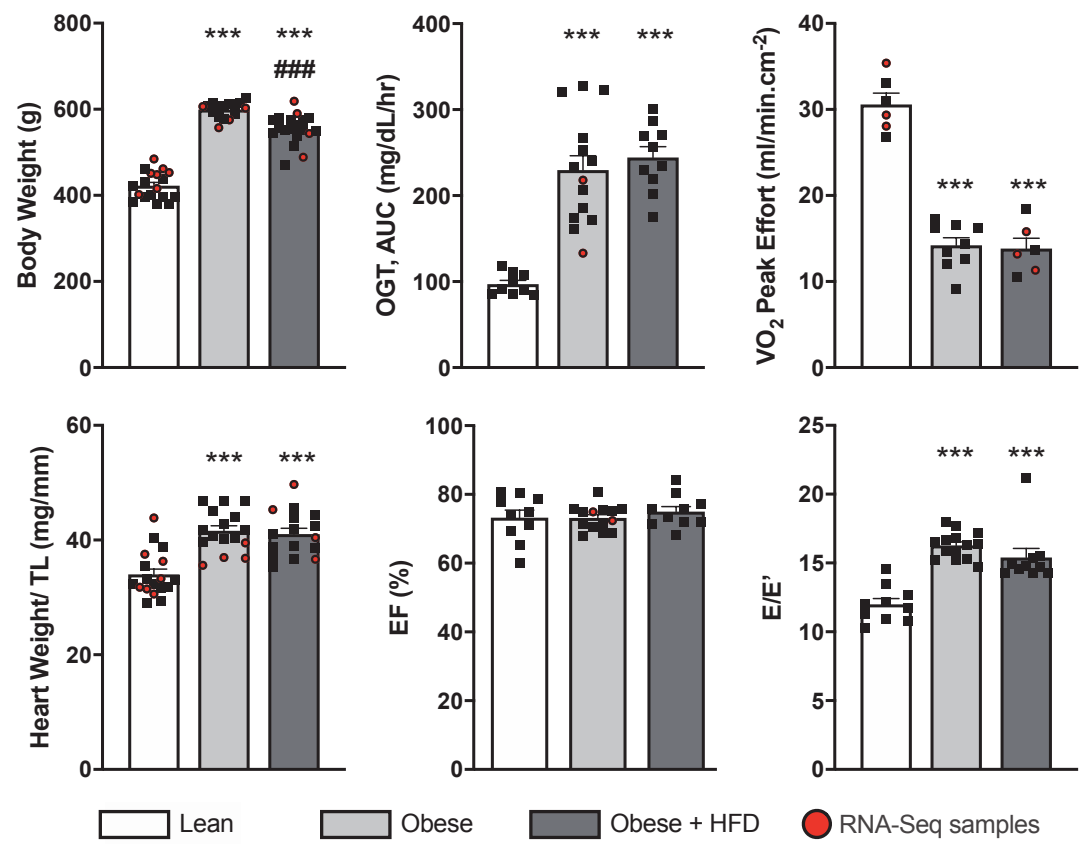

Figure 1: Morphometric, metabolic and echocardiographic characterization of ZSF1-Lean, ZSF1. Obese and HFD fed ZSF1-Obese rats. OGT, oral glucose tolerance; AUC, area under curve; EF, ejection fraction; E/E', ratio of peak $E$ wave velocity of pulsed-wave Doppler mitral flow to peak $E^{\prime}$ wave velocOity of tissue-doppler at the lateral mitral annulus; $n$ amounted to $\geq 9$ animals per experimental group for each parameter, except for $\mathrm{VO}_{2}$ measurements ( $n=6-9$ per group). Values are mean $\pm S E M$. One-way ANOVA with Bonferroni post hoc test: $P<0.001:{ }^{* * *}$ vs Lean; ${ }^{\# \#}$ vs Obese.

Feeding ZSF1-Obese rats with a HFD was associated with increased caloric intake and a marked rise in water intake and urine output (Supplementary Table S2). However, both insulin resistance and $\mathrm{VO}_{2}$ were comparable to the obese group on a standard diet.

As far as cardiac geometry and function are concerned, ZSF1-Obese and ZSF1-Obese+HFD groups showed more LV hypertrophy based on increased LV weight (normalised to tibia length) and echocardiographically determined LV mass, as compared to lean. Furthermore, the echocardiography analysis showed preserved ejection fraction (EF) with normal systolic 
function in all groups as assessed by fractional shortening (FS) and cardiac index (Cl) at 20 weeks of age. Notably, the obese groups presented increased ratio of $E$ to early diastolic tissue-doppler at lateral mitral annulus velocity (E', Figure 1) and increase of left atrial area (LAA), indicating impaired diastolic function. Feeding ZSF1-Obese rats with a HFD did not aggravate diastolic function further.

These findings are fully in line with our previous studies in which pressure-volume analysis was performed in addition to echocardiography to assess diastolic function. ${ }^{9}$ In conclusion, compared to hypertensive ZSF1-Lean rats, hypertensive and diabetic ZSF1-Obese rats developed diastolic dysfunction and HFpEF, an effect that is not worsened upon HFD feeding.

\subsection{Cardiac transcriptome analysis}

RNA sequencing of LV samples of the three groups yielded 12,981 genes with more than 1 count $/ 10^{6}$ reads, marking them as being expressed in the heart. Principal component analysis (PCA) demonstrated that the cardiac transcriptome of ZSF1-Lean group markedly differed from both obese groups (Figure 2A). In line with the cardiac phenotyping, a clear effect of HFD could not be discerned amongst the two ZSF1-Obese groups.

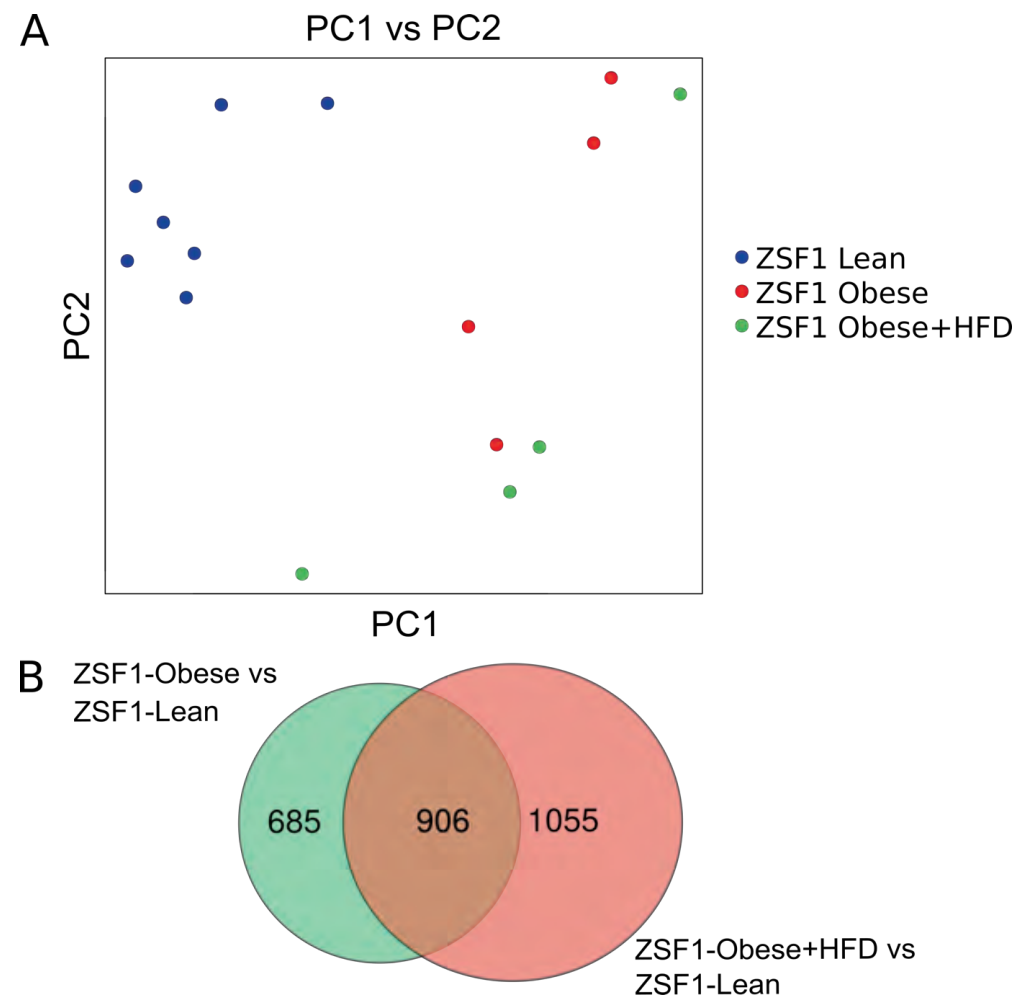

Figure 2: Principal component analysis of the mRNA expression data. ZSF1 Lean samples are in blue, ZSF1-Obese in red and ZSF1-Obese+HFD in green (Panel A). Venn diagram showing the overlapping of differentially expressed genes (FDR < 0.05) for the two comparisons (Panel B). 
In total, 1591 (770 up, 821 down) and 1961 (933 up, 1028 down) genes showed differential expression (at FDR < 0.05) when comparing ZSF1-Obese vs. Lean and ZSF1-Obese+HFD vs. Lean, respectively. The Venn diagram shows that, although both comparisons have many differentially expressed genes in common, there also is quite a large number of genes, that is specific to the individual comparisons (Figure 2B); 685 genes (43\%) for obese vs lean and 1055 genes (53.8\%) for ZSF1-Obese+HFD vs Lean.

\subsection{Gene enrichment analysis}

Next, to identify biological processes relevant to the cardiac disease phenotype the set of differentially expressed genes was interrogated for gene enrichment using standard Gene Ontology (GO) and KEGG pathway analysis. Mitochondrial metabolism-related terms (fatty acid beta-oxidation, in particular) were highly prevalent among the enriched GO biological processes when comparing ZSF1-Obese vs Lean (Figure 3) and ZSF1-Obese+HFD vs lean (Supplementary Figure S1). The only directly cardiac relevant terms were "cardiac muscle contraction" and "ventricular cardiac muscle tissue morphogenesis" (Figure 3).

Top 10 Processes Obese vs. Lean

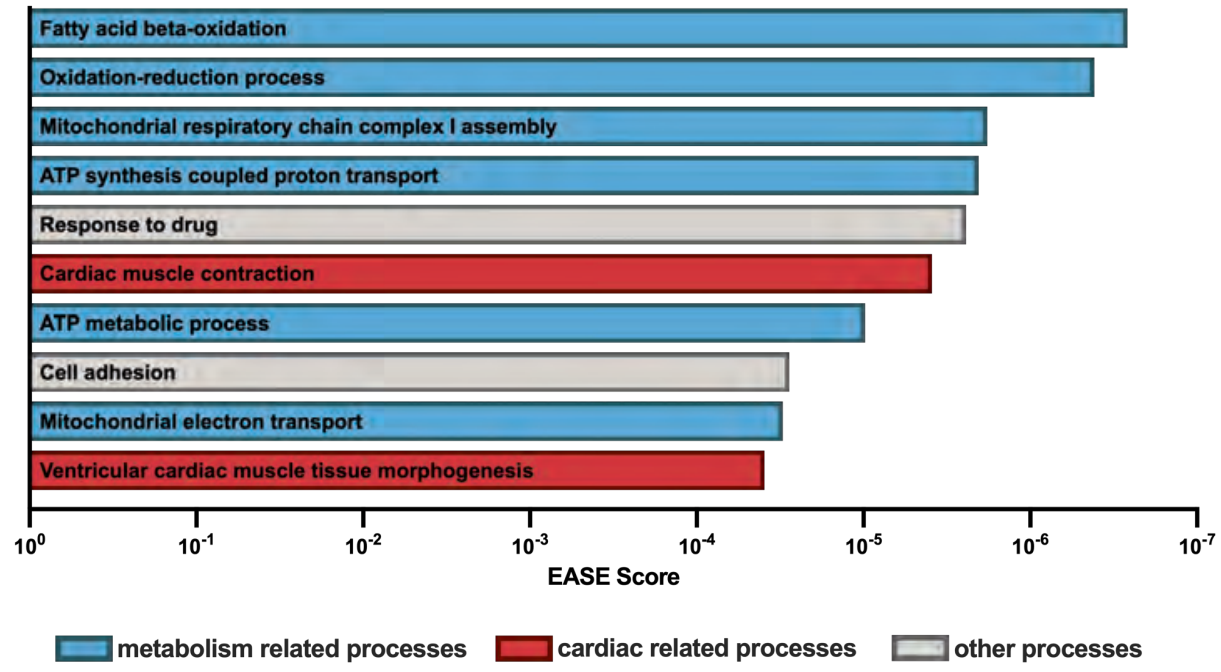

Figure 3: Enriched biological processes in ZSF1-Obese rats with HFpEF versus ZSF1-Lean rats. The top 10 enriched biological processes from Gene Ontology for were ranked according to their EASE score. An EASE score < 0.1 was considered significant

KEGG pathway analysis yielded a slightly more varied pattern as in addition to mitochondrial metabolism-related processes, various diseases with strong metabolic component, among which fatty liver disease and some neuronal diseases, also popped up (see supplementary website https://github.com/gsummer/cdna for detailed information). 


\subsection{Cardiome-directed network analysis - CDNA}

As an alternative approach to identifying biological processes and genes that might be involved in the development of HFpEF we selected 11 processes (Table 1) that have been linked to cardiac pathogenesis and used these processes to construct a cardiac process protein-protein interaction (PPI) network based on the STRING database. A gene was considered to be linked to a cardiac process if it had a protein-protein interaction with a confidence of $\geq 0.4$ to the bait genes representing the cardiac process. The number of genes linked to a process (core size) ranged from 152 to 887 (Table 2). The entire STRING network comprised 3.460 genes (nodes) and 186.653 edges. Based on our RNA-seq data, the majority of these genes (68\%) were expressed in the heart. Among these, the percentage of differentially expressed genes per process ranged from 15-39\% for the ZSF1-Obese vs Lean comparison (Table 2) and from $16-32 \%$ for ZSF1-Obese+HFD vs Lean (Supplementary Table S3).

Table 2: Cardiac core processes and numbers of differentially expressed genes per process between ZSF1-Obese and Lean rats.

\begin{tabular}{cccc} 
Process & Core Sizes & Expressed (\%) & $\begin{array}{c}\text { Diff. expressed } \\
\text { ZSF1-Obese vs. Lean (\%) }\end{array}$ \\
\hline Sarcomere/cytoskeleton & 441 & $359(81.41)$ & $67(18.66)$ \\
Calcium homeostasis & 191 & $144(75.39)$ & $30(20.83)$ \\
Ion balance & 221 & $144(65.16)$ & $23(15.97)$ \\
Substrate metabolism & 291 & $239(82.13)$ & $62(25.94)$ \\
Mitochondrial respiration & 152 & $122(80.26)$ & $48(39.34)$ \\
Extracellular matrix & 543 & $409(75.32)$ & $64(15.64)$ \\
Endothelial function & 752 & $561(74.60)$ & $96(17.11)$ \\
Inflammation & 887 & $660(74.41)$ & $97(14.70)$ \\
Reactive Oxygen Species & 172 & $132(76.74)$ & $20(15.15)$ \\
Apoptosis/autophagy & 884 & $676(76.47)$ & $95(15.05)$ \\
Neurohumoral signalling & 876 & $443(50.57)$ & $73(16.47)$ \\
\hline Total network & $\mathbf{3 4 6 0}$ & $\mathbf{2 3 5 7 ( 6 8 . 1 2 )}$ & $\mathbf{4 0 7 ( 1 7 . 2 6 )}$
\end{tabular}

Number of genes in STRING linked to bait genes with a confidence level of $\geq 0.4$ defines the core size of each process. The size of the entire network is less than the sum of the individual processes due to genes participating in multiple processes.

After associating the differentially regulated genes with cardiac processes the focus shifted on how these processes interact within the network. The number of differentially expressed genes that are shared between individual processes for the ZSF1-Obese vs Lean comparison are visualized in Figure 4. The network revealed strong interactions between 5 core processes in particular, namely, inflammation, endothelial function, reactive oxygen species, apoptosis/autophagy and extracellular matrix. It is worth noting that the core processes mitochondrial respiration and substrate metabolism by far showed the highest percentage of 
differentially expressed genes (Table 2), but at the same time both were only loosely connected to the other core processes (Figure 4). Applying this strategy to the ZSF1Obese+HFD versus ZSF1-Lean comparison yielded a comparable outcome (Supplementary Figure S2).

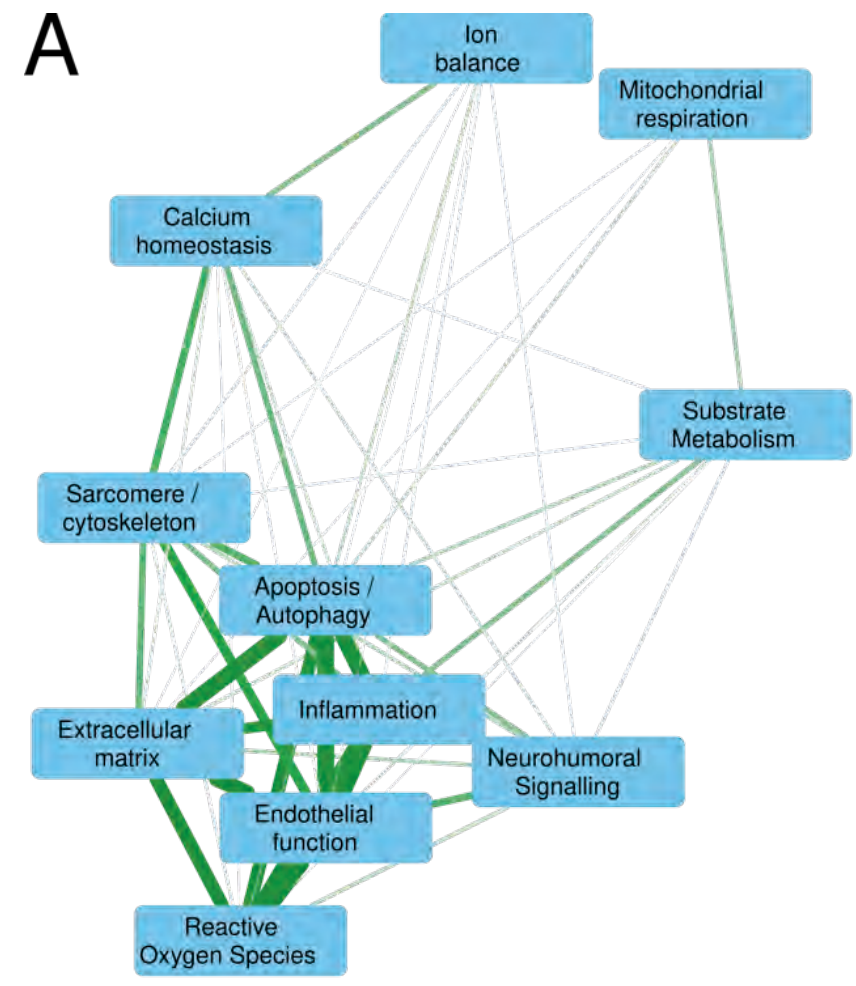

Figure 4: The cardiac core processes connected by the number of shared and differentially expressed genes when comparing ZSF1-Obese and Lean rats. The edge thickness and colour intensity correspond to the number of shared genes.

As a next step, the interactions between the differentially expressed genes of all cardiac processes were extracted from STRING-DB. The resulting network for the ZSF1-Obese vs Lean comparison (Figure 5) was used to identify genes that acted as important hubs (genes with many connections to other genes) and bottlenecks (genes acting as intersections between modules in the network). 


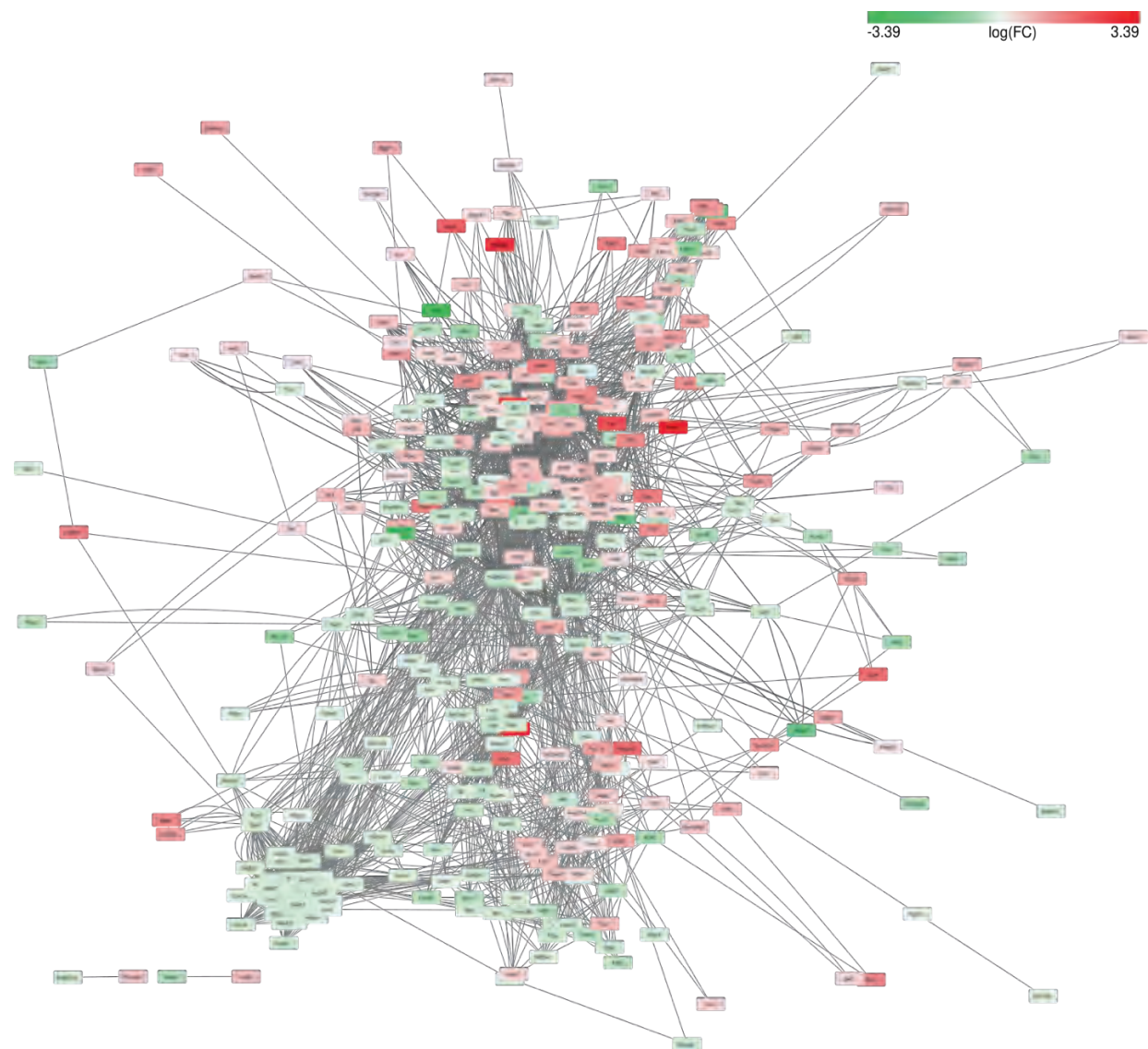

Figure 5: The core network based on the ZFS1-Obese versus Lean comparison. Differentially expressed genes are connected with protein-protein interactions from STRING with a confidence of $\geq 0.4$. Each gene is coloured with a gradient from green (decreased) to red (increased) representing the log fold change. The network for the ZSF1-Obese+HFD vs Lean comparison is shown as Supplementary Figure S3.

The 10 genes with the highest connectivity and betweenness centrality scores in both core networks are depicted in Table 3 (complete list of genes provided on the Supplementary website https://github.com/gsummer/cdna). The CDNA was also applied to the set of differentially expressed genes form the ZSF1-Obese+HFD versus Lean comparison (Supplementary Figure S3), resulting in a slightly different ranking of hub and bottleneck genes (Supplementary Table S4). 
Table 3: Important genes involved in HFpEF development according to their connectivity or centrality within the network.

ZSF1-Obese vs Lean

\begin{tabular}{ccc|ccc}
\hline \multicolumn{3}{c|}{ Hubs } & \multicolumn{3}{c}{ Bottlenecks } \\
\hline Gene & $\begin{array}{c}\text { Up/Down } \\
\text { log FC }\end{array}$ & Degrees & Gene & $\begin{array}{c}\text { Up/Down } \\
\text { log FC }\end{array}$ & $\begin{array}{c}\text { Betweenness } \\
\text { Centrality }\end{array}$ \\
\hline Akt1 & -0.40 & 126 & Akt1 & -0.40 & 0.165 \\
Cycs & -0.33 & 96 & Hsp90aa1 & -0.77 & 0.079 \\
Hsp90aa1 & -0.77 & 86 & Hsp90ab1 & -0.34 & 0.074 \\
Hsp90ab1 & -0.34 & 86 & Myc & +0.58 & 0.050 \\
Csf1r & +0.48 & 82 & Fras1 & -0.95 & 0.037 \\
Myc & +0.58 & 73 & Decr1 & +0.85 & 0.037 \\
Jak2 & +0.41 & 62 & Ppara & -0.28 & 0.028 \\
Hck & +0.76 & 58 & Jak2 & +0.41 & 0.028 \\
Akt2 & -0.31 & 56 & Cat & +0.39 & 0.026 \\
Sdhb & -0.25 & 52 & Akt2 & -0.31 & 0.026 \\
\hline
\end{tabular}

The top 10 of hub and bottleneck genes in the ZSF1-Obese vs. Lean network ranked according to the number of connections (hub genes) or according to their betweenness centrality (bottleneck genes) in the core network. Hub genes are genes with many connections (degrees) to other genes, whereas bottleneck genes act as important intersections between modules in the network. Differences in expression are indicated as log2 fold changes.

The identification of Akt1 and of the two heat-shock proteins (Hsp90) as the genes with the highest centrality scores, both as hub genes and bottleneck genes, in both comparisons is in line with the crucial role of the kinase Akt1 in cellular signalling in both diabetes and cardiac hypertrophy ${ }^{24}$, and the role of $\mathrm{Hsp} 90$ as a molecular chaperone for a substantial part of the proteome. ${ }^{25}$ Of note is the high connectivity in combination with a relatively low betweenness score of Cytochrome C (Cycs) for the ZSF1-Obese vs Lean comparison (not differentially regulated in the Obese+HFD vs lean comparison), which points to a high level of interaction, but primarily with genes that are part of its own module.

Remarkably, the oncogene Myc, the mitochondrial enzyme Decr1 (2,4-Dienoyl-CoA Reductase-1), and the nuclear hormone receptor Ppara (Peroxisome Proliferator-Activated Receptor- $\alpha$ ) were identified as important bottleneck genes in both the ZSF1-Obese vs. Lean (Table 3) and ZSF1-Obese+HFD vs. Lean (Supplementary Table S4) comparison. Differential expression of the bottleneck genes was validated by $\mathrm{QPCR}$, demonstrating that mRNA levels of Akt1, Hsp90ab, Ppara and Decr1, but not Hsp90aa and Myc, were statistically different between experimental groups (Supplementary Figure S4).

\subsection{Hypothesis-driven interrogation of the network}

Above we used an unbiased approach to identify genes that, based on their centrality in the network, are of potential interest in the aetiology of HFpEF. Alternatively, one can use hypothesis-driven approaches to interrogate the network. One of the most popular hypotheses for the development of HFpEF states that low-grade inflammation initially 
affects the endothelium, leading to cardiac microvascular dysfunction. ${ }^{6}$ Our analysis of the interaction among core processes in the ZSF1-Obese vs Lean network (Figure 4) revealed important overlap between inflammation and endothelial function. Figure 6 highlights the differentially expressed genes that are linked to both the inflammation process and the endothelial-linked process in the network. Conceivably, these genes provide a functional link between the two processes. Intriguingly, the nuclear transcription factor Ppara, identified as an important bottleneck gene in the network (Table 3), also emerged as one of the genes linking these two processes. Given the well-established role of Ppara as a key-regulator of cardiac fatty acid metabolism ${ }^{26}$, the relation of Ppara to other genes in the network was further explored (Figure 7). Indeed, Ppara along with its isoform Ppard and their heterodimerization partner Rxrb were the only genes that connected the process of cardiac metabolism, on the one hand, with inflammation and endothelial function, on the other. Applying this approach to the ZSF1-Obese+HFD vs Lean comparison (Supplementary Figures S5, S6) confirmed the central role of PPARa in linking these processes in the network. 


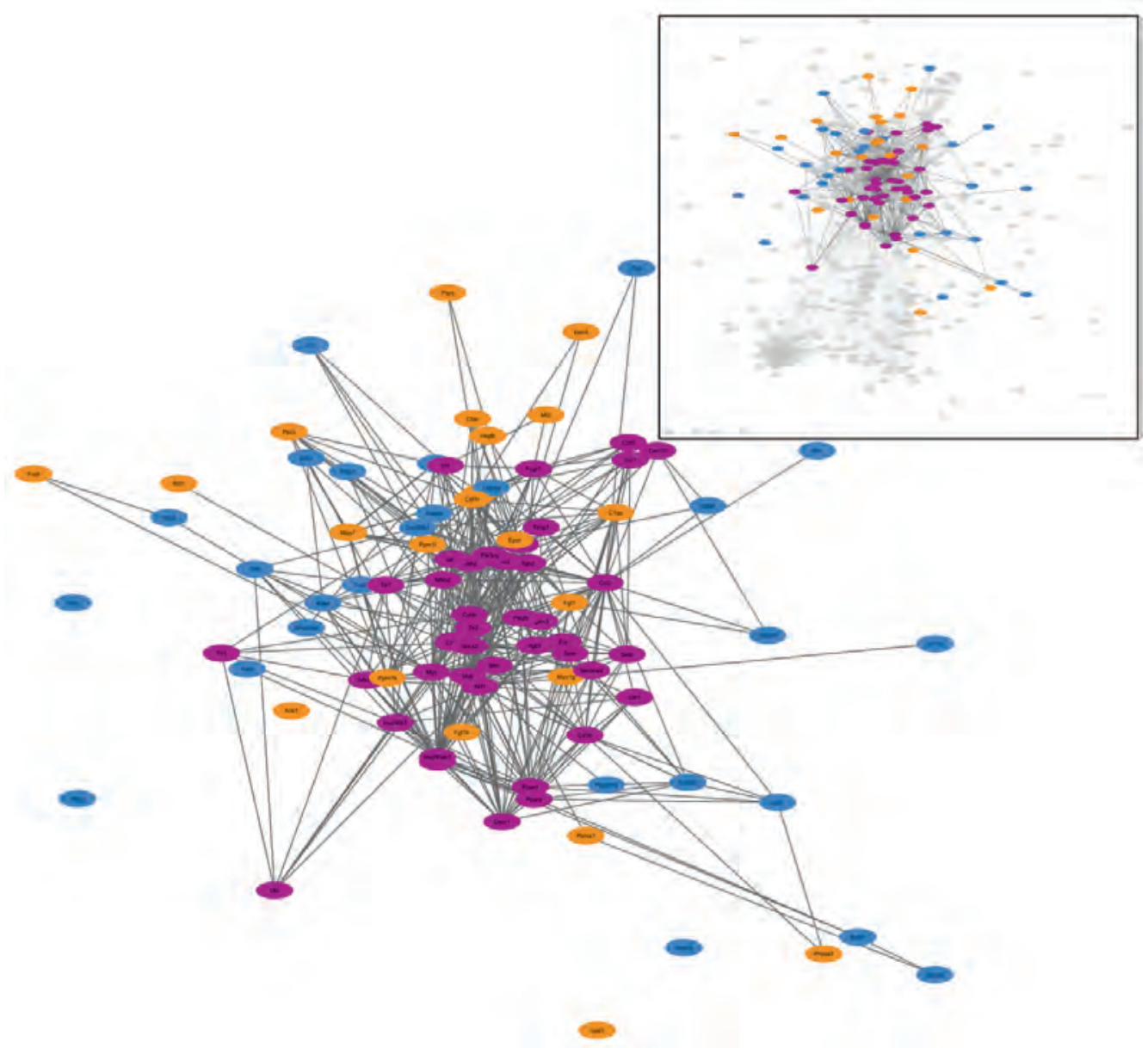

Figure 6: Endothelium and inflammation processes in the core network of the ZFS1-Obese versus Lean comparison. Top-right box indicates the process-related genes in the context of the complete core network. Differentially expressed genes that are part of the endothelium (orange) and inflammation (blue) processes are highlighted. Genes linked to both processes are marked in purple. The same figure for the ZSF1-Obese+HFD vs Lean comparison is provided as Supplementary Figure S5. 


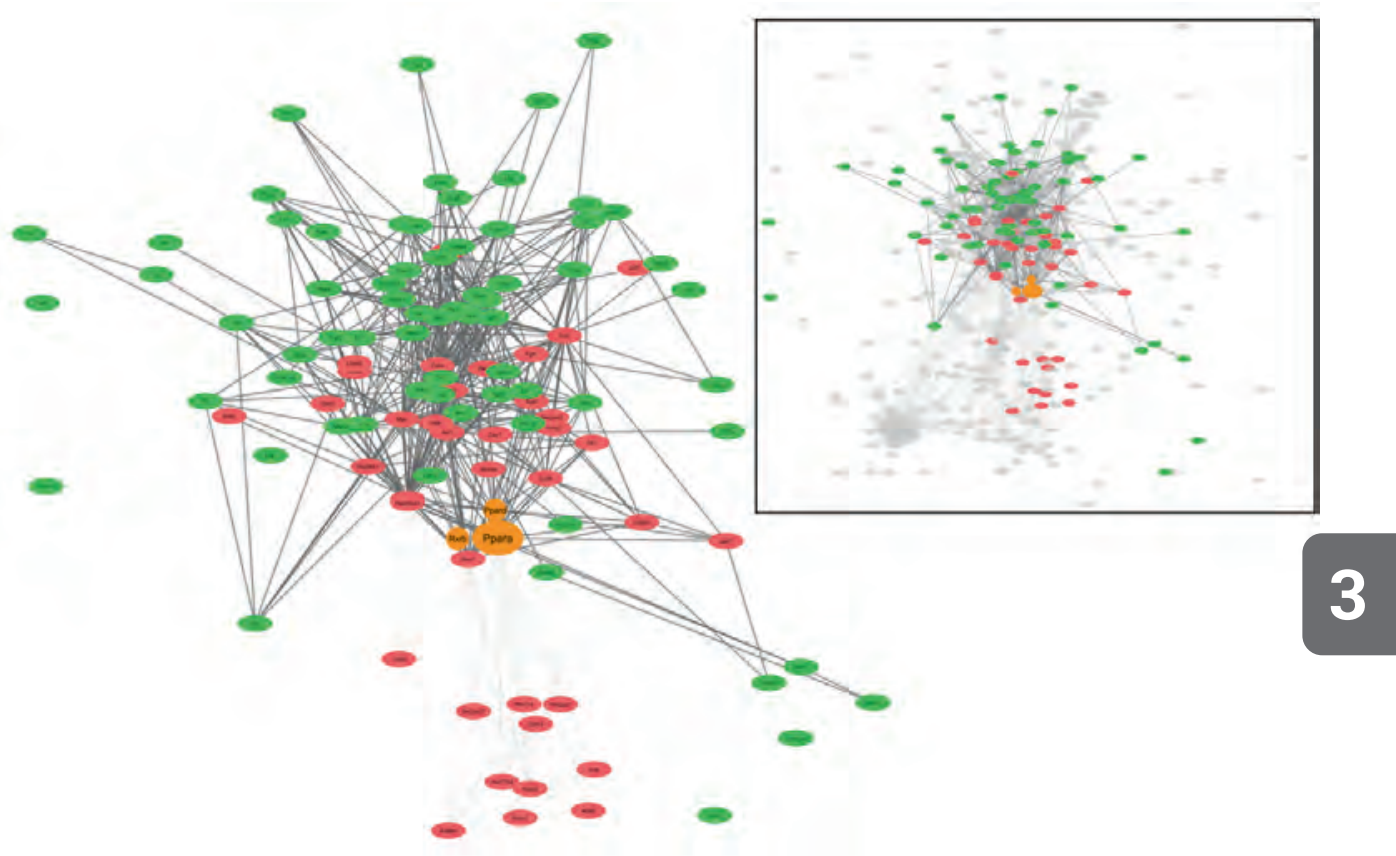

Figure 7: The Interplay between Ppara and the endothelium and inflammation genes in the ZSF1Obese vs Lean cardiac core network. Top-right box indicates process and Ppara related genes in the context of the complete core network. Ppars and their Rxr heterodimerization partners are highlighted in orange. Genes linked to endothelium and inflammation are coloured in green. Genes linked to Ppara but not part of the endolthelium and inflammation processes are coloured in red. The same figure for the Obese+HFD vs Lean comparison is provided as Supplementary Figure S6. 


\section{Discussion}

In the present study we developed a novel network approach to explore cardiac transcriptome data. Based on predefined biological processes involved in cardiac disease a STRING-based PPI network was created onto which cardiac expression data were projected. This cardiomedirected network analysis (CDNA) approach was used to interrogate RNA-seq based cardiac transcriptome data of ZSF1 rats with and without HFpEF. Our network analysis shows that inflammation, endothelial dysfunction, ECM remodelling and apoptosis/autophagy are important disease processes. Furthermore, the oncogene Myc and the nuclear hormone receptor Ppara are identified as important bottlenecks in the network, suggesting that these transcription factors play an important role in the development of HFpEF.

\section{ZSF1 rat as model of HFpEF}

The ZSF1-Obese rat is a well-characterized animal model in which multiple risk factors of the metabolic syndrome (hypertension, obesity, diabetes) are clustered. The cardiac function of these rats has been extensively phenotyped (echocardiography, pressure-volume analysis, cardiomyocyte stiffness), showing that these rats develop HFpEF. 9, 11, 27 In order to assess if a western-type diet further aggravated HFpEF, a subgroup of ZSF1-Obese rats was put on a high-fat diet (HFD). HFD led to an increase in caloric intake, water intake and urine output, but body weight did not increase further. Intriguingly, insulin resistance, cardiac hypertrophy and diastolic dysfunction were not worsened by the HFD. We conducted RNA-seq based transcriptomics and network analysis on ZSF1-Obese rats on a standard diet and HFD and compared them to the ZSF1-Lean control group (no HFpEF) to find cues as to how the combination of obesity, diabetes and hypertension drives the progression of HFpEF.

\section{Bioinformatic analysis}

The standard approaches to mine transcriptome data are based on gene ontology and pathway analysis. This allows one to assess if differentially expressed genes are overrepresented in certain predefined biological processes or pathways. In the present study, gene ontology and pathway analysis revealed metabolic processes to be mainly affected. 'Cardiac muscle contraction' and 'ventricular cardiac muscle tissue morphogenesis' also emerged as enriched processes. Generally speaking, however, terms and pathways directly associated with cardiac physiology and pathophysiology are poorly represented in these bioinformatics tools and, if available, they only cover a limited number of genes. To illustrate, the KEGG pathways related to the process "cardiac muscle contraction" (hsa04260) and to the cardiac disease 'hypertrophic cardiomyopathy' (hsa05410) encompass less than 100 genes. Moreover, these pathways primarily consist of well-known genes ('the usual suspects') implicated in cardiac (dys)function, namely ion channel, calcium handling and sarcomeric proteins. 


\section{Building a cardiome-directed network}

Given the limited relevance of the information regarding HFpEF development that can be extracted from GO and pathway analysis, we sought for alternative approaches to mine and provide biological meaning to cardiac transcriptome data sets. Thereto we used the public database STRING as a starting point. In short, STRING is a protein-protein interaction (PPI) network, merging several forms of evidence (curated interaction and pathway collections, text mining and predictions based on co-expression, genetic location and phylogenetics) to assign a weighted confidence score to the relatedness of proteins and genes. In this way, one can build a PPI network around a protein (gene), or a set of proteins (genes), of interest. We defined 11 biological processes that have been shown to become deranged in cardiac disease and selected genes (so called "bait genes") to build networks around these processes in STRING (so called "core networks"). The selection of these genes was based on an iterative process, based on prior knowledge and testing the ability of candidate genes to build a network for the process they represent.

An important choice in building the core networks is the threshold for the confidence score used to connect genes. A higher confidence value only allows for edges with a strong experimental evidence but reduces the size of the core networks. The effect of confidence levels on network size is shown in Supplementary Figure S7. For this study, we selected a threshold of 0.4 , yielding a network of almost 2.400 cardiac expressed genes to explore.

An alternative approach to construct networks from transcriptomics data is the Weighted Correlation Network Analysis (WGCNA). As the WGCNA modules are entirely based on correlations this analysis requires input of a substantially higher number of samples. Moreover, WGCNA in itself is unable to assign functions to modules. Typically, gene enrichment methods are subsequently used to characterize these modules. In contrast, our proposed methodology focuses on PPI within and between predefined processes. The selection of bait genes representing biological processes imparts functional characteristics on all connected genes. The basic principle is that genes connected to a bait interact with it in a biological meaningful way, implying they function in the same biological process. The current selection of processes and bait genes makes this CDNA approach directly applicable to all kinds of cardiac disease.

\section{Processes and genes driving HFpEF}

Routine gene enrichment analysis of our RNA-seq data revealed that mitochondrial oxidative metabolism is the main process affected in ZSF1-Obese rats suffering from HFpEF. Indeed, many genes involved in mitochondrial respiration were found to be downregulated. Substrate metabolism and mitochondrial respiration play a significant role in the development of HFpEF especially in view of the comorbidities commonly present in patients (diabetes, obesity) and as reflected in the ZSF1 model of cardiometabolic disease. ${ }^{2}$ Mechanistically, it is well feasible that impaired oxidative metabolism, and the reduced ATP synthesis associated with that, leads to diastolic dysfunction by compromising ATP demanding processes, like calcium handling and sarcomere function. Alternatively, the disturbances in respiratory chain activity 
may stimulate the production of reactive oxygen species (ROS), thereby affecting cardiac function.

Our CDNA approach revealed strong regulation in various cardiac disease associated core processes in ZSF1-Obese versus Lean rats. Moreover, upon closer assessment of the network, some of these core processes were found to be highly interconnected as they share a substantial number of differentially regulated genes (see Figures 4 and S3). This is particularly true for the processes endothelial function, inflammation, apoptosis/autophagy, reactive oxygen species and extracellular matrix, suggesting that these processes are interdependent and are important for HFpEF development. This fits with one of the prevailing hypotheses regarding HFpEF development. This hypothesis states that highly common comorbidities, such as obesity, diabetes and hypertension, induce systemic low-grade inflammation, evoking inflammation and increased ROS production in coronary microvascular endothelial cells. ${ }^{6,18}$ These maladaptive signals are conveyed to adjacent cardiomyocytes and fibroblasts leading to increased cardiomyocyte stiffness and extracellular matrix deposition and ultimately left ventricular diastolic dysfunction. Hence, the high interconnectivity of these processes in our network analysis supports this hypothesis of HFpEF development. Notably, we show that the core process apoptosis/autophagy is also highly interconnected (see Figure 4), suggesting that there also might be a role for apoptosis and autophagy in HfpEF development. Intriguingly, the two most differentially regulated processes, substrate metabolism and mitochondrial respiration, are not extensively connected to the other core processes, but only via a small number of genes, including Ppara.

Using our CDNA the transcription factors Myc and Ppara were identified as bottle neck genes in the network. Myc is a proto-oncogene that has been associated with tumour cell proliferation, apoptosis and metabolic reprogramming. ${ }^{28}$ Cardiac expression of Myc is rapidly induced after applying pressure overload. ${ }^{29}$ Forced expression of Myc is sufficient to induce cardiac hypertrophy and cell cycle re-entry of cardiomyocytes ${ }^{30}$, whereas knock out of Myc attenuates cardiomyocyte growth under hemodynamic stress. ${ }^{31}$ Notably, Myc also plays an important role in the regulation of cardiac metabolism, most likely by interfering with Ppargc1a function, a co-activator of Ppara. ${ }^{31,32}$

Ppara belongs to the family of ligand-activated nuclear hormone receptors and is abundantly present in tissues with a high fatty acid metabolism, such as the heart. Longchain fatty acids (LCFA) act as natural ligands for Ppars and ligand-bound Ppars binds to target genes to stimulate transcription of genes involved in LCFA uptake and metabolism. ${ }^{33}$ In addition, Ppara regulates the expression of genes involved in the oxidative stress response and antagonizes the function of other transcription factors, such as NFKB, thereby reducing the expression of proinflammatory genes. ${ }^{34}$ Concordant with the phenotype and the function of Ppar, in the ZSF1 rat model of cardiometabolic disease the cardiac expression of the majority of genes involved in LCFA metabolism is increased. At the same time, the expression of many genes that are part of the mitochondrial respiratory chain was found to decrease. Conceivably, this leads to a mismatch between the uptake 
the ultimate oxidation of FA, resulting in lipotoxicity and impairment of energy regenerating processes.

The enzyme Decr1 also emerges as an important bottleneck gene in the network. Decr1 is markedly upregulated in ZSF1-Obese rats, especially when feeding a HFD (see supplementary Figure S4). It catalyses the NADPH-dependent reduction of double bonds of unsaturated long-chain fatty acids, thereby preparing them for mitochondrial beta-oxidation ${ }^{35}$, and has been identified as a target of both c-myc ${ }^{36}$ and Ppara. ${ }^{37}$ The role of this enzyme in cardiac disease has, to the best of our knowledge, never been studied and warrants further investigation.

In conclusion, in the current study, we present a novel cardiome-directed network analysis (CDNA) based on STRING-based protein-protein interactions. This approach is directly applicable to other cardiac disease derived transcriptome data sets and, after adjusting the selection of processes and bait genes, can be easily applied to other organs and diseases. Using this novel bioinformatics approach, we identified Myc, Ppara and Decr1 as important nexuses in the HFpEF network. This warrants further investigation into the role of these genes in the development of HFpEF. 


\section{Funding}

This work was supported by grants from the European Commission (FP7-Health-2010, MEDIA-261409 to S.H. and A.F.L-M.), the European Research Area Network (ERA-CVD LYMIT-DIS project; Netherlands Heart Foundation and NWO-ZonMw Grant no. 2016T091 to M.v.B.), the Fundo Europeu de Desenvolvimento Regional (FEDER) through Compete 2020 - Programa Operacional Competitividade E Internacionalização $(\mathrm{POCl})$, the project DOCNET (norte-01-0145-feder-000003), supported by Norte Portugal regional operational programme (norte 2020), under the Portugal 2020 partnership agreement, through the European Regional Development Fund (ERDF), the project NETDIAMOND (POCI-01-0145-FEDER-016385), supported by European Structural And Investment Funds, Lisbon's regional operational program 2020. D.M-S. was funded by Fundação para a Ciência e Tecnologia (FCT) by fellowship grants (SFRH/BD/87556/2012).

\section{Acknowledgements}

The authors thank Dulce Fontoura and Sara Leite for their technical assistance in animal handling.

\section{Disclosures}

None 


\section{References}

1. Perrone-Filardi $P$, Paolillo $S$, Costanzo $P$, Savarese G, Trimarco B, Bonow RO. The role of metabolic syndrome in heart failure. Eur Heart J 2015;36:2630-2634.

2. Miranda-Silva D, Wust RCI, Conceicao G, Goncalves-Rodrigues P, Goncalves N, Goncalves A, Kuster DWD, Leite-Moreira $A F$, van der Velden J, de Sousa Beleza JM, Magalhaes J, Stienen GJM, FalcaoPires I. Disturbed cardiac mitochondrial and cytosolic calcium handling in a metabolic risk-related rat model of heart failure with preserved ejection fraction. Acta Physiol (Oxf) 2020;228:e13378.

3. Borbely A, Falcao-Pires I, van Heerebeek L, Hamdani N, Edes I, Gavina C, LeiteMoreira AF, Bronzwaer JG, Papp Z, van der Velden J, Stienen GJ, Paulus WJ. Hypophosphorylation of the Stiff N2B titin isoform raises cardiomyocyte resting tension in failing human myocardium. Circ Res 2009;104:780-786.

4. LeWinter MM, Meyer M. Mechanisms of diastolic dysfunction in heart failure with a preserved ejection fraction: If it's not one thing it's another. Circ Heart Fail 2013;6:1112-1115.

5. Grundy SM. Metabolic syndrome pandemic. Arterioscler Thromb Vasc Biol 2008;28:629-636.

6. Paulus WJ, Tschope C. A novel paradigm for heart failure with preserved ejection fraction: comorbidities drive myocardial dysfunction and remodeling through coronary microvascular endothelial inflammation. $\mathrm{J} A m$ Coll Cardiol 2013;62:263-271.

7. Schlotter F, Halu A, Goto S, Blaser MC, Body SC, Lee LH, Higashi H, DeLaughter DM, Hutcheson JD, Vyas $P$, Pham $T$, Rogers MA, Sharma A, Seidman CE, Loscalzo J, Seidman JG, Aikawa M, Singh SA, Aikawa E. Spatiotemporal MultiOmics Mapping Generates a Molecular Atlas of the Aortic Valve and Reveals Networks Driving Disease. Circulation 2018;138:377-393.

8. Barabasi AL, Gulbahce N, Loscalzo J. Network medicine: a network-based approach to human disease. Nat Rev Genet 2011;12:56-68.

9. Hamdani N, Franssen C, Lourenco A, Falcao-Pires I, Fontoura D, Leite S, Plettig L, Lopez B, Ottenheijm CA, Becher PM, Gonzalez A, Tschope C, Diez J, Linke WA, Leite-Moreira AF, Paulus WJ.
Myocardial titin hypophosphorylation importantly contributes to heart failure with preserved ejection fraction in a rat metabolic risk model. Circ Heart Fail 2013;6:1239-1249

10. van Dijk CG, Oosterhuis NR, Xu YJ, Brandt M, Paulus WJ, van Heerebeek L, Duncker DJ, Verhaar MC, Fontoura D, Lourenco AP, Leite-Moreira AF, FalcaoPires I, Joles JA, Cheng C. Distinct Endothelial Cell Responses in the Heart and Kidney Microvasculature Characterize the Progression of Heart Failure With Preserved Ejection Fraction in the Obese ZSF1 Rat With Cardiorenal Metabolic Syndrome. Circ Heart Fail 2016;9:e002760.

11. Leite S, Oliveira-Pinto J, Tavares-Silva M, Abdellatif M, Fontoura D, Falcao-Pires I, Leite-Moreira AF, Lourenco AP. Echocardiography and invasive hemodynamics during stress testing for diagnosis of heart failure with preserved ejection fraction: an experimental study. Am J Physiol Heart Circ Physiol 2015;308:H1556-1563.

12. Leite $S$, Cerqueira RJ, Ibarrola J, Fontoura D, Fernandez-Celis A, Zannad F, FalcaoPires I, Paulus WJ, Leite-Moreira AF, Rossignol P, Lopez-Andres N, Lourenco AP. Arterial Remodeling and Dysfunction in the ZSF1 Rat Model of Heart Failure With Preserved Ejection Fraction. Circ Heart Fail 2019;12:e005596.

13. Valero-Munoz M, Backman W, Sam F. Murine Models of Heart Failure with Preserved Ejection Fraction: a "Fishing Expedition". JACC Basic Transl Sci 2017;2:770-789.

14. Szklarczyk D, Morris JH, Cook H, Kuhn M, Wyder S, Simonovic M, Santos A, Doncheva NT, Roth A, Bork P, Jensen LJ, von Mering $C$. The STRING database in 2017: quality-controlled protein-protein association networks, made broadly accessible. Nucleic Acids Res 2017;45:D362-D368.

15. Hannon GJ. FASTX-Toolkit. 2010.

16. Martin M. Cutadapt removes adapter sequences from high-throughput sequencing reads. EMBnetjournal; Vol 17, No 1: Next Generation Sequencing Data Analysis 2011

17. Kim D, Pertea G, Trapnell C, Pimentel H, Kelley R, Salzberg SL. TopHat2: accurate alignment of transcriptomes in the 
presence of insertions, deletions and gene fusions. Genome Biol 2013;14:R36.

18. Trapnell C, Williams BA, Pertea G, Mortazavi A, Kwan G, van Baren MJ, Salzberg SL, Wold BJ, Pachter L. Transcript assembly and quantification by RNA-Seq reveals unannotated transcripts and isoform switching during cell differentiation. Nat Biotechnol 2010;28:511-515.

19. Anders S, Pyl PT, Huber W. HTSeq--a Python framework to work with highthroughput sequencing data. Bioinformatics 2015;31:166-169.

20. Robinson MD, McCarthy DJ, Smyth GK. edgeR: a Bioconductor package for differential expression analysis of digital gene expression data. Bioinformatics 2010;26:139-140.

21. Huang da W, Sherman BT, Lempicki RA. Bioinformatics enrichment tools: paths toward the comprehensive functional analysis of large gene lists. Nucleic Acids Res 2009;37:1-13.

22. Summer G, Kelder T, Ono K, Radonjic M, Heymans S, Demchak B. cyNeo4j: connecting Neo4j and Cytoscape. Bioinformatics 2015;31:3868-3869.

23. Shannon P, Markiel A, Ozier O, Baliga NS, Wang JT, Ramage D, Amin N, Schwikowski B, Ideker T. Cytoscape: a software environment for integrated models of biomolecular interaction networks. Genome Res 2003;13:24982504.

24. Poornima IG, Parikh P, Shannon RP. Diabetic cardiomyopathy: the search for a unifying hypothesis. Circ Res 2006;98:596-605.

25. Makhnevych T, Houry WA. The role of Hsp90 in protein complex assembly. Biochim Biophys Acta 2012;1823:674682.

26. Warren JS, Oka SI, Zablocki D, Sadoshima J. Metabolic reprogramming via PPARalpha signaling in cardiac hypertrophy and failure: From metabolomics to epigenetics. $A m \mathrm{~J}$ Physiol Heart Circ Physiol 2017;313:H584-H596.

27. Franssen C, Chen S, Unger A, Korkmaz HI, De Keulenaer GW, Tschope C, LeiteMoreira AF, Musters R, Niessen HW, Linke WA, Paulus WJ, Hamdani N. Myocardial Microvascular Inflammatory Endothelial Activation in Heart Failure With Preserved Ejection Fraction. JACC Heart Fail 2016;4:312-324.
28. Wolpaw AJ, Dang CV. MYC-induced metabolic stress and tumorigenesis. Biochim Biophys Acta Rev Cancer 2018;1870:43-50.

29. Izumo S, Nadal-Ginard B, Mahdavi V. Protooncogene induction and reprogramming of cardiac gene expression produced by pressure overload. Proc Natl Acad Sci U S A 1988;85:339-343.

30. Xiao G, Mao S, Baumgarten G, Serrano J, Jordan MC, Roos KP, Fishbein MC, MacLellan WR. Inducible activation of $\mathrm{C}$ Myc in adult myocardium in vivo provokes cardiac myocyte hypertrophy and reactivation of DNA synthesis. Circ Res 2001;89:1122-1129.

31. Ahuja $P$, Zhao $P$, Angelis $E$, Ruan $H$, Korge $P$, Olson A, Wang Y, Jin ES, Jeffrey FM, Portman M, Maclellan WR. Myc controls transcriptional regulation of cardiac metabolism and mitochondrial biogenesis in response to pathological stress in mice. $J$ Clin Invest 2010;120:1494-1505.

32. Dadson K, Hauck L, Hao Z, Grothe D, Rao V, Mak TW, Billia F. The E3 ligase Mule protects the heart against oxidative stress and mitochondrial dysfunction through Myc-dependent inactivation of Pgc-1alpha and Pink1. Sci Rep 2017;7:41490.

33. Gilde AJ, van der Lee KA, Willemsen $\mathrm{PH}$, Chinetti G, van der Leij FR, van der Vusse GJ, Staels B, van Bilsen M. Peroxisome proliferator-activated receptor (PPAR) alpha and PPARbeta/delta, but not PPARgamma, modulate the expression of genes involved in cardiac lipid metabolism. Circ Res 2003;92:518-524.

34. Yue TL, Bao W, Jucker BM, Gu JL, Romanic AM, Brown PJ, Cui J, Thudium DT, Boyce R, Burns-Kurtis CL, Mirabile $\mathrm{RC}$, Aravindhan K, Ohlstein EH. Activation of peroxisome proliferator-activated receptor-alpha protects the heart from ischemia/reperfusion injury. Circulation 2003;108:2393-2399.

35. Yu W, Chu X, Chen G, Li D. Studies of human mitochondrial 2,4-dienoyl-CoA reductase. Arch Biochem Biophys 2005;434:195-200.

36. Li Z, Zheng W, Wang Z, Zeng Z, Zhan H, Li C, Zhou L, Yan C, Spitsbergen JM, Gong Z. A transgenic zebrafish liver tumor model with inducible Myc expression reveals conserved Myc signatures with mammalian liver tumors. Dis Model Mech 2013;6:414-423. 
37. Miyazaki M, Nakagawa I, Koga S, Kasahara Y, Patricelli MP. Proteomics analysis of cardiac muscle from rats with peroxisomal proliferator-activated receptor alpha (PPARalpha) stimulation. $J$ Toxicol Sci 2010;35:131-135. 


\section{Supplementary Material}

Figure S1: Enriched biological processes in ZSF1-Obese+HFD rats with HFpEF versus ZSF1Lean rats.

\section{Top 10 Processes Obese + HFD vs. Lean}

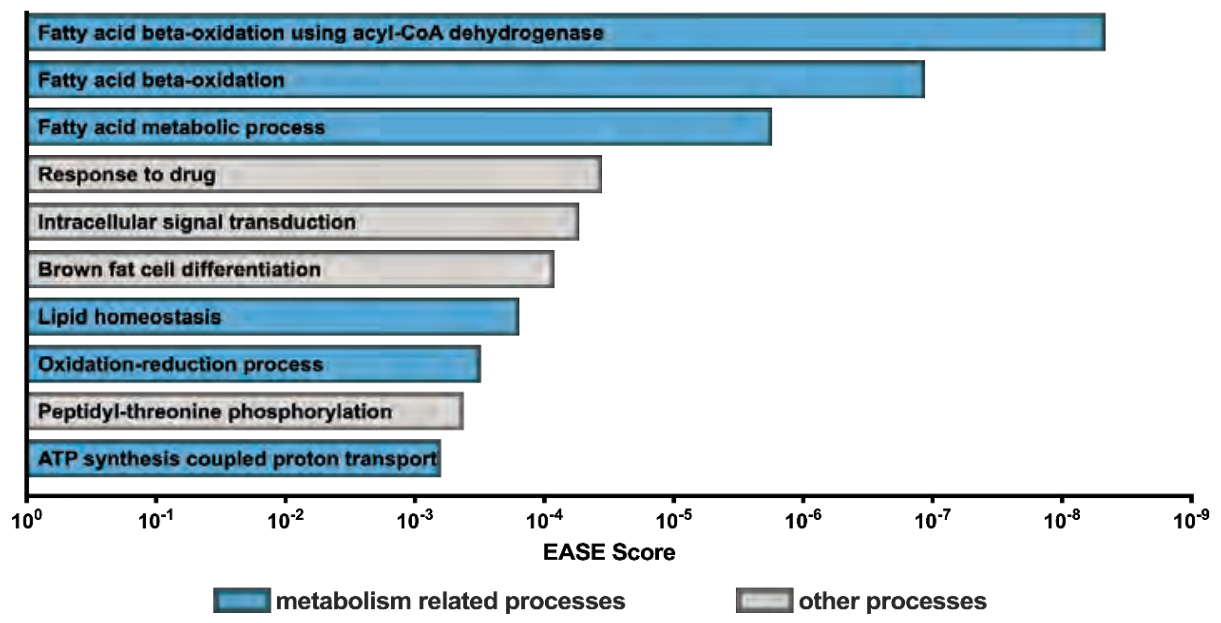

The top 10 enriched biological processes from Gene Ontology were ranked according to their EASE score. An EASE score $<0.1$ was considered significant. 
Figure S2: The cardiac core processes connected by the number of shared and differentially expressed genes when comparing ZSF1-Obese+HFD and ZSF1-Lean rats.

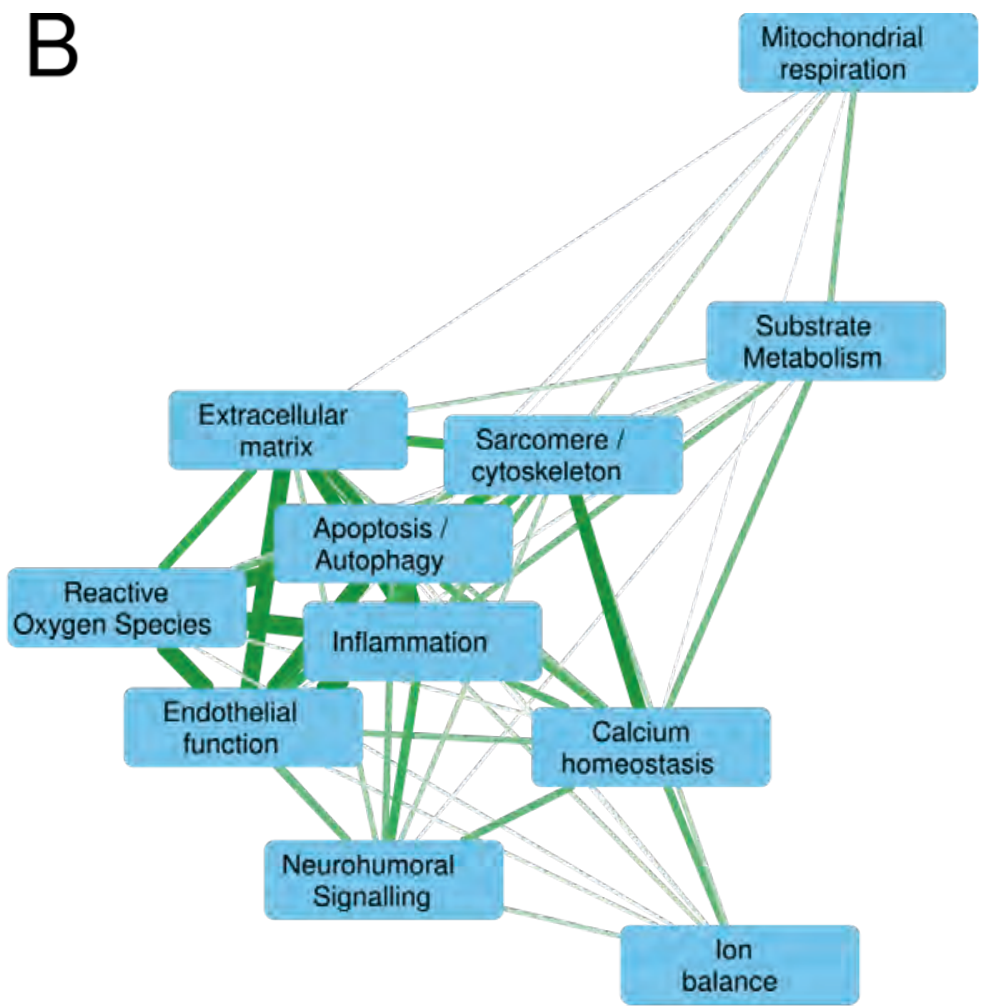

The edge thickness and colour intensity correspond to the number of shared genes. 
Figure S3: The core network based on the ZSF1-Obese+HFD versus Lean comparison.

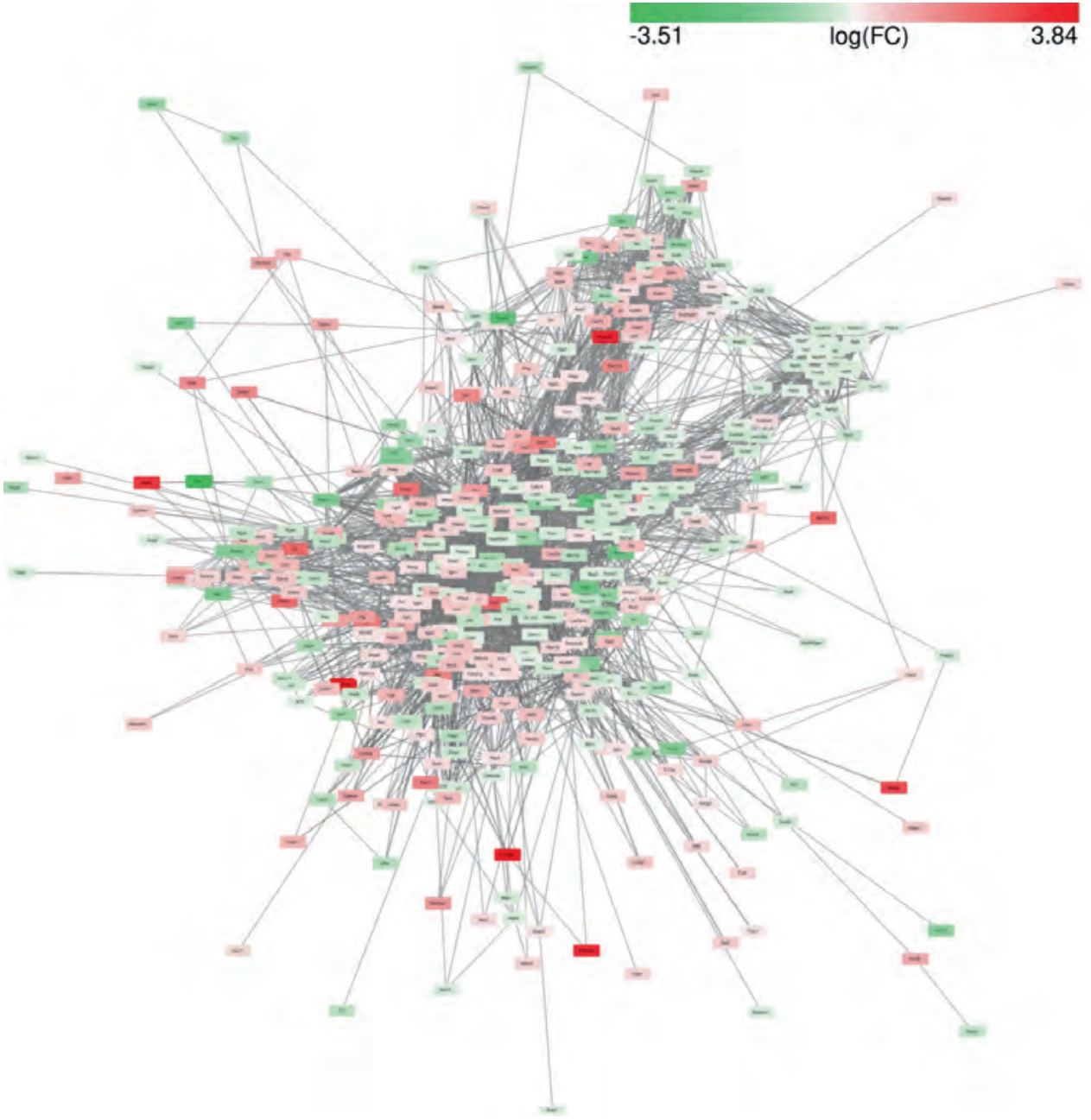

Differentially expressed genes are connected with protein-protein interactions from STRING-DB with a confidence of $\geq 0.4$. Each gene is coloured with a gradient from green (decreased) to red (increased) representing the log fold change. 
Figure S4: Gene expression analysis of important genes involved in HFpEF development in the ZSF1-Obese and ZSF1-Obese+HFD rat compared to ZSF1-Lean rats
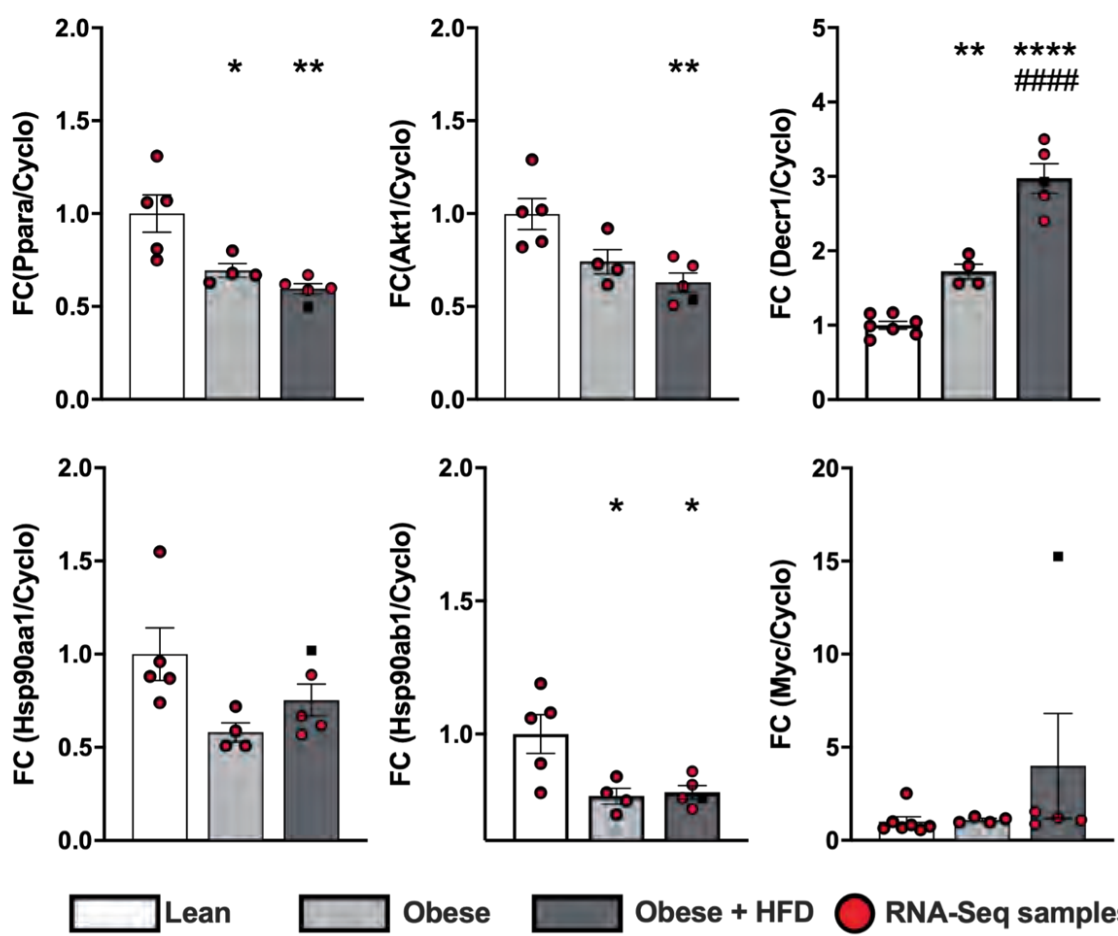

Obese

\section{$\square$ Obese + HFD}

RNA-Seq samples

Expression of bottleneck genes in ZSF1-Lean, Obese and Obese+HFD ( $n \geq 4$ per group). Values are mean \pm SEM. One-way ANOVA with Bonferroni post hoc test: $P<0.05:{ }^{*}$ vs. Lean, $P<0.01:{ }^{*}$ vs. Lean,

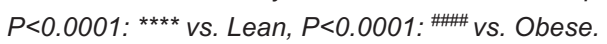


Figure S5: Endothelium and inflammation processes in the core network of the ZFS1-Obese+HFD versus Lean comparison

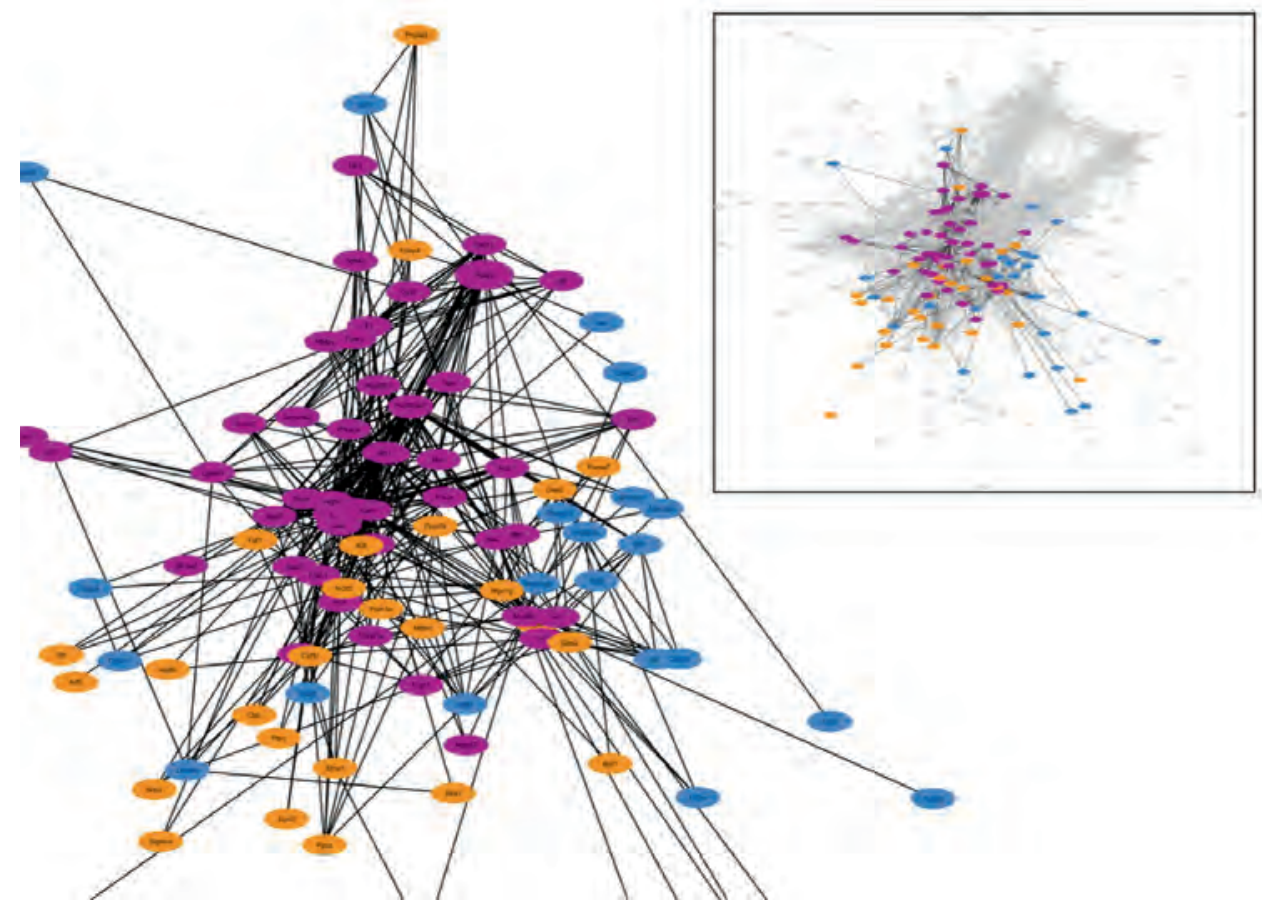

Top-right box indicates the process-related genes in the context of the complete core network. Differentially expressed genes that are part of the endothelium (orange) and inflammation (blue) processes are highlighted. Genes linked to both processes are marked in purple. 
Figure S6: The Interplay between PPARa and the endothelium and inflammation genes in the ZSF1-Obese+HFD versus Lean cardiac core network.

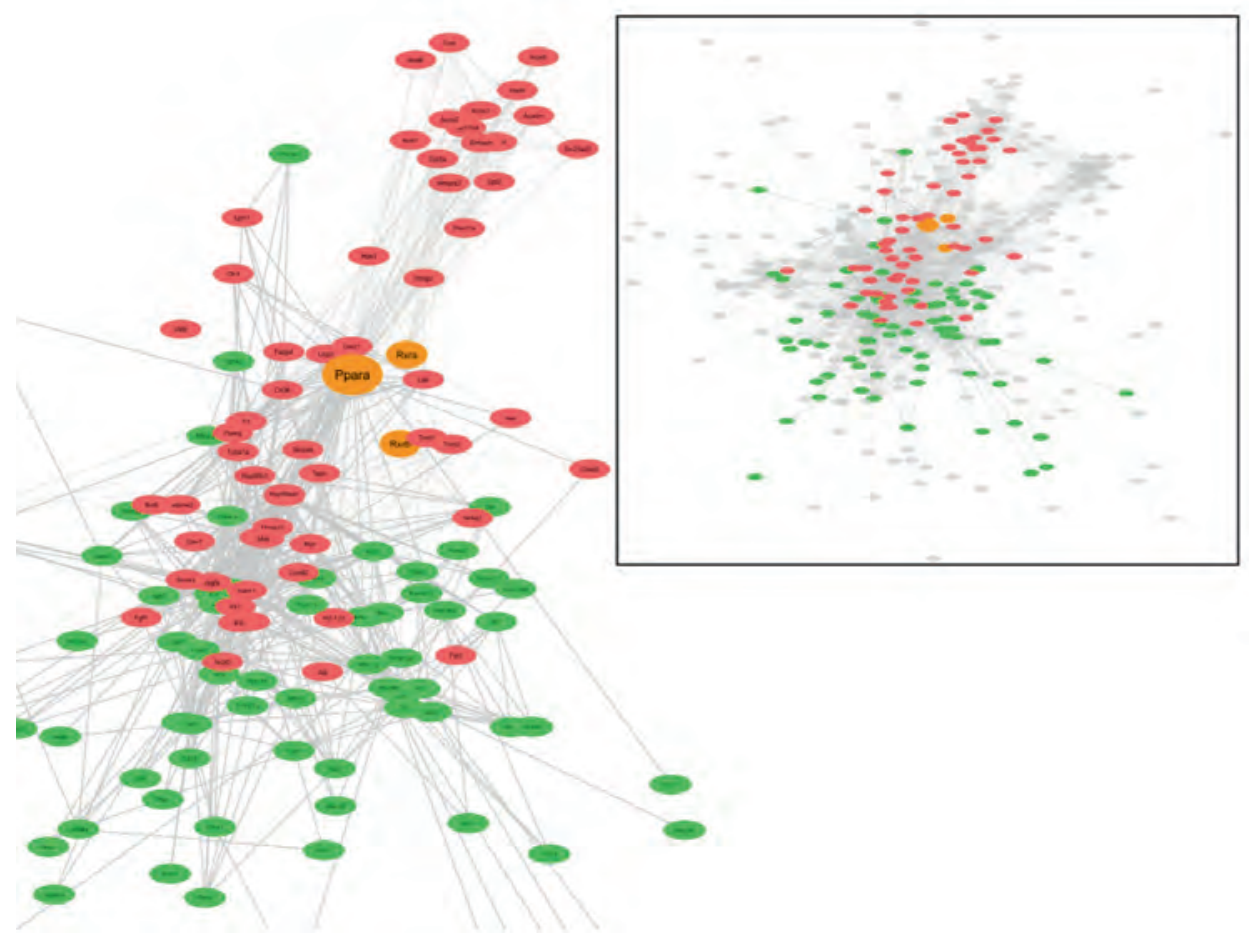

Top-right box indicates process and Ppara related genes in the context of the complete core network. Ppars and their Rxr heterodimerizationpartners are highlighted in orange. Genes linked to endothelium and inflammation are coloured in green. Genes linked to Ppara but not part of the endothelium and inflammation processes are coloured in red. 
Figure S7: Effect of confidence score on network size

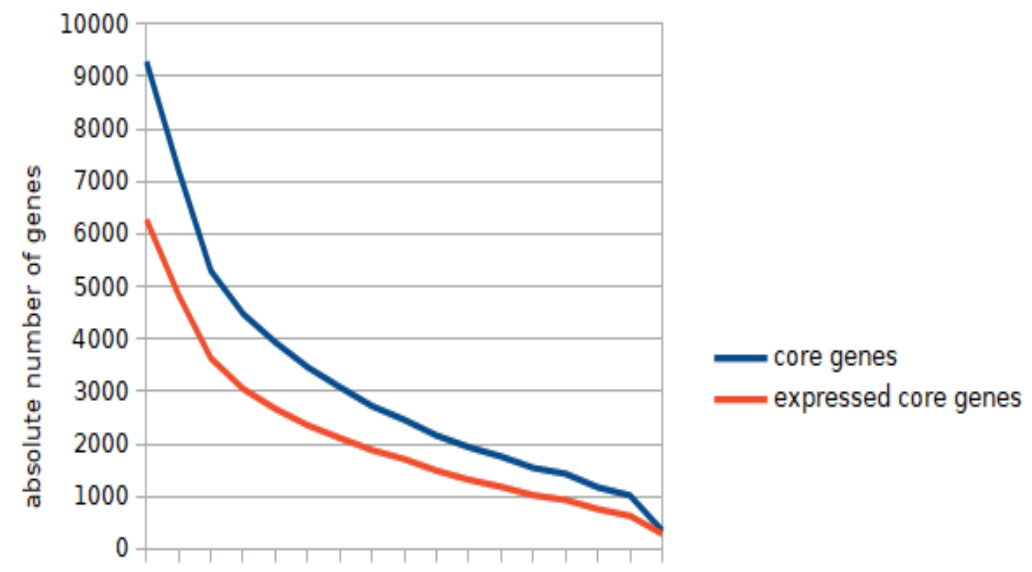

The number of genes connected to bait genes per confidence score. In blue are all core genes connected in STRING, in red only those that are expressed in the heart according to the RNA-seq dataset. The smallest confidence provided by STRING-DB is 0.15 .

Choice of confidence level: The core networks are built from the bait genes (Table 1) and their interactions with other genes. The STRING database assigns a level of confidence to each interaction between the members of the network. Accordingly, the ultimate size of the core network is dependent on the selected confidence level. The figure above shows the relation between confidence level and the size of the entire network. The network size decreases with increasing confidence level, but the ratio of total core genes and expressed core genes remained fairly constant over a broad range of confidence scores. Based on this information we selected a confidence score of $\geq 0.4$ for our CDNA.

Applying a higher confidence limits the size of the core network and ensures that most of the connections (edges) are backed by strong experimental evidence but, at the same time, blinds to lesser studied interactions and potential new discoveries. Indeed, increasing the confidence score from 0.4 to 0.7 almost halved network size (from 407 to 209 differentially expressed genes) for the ZSF1-Obese - Lean comparison. Conversely, to increase the network size one could reduce the threshold to values lower than 0.4. In view of the limited evidence supporting the connections obtained in that case, this is not advisable. Notably, the top 10 list of hub and bottleneck genes was only modestly affected by increasing the confidence score from 0.4 to 0.7 (see Supplementary website https://github.com/gsummer/cdna).

Table S1: Primer sequences for qPCR gene expression analyses.

\begin{tabular}{ccc} 
Target & Forward Primer Sequence & Reverse Primer Sequence \\
\hline Myc & TGGAAAACCCGACAGTCACG & ATGAAATAGGGCTGCACCGA \\
Hsp90aa1 & ATGATGACGAGCAGTACGCC & CGACCCATTGGTTCACCTGT \\
Hsp90ab1 & TTCTGATGCCCTGGACAAGA & AATCTTCAGCTCTTTCCCGCT \\
Decr1 & TGTGATCGCGAGCAGGAATA & GATCTCGAACGTCACACCGA \\
Ppara & ACTATGGAGTCCACGCATGTGA & TTGTCGTACGCCAGCTTTAGC \\
Akt1 & TGTATGAGAAGAGCTGAGCCCAC & CCGTTCACTGTCCACACACTCC \\
Cyclo & CAAATGCTGGACCAAACACAA & TTCACCTTCCCAAAGACCACAT \\
\hline
\end{tabular}


Table S2: Morphometric, metabolic and cardiac functional characterization of ZSF1-Lean, ZSF1Obese, and ZSF1-Obese rats on a HFD.

\begin{tabular}{|c|c|c|c|}
\hline Parameter & Lean & Obese & Obese+HFD \\
\hline Body weight (g) & $423 \pm 8$ & $600 \pm 7^{* * *}$ & $554 \pm 8^{* * *, t t \dagger}$ \\
\hline Tibial length (mm) & $40.9 \pm 0.1$ & $40.0 \pm 0.0$ & $38.4 \pm 0.1^{* *}$ \\
\hline Heart weight/TL (mg/mm) & $34.0 \pm 0.9$ & $41.6 \pm 0.9^{* * *}$ & $41.0 \pm 1.0^{* * *}$ \\
\hline $\mathrm{RV}$ weight/TL (mg/mm) & $3.3 \pm 0.3$ & $4.2 \pm 0.3$ & $4.2 \pm 0.4$ \\
\hline Lung weight/TL (mg/mm) & $46.1 \pm 1.9$ & $56.4 \pm 2.9^{*}$ & $58.6 \pm 3.4^{* *}$ \\
\hline Perirenal fat weight/TL (mg/mm) & $52.1 \pm 3.6$ & $331.1 \pm 19.0^{* * *}$ & $407.0 \pm 21.5^{* * *, t \dagger}$ \\
\hline Perigonadal fat weight/TL $(\mathrm{mg} / \mathrm{mm})$ & $57.3 \pm 4.2$ & $144.0 \pm 10.4^{* * *}$ & $141.8 \pm 4.5^{* * *}$ \\
\hline Gastrocnemius weight/TL (mg/mm) & $63.0 \pm 1.5$ & $53.7 \pm 1.3^{* * *}$ & $48.8 \pm 0.7^{* * *, \dagger}$ \\
\hline Glycaemia (mg/dL) & $72.4 \pm 4.4$ & $174.7 \pm 12.7^{* * *}$ & $186.3 \pm 13.4^{* * *}$ \\
\hline OGT, AUC (mg/dL per hour) & $97.1 \pm 4.2$ & $229.6 \pm 16.8^{* * *}$ & $244.4 \pm 12.5^{* * *}$ \\
\hline Insulin resistance, AUC (mg/dL per hour) & $57.1 \pm 3.6$ & $149.3 \pm 6.8^{* * *}$ & $153.4 \pm 14.5^{* * *}$ \\
\hline Caloric intake/weight (Kcal/Kg per day) & $164 \pm 15$ & $160 \pm 8$ & $255 \pm 11^{* * *, \mathrm{tt \dagger}}$ \\
\hline Water intake/weight (mL/Kg per day) & $52.8 \pm 7.4$ & $85.1 \pm 11.7$ & $202.9 \pm 17.0^{* * *, t+t}$ \\
\hline Urine output/weight (mL/Kg per day) & $31.5 \pm 2.8$ & $72.7 \pm 11.0$ & $198.5 \pm 16.3^{* * *, \mathrm{tt} \dagger}$ \\
\hline $\mathrm{VO}_{2}$ - Peak Effort Testing $\left(\mathrm{mL} / \mathrm{min} \cdot \mathrm{cm}^{-2}\right)$ & $30.6 \pm 1.3$ & $14.2 \pm 0.9^{* * *}$ & $13.8 \pm 1.2^{* * *}$ \\
\hline $\mathrm{VCO}_{2}$ - Peak Effort Testing $\left(\mathrm{mL} / \mathrm{min} . \mathrm{cm}^{-2}\right)$ & $27.5 \pm 1.2$ & $14.5 \pm 0.8^{* * *}$ & $13.4 \pm 0.9^{* * *}$ \\
\hline $\mathrm{VO}_{2}$ - Endurance Testing (mL/min. $\left.\mathrm{cm}^{-2}\right)$ & $28.0 \pm 1.0$ & $16.9 \pm 0.8^{* * *}$ & $21.3 \pm 1.6^{* *, \dagger}$ \\
\hline $\mathrm{VCO}_{2}$ - Endurance Testing (mL/min. $\mathrm{cm}^{-2}$ ) & $22.2 \pm 0.7$ & $14.5 \pm 0.5^{* * *}$ & $15.1 \pm 0.5^{* * *}$ \\
\hline HR (bpm) & $320 \pm 10$ & $310 \pm 7$ & $319 \pm 7$ \\
\hline dLVPW (mm) & $14.5 \pm 0.3$ & $15.1 \pm 0.2$ & $14.9 \pm 0.0$ \\
\hline LVMI (mg) & $562 \pm 27$ & $777 \pm 16^{* * *}$ & $695 \pm 21^{* * *, \dagger}$ \\
\hline FS (\%) & $37.9 \pm 1.7$ & $37.8 \pm 0.8$ & $39.5 \pm 1.3$ \\
\hline EF (\%) & $73.2 \pm 2.2$ & $73.2 \pm 0.9$ & $75.0 \pm 1.5$ \\
\hline $\mathrm{S}^{\prime}(\mathrm{mm} / \mathrm{s})$ & $47.7 \pm 4.6$ & $53.9 \pm 1.9^{* *}$ & $49.3 \pm 3.8$ \\
\hline $\mathrm{Cl}\left(\mu \mathrm{L} / \mathrm{min} / \mathrm{cm}^{2}\right)$ & $203 \pm 12$ & $217 \pm 6^{* *}$ & $252 \pm 13^{\dagger}$ \\
\hline MPI (Tei) & $0.70 \pm 0.04$ & $0.62 \pm 0.02$ & $0.75 \pm 0.04^{\dagger}$ \\
\hline E/A & $1.56 \pm 0.09$ & $1.26 \pm 0.03^{* *}$ & $1.42 \pm 0.07$ \\
\hline$E / E^{\prime}$ & $12.0 \pm 0.5$ & $16.3 \pm 0.3^{* * *}$ & $15.4 \pm 0.7^{* * *}$ \\
\hline $\operatorname{LAA}\left(\mathrm{mm}^{2}\right)$ & $0.27 \pm 0.01$ & $0.35 \pm 0.01^{* * *}$ & $0.34 \pm 0.01^{* * *}$ \\
\hline EDVI $\left(\mu \mathrm{L} / \mathrm{cm}^{2}\right)$ & $1.95 \pm 0.09$ & $2.20 \pm 0.07$ & $2.01 \pm 0.06$ \\
\hline
\end{tabular}

$T L$, tibia length; LV, left ventricle; IVS, interventricular septum; RV, right ventricle; AUC, area under curve; HR, heart rate; $d L V P W$, left ventricular posterior wall measured in diastole; LVMI, left ventricular mass indexed for body surface area; FS, fractional shortening; EF, ejection fraction; S', peak systolic tissue Doppler velocity at the mitral annulus; Cl, cardiac index; MPI, myocardial performance index or Tei index; E/A, ratio between peak $E$ and $A$ waves of pulsed-wave Doppler mitral flow velocity; E/E', ratio between peak $E$ wave velocity of pulsed-wave Doppler mitral flow and peak $E$ ' wave velocity of tissue Doppler at the lateral mitral annulus; LAA, left atrial area; EDVI, end-diastolic volume indexed for body surface area; Values are mean \pm SEM. $n$ amounted to $\geq 9$ animals per experimental group for each parameter, except for VO2 measurements ( $n=6-9$ per group). One-way ANOVA with Bonferroni post hoc test: $P<0.05:{ }^{*}$ vs ZSF1-Lean, ${ }^{\dagger}$ vs ZSF1-Obese; $P<0.01:{ }^{* *}$ vs ZSF1-Lean, ${ }^{t+}$ vs ZSF1-Obese; $P<0.001:{ }^{* * *}$ vs ZSF1-Lean; ${ }^{t t+}$ vs ZSF1-Obese. 
Table S3: Cardiac core processes and numbers of differentially expressed genes per process between ZSF1-Obese+HFD and Lean rats.

\begin{tabular}{cccc} 
Process & Core Sizes & Expressed (\%) & $\begin{array}{c}\text { Diff expressed } \\
\text { ZSF1-Obese+HFD } \\
\text { vs. Lean (\%) }\end{array}$ \\
\hline Sarcomere/cytoskeleton & 441 & $359(81.41)$ & $82(22.84)$ \\
Calcium homeostasis & 191 & $144(75.39)$ & $33(22.92)$ \\
Ion balance & 221 & $144(65.16)$ & $35(24.31)$ \\
Substrate metabolism & 291 & $239(82.13)$ & $74(30.96)$ \\
Mitochondrial respiration & 152 & $122(80.26)$ & $39(31.97)$ \\
Extracellular matrix & 543 & $409(75.32)$ & $67(16.38)$ \\
Endothelial function & 752 & $561(74.60)$ & $111(19.79)$ \\
Inflammation & 887 & $660(74.41)$ & $113(17.12)$ \\
Reactive Oxygen Species & 172 & $132(76.74)$ & $25(19.84)$ \\
Apoptosis/autophagy & 884 & $676(76.47)$ & $129(19.08)$ \\
Neurohumoral signalling & 876 & $443(50.57)$ & $93(20.99)$ \\
\hline Total network & $\mathbf{3 4 6 0}$ & $\mathbf{2 3 5 7 ( 6 8 . 1 2 )}$ & $\mathbf{4 7 8 ( 2 0 . 2 8 )}$
\end{tabular}

Number of genes in STRING linked to bait genes with a confidence level of $\geq 0.4$ defines the core size of each process. The size of the entire network is less than the sum of the individual processes due to genes participating in multiple processes.

Table S4: Important genes involved in HFpEF development in ZSF1-Obese +HFD according to their degree of connectivity or within the network.

ZSF1-Obese+HFD vs Lean

\begin{tabular}{ccc|ccc}
\hline & Hubs & \multicolumn{3}{c}{ Bottlenecks } \\
\hline Gene & $\begin{array}{c}\text { Up/Down } \\
\text { log FC }\end{array}$ & Degrees & Gene & $\begin{array}{c}\text { Up/Down } \\
\text { log FC }\end{array}$ & $\begin{array}{c}\text { Betweenness } \\
\text { Centrality }\end{array}$ \\
\hline Akt1 & -0.54 & 144 & Akt1 & -0.54 & 0.141 \\
Hsp90aa1 & -0.50 & 107 & Hsp90ab1 & -0.25 & 0.062 \\
Hsp90ab1 & -0.25 & 106 & Hsp90aa1 & -0.50 & 0.056 \\
Myc & +0.79 & 84 & Decr1 & +1.62 & 0.047 \\
Actc1 & -0.37 & 68 & Myc & +0.79 & 0.041 \\
Decr1 & +1.62 & 67 & Gnat3 & +0.82 & 0.034 \\
Vegfa & -0.31 & 65 & Ppara & -0.28 & 0.034 \\
Actb & -0.25 & 65 & Prkaca & -0.19 & 0.033 \\
Prkaca & -0.19 & 63 & Myd88 & +0.30 & 0.029 \\
Ppara & -0.28 & 61 & Icam1 & +0.56 & 0.029 \\
\hline
\end{tabular}

The top 10 of hub and bottleneck genes in the ZSF1-Obese+HFD vs. Lean network ranked according to the number of connections (hub genes) or according to their betweenness centrality (bottleneck genes) in the core network. Hub genes are genes with many connections (degrees) to other genes, whereas bottleneck genes act as important intersections between modules in the network. Differences in expression are indicated as log2 fold changes. 


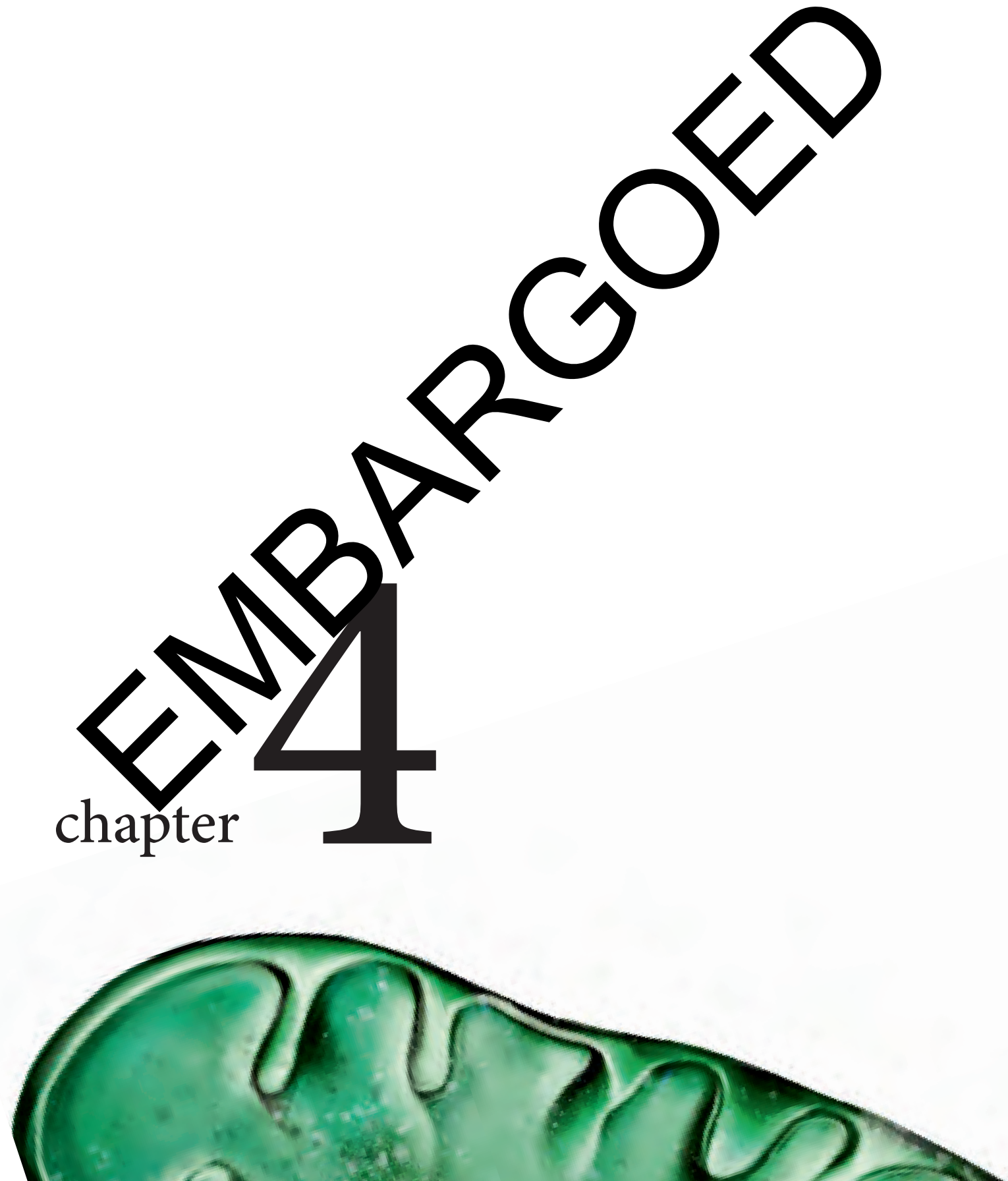


\section{Dysfunctional mitochondrial y Atab isp is a hallma 1 HFy EF}

Annika R. Kuhn ${ }^{1}$, Georg Summer ${ }^{2}$, Ilona Cuijp $r^{2,3}$, Ric van Leeuwen ${ }^{2}$, Blanche S broen $^{2}$, J arc van Bilsen ${ }^{1}$

${ }^{1}$ CARIM Schnol fol Vardiova ular Diseases, Physiology, 2 CARIK Schn University, The Netherlands
Maastricht University, The Netherlands

${ }^{3}$ Centre for $\mathrm{A}$ Vic lar and ascular Biology, Cardiovascular Science, KU Leuven, Belgium 

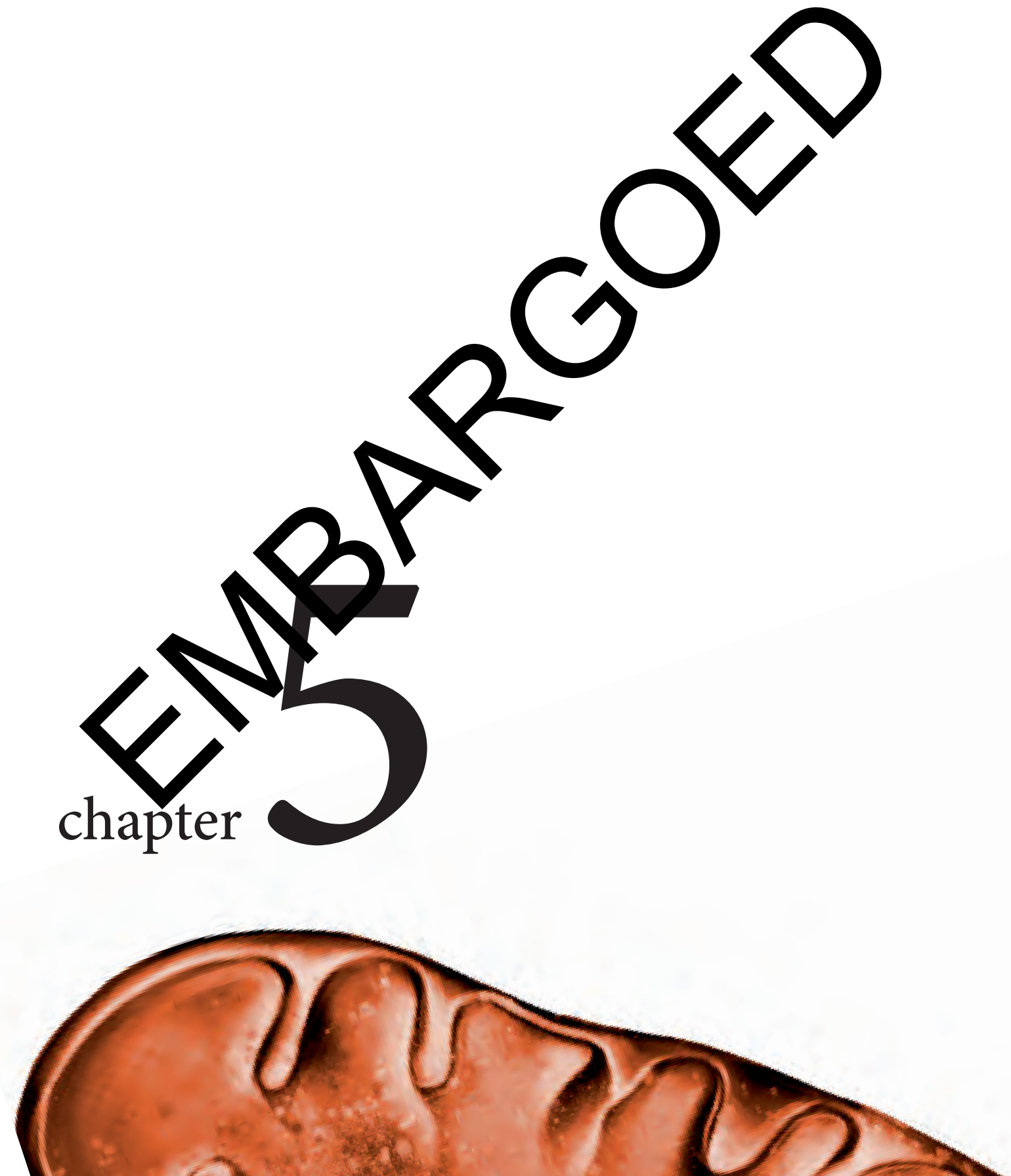


\section{Metabolic cues modulate cardiar Mbro las phenotype a d anction}

Annika R. Kuhn ${ }^{1}$, Chantal Munts ${ }^{1}$, Deping an ${ }^{1}$, Rid van Leeuwen ${ }^{2}$, Wouter Verhesen ${ }^{2}$, Paul Mr der ${ }^{3}, y$ ns van Nieuwenhoven ${ }^{1}$, BI רche Sch en $^{2}$, Marc van Bilsen ${ }^{1}$

${ }^{1}$ CARIV Schoo or Cardiovascular Diseases, Physiology, stricht University, The Netherlands

2 QIM Sch for Cardiovascular Diseases, Cardiology, Maastricht University, The Netherlands

${ }^{3}$ Normandy University, UNIROUEN, Inserm U1096, Rouen, France 

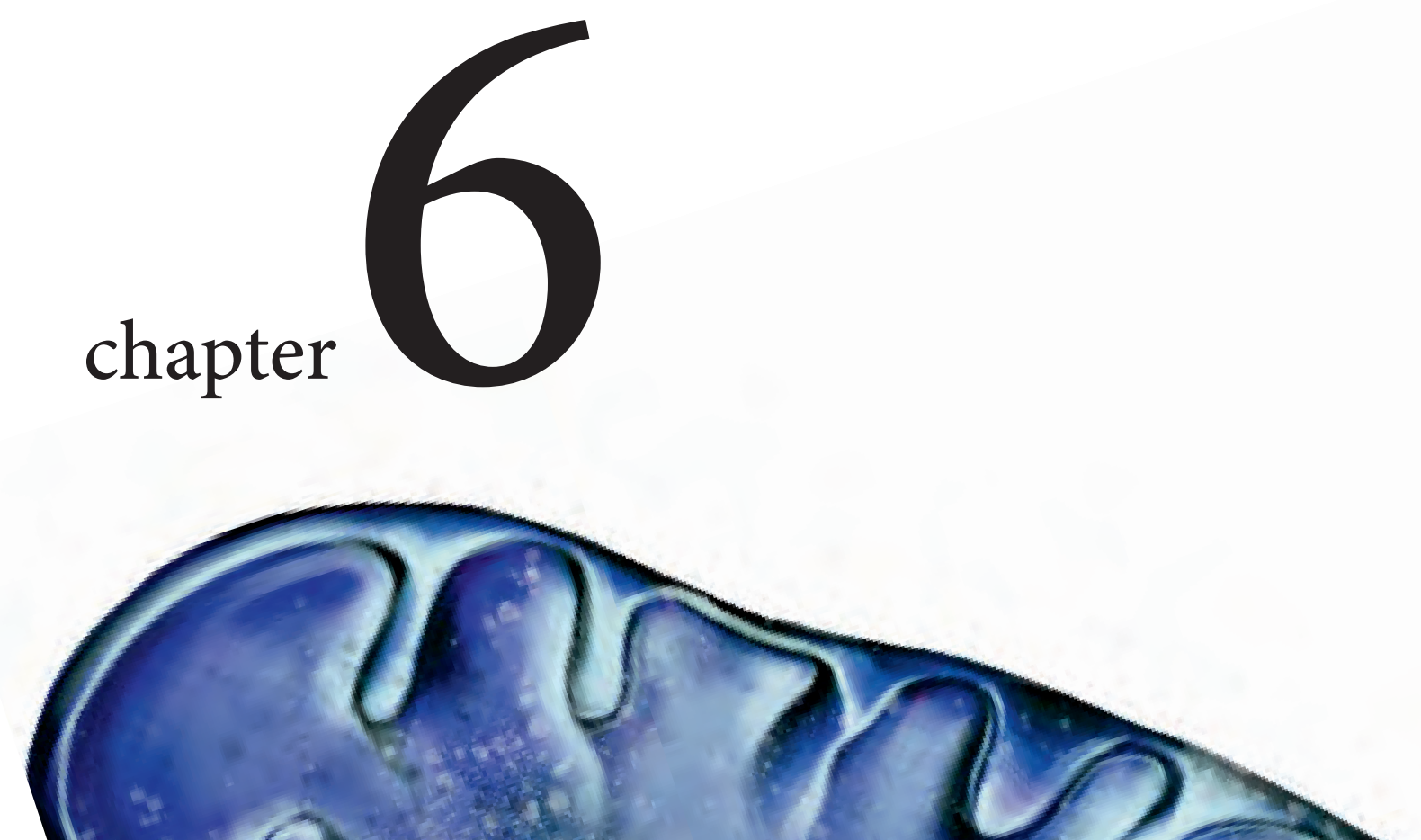


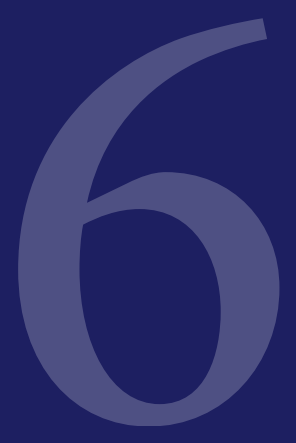

\section{AntagomiR-103/107 treatment affects cardiac function and metabolism}

Monika Rech ${ }^{* 1}$, Annika R. Kuhn ${ }^{* 2}$, Joost Lumens ${ }^{3}$, Paolo Carai ${ }^{1,4}$, Rick van Leeuwen ${ }^{1}$, Wouter Verhesen ${ }^{1}$, Robin Verjans ${ }^{1}$, Julie Lecomte ${ }^{1}$, Yilin Liu $^{5}$, Joost J.F.P Luiken ${ }^{5}$, Ronny Mohren ${ }^{6}$, Berta Cillero-Pastor ${ }^{6}$, Stephane Heymans $^{1,4,8}$, Kèvin Knoops ${ }^{7}$, Marc van Bilsen ${ }^{2}$, Blanche Schroen ${ }^{1}$

${ }^{1}$ CARIM School for Cardiovascular Diseases, Cardiology, Maastricht University, The Netherlands

${ }^{2}$ CARIM School for Cardiovascular Diseases, Physiology, Maastricht University, The Netherlands

${ }^{3}$ CARIM School for Cardiovascular Diseases, Biomedical Engineering, Maastricht University, The Netherlands

${ }^{4}$ Department of Cardiovascular Sciences, Katholieke Universiteit Leuven, Belgium

${ }^{5}$ CARIM School for Cardiovascular Diseases, Molecular Genetics, Maastricht University, The Netherlands

${ }^{6}$ The Maastricht Multimodal Molecular Imaging Institute (M4I), Division of Imaging Mass Spectrometry, Maastricht University, The Netherlands

7 The Maastricht Multimodal Molecular Imaging Institute (M4I), Microscopy CORE Lab, Maastricht University, The Netherlands

${ }^{8}$ Netherlands Heart Institute, The Netherlands

* These authors contributed equally to this work 


\begin{abstract}
MicroRNA-103/107 regulate systemic glucose metabolism and insulin sensitivity. For this reason, inhibitory strategies for these microRNAs are currently being tested in clinical trials. Given the high metabolic demands of the heart and the abundant cardiac expression of miR103/107, we questioned whether antagomir-mediated inhibition of miR-103/107 in C57BI/6J mice impacts on cardiac function. Notably, fractional shortening decreased after 6 weeks of antagomiR-103/107 treatment. This was paralleled by a prolonged systolic radial and circumferential time to peak and by a decreased global strain rate. Histology and electron microscopy showed reduced cardiomyocyte area, decreased mitochondrial volume and mitochondrial cristae density following antagomiR-103/107. In line, antagomiR-103/107 treatment decreased mitochondrial OXPHOS complexes protein levels compared to scrambled, as assessed by mass spectrometry-based label-free quantitative proteomics. MiR$103 / 107$ inhibition in primary cardiomyocytes did not affect glycolysis rates, but decreased mitochondrial reserve capacity, reduced mitochondrial membrane potential and altered mitochondrial network morphology as assessed by live cell imaging. Our data indicate that antagomiR-103/107 decrease cardiac function, cardiomyocyte size and mitochondrial oxidative capacity in absence of pathological stimuli. These data raise concern about the possible cardiac implications of the systemic use of antagomiR-103/107 in the clinical setting, and careful cardiac phenotyping within ongoing trials is highly recommended.
\end{abstract}

Keywords: Cardiomyocyte - cardiac - microRNA - miR-103 - miR-107 - antagomiR; mitochondria - metabolism - mass spectrometry - electron microscopy 


\section{Introduction}

The heart is the most metabolically demanding organ within the body due to its specialized function and limited capacity for energy substrate storage. In the healthy heart, approximately $70 \%$ of the energy demand is covered by the mitochondrial oxidation of fatty acids while the remaining $30 \%$ stems from carbohydrates, ketones, lactate and amino acids. ${ }^{1}$ The ATP generated in this way is mainly consumed by the myofibrillar actin-myosin ATPase for the contraction/relaxation of the cardiac muscle and by the $\mathrm{Ca}^{2+}$ ATPase for calcium reuptake in the sarcoplasmatic reticulum. ${ }^{2}$ Without tightly controlled energy supply and expenditure, cardiac function becomes severely compromised ${ }^{2}$ and derangements of cardiac substrate and energy metabolism are considered to play a key role in the pathogenesis of heart failure. Indeed, therapies to prevent the progression of heart failure by improving the oxidative capacity of the heart are subject of recent investigations. ${ }^{3,4}$

MicroRNAs (miRNAs) are a class of small non-coding RNA molecules that act as posttranscriptional modulators of gene expression and are regulators of all major cell functions, including metabolism and growth, ${ }^{5}$ and have been implicated in the development of cardiovascular disease. ${ }^{6}$ MiRNAs have been shown to regulate cardiac hypertrophy and fibrosis. ${ }^{7,8}$ Other miRNAs have been implicated in the regulation of metabolic pathways in general ${ }^{9}$ or emerged as potential contributors to the metabolic substrate transition in cardiac diseases, more specifically. ${ }^{10-12}$ Recently, the paralog miRNAs miR-103 and miR-107 were shown to regulate insulin resistance. ${ }^{13}$ Indeed, AntagomiR-mediated silencing of miR-103/107 had marked effects on hepatic and adipose tissue metabolism, thereby significantly improving systemic glucose tolerance and insulin sensitivity in obese mice. ${ }^{13}$ These miRNAs are therefore considered promising therapeutic targets for the treatment of diabetes and, actually, a clinical Phase I/IIA trial with antagomiR-103/107 to treat patients suffering from type 2 diabetes and liver disease, is currently ongoing (NCT02826525).

MiR-103/107 have been shown to be expressed at medium-to-high levels across many tissue types, including the heart. ${ }^{14}$ Importantly, the specific effects of antagomiR-103/107 in the heart have not been investigated yet. Considering the chief importance of balanced metabolism for the heart and the impact of miR-103/107 on systemic metabolism, it is essential to determine the role of miR-103/107 on cardiac function. Accordingly, in the present study we investigated if antagomiR-mediated inhibition of miR-103/107 in mice had an impact on cardiac function and, if so, if this was related to alterations in cardiac metabolism. We found that antagomiR$103 / 107$ treatment compromised mitochondrial function and led to cardiac structural and functional remodeling in the absence of any (patho)physiological trigger. 


\section{Materials and Methods}

\section{Animals}

All animal experiments were approved by the Institutional Animal Care and User Committee of Maastricht and Leuven Universities, and performed adhering to the Dutch and Belgian law. C57BI/6J male mice were included in the experiment at the starting age of seven weeks (figure 1A). C57BI6J mice (7 per group) were injected with either scrambled RNA (40 $\mathrm{mg} / \mathrm{kg} / \mathrm{d}$ ) or antagomiR-103/107 (40 mg/kg/d) at experimental days 0, 1, 8, 29. AntagomiRs were RNA oligos complementary to miR-103 and miR-107, 2'-0-methyl modified, harboring a 3'-cholesterol type 1 modification and 5-7 phosphorothioate internucleotide linkages. Sequences were as follows: antagomir miR-107-3p: 5'$U^{*} G^{*}$ AUAGCCCUGUACAAUGCU* $G^{*} C^{*} U^{*} \mathrm{Chol}^{*} T-3^{\prime}$, antagomir miR-103a1-3p: 5'$U^{*} C^{*}$ AUAGCCCUGUACAAUGCU* $G^{*} C^{*} U^{*} \mathrm{Cho}^{*} \mathrm{~T}-3^{\prime}$, antagomir scrambled: 5' $C{ }^{*} A^{*} G C U G A A G U A A A U A C C G A C{ }^{*} C^{*} A^{*} G^{*} C^{*}{ }^{*} T-3$ (Fidelity Systems Inc., Gaithersburg, $M D)$. Systolic blood pressure was monitored at week three and six by means of tail cuff (CODA, Kent Scientific, Torrington, CT). Glycaemia was assessed at day 21 in plasma after a 6 hours fast. Cardiac function was assessed by echocardiography at days 0,28 and 41 under isoflurane anesthesia (mean 1\% in oxygen) with the Vevo model 2100 from FUJIFILM (VisualSonics, Amsterdam, The Netherlands), with probe MS400 18-38 MHz. For the duration of the study, mice were housed in groups of four to five in ventilated cages in a temperaturecontrolled room with a 12-hour light/dark cycle and ad libitum access to food and water. At day 42, animals were euthanized; blood and organs were processed for electron microscopy, histological and molecular analyses.

\section{Echocardiographic analysis}

Echocardiographic M-mode and B-mode images were acquired in mid-ventricular views at the height of the papillary muscles. Heart rate was obtained from the short axis B-mode. LV dimensions were measured in systole and diastole. Cardiac strain measurements were obtained from parasternal short-axis B-mode images using the VevoStrain software (Visualsonics). Images with clear visibility of endocardial and epicardial borders throughout the cardiac cycle and with minimal image artefacts were selected for strain analysis. Three to four consecutive cardiac cycles were selected, then endocardial and epicardial borders were traced semi-automatically and manually adjusted for tracking during the cardiac cycle. Using speckle-tracking based strain analysis, circumferential and radial strain and strain rate (SR) time curves were quantified in six adjacent segments. Frame rate was 333 per second for all 2D B-mode acquisitions. Several LV systolic function metrics were obtained from the circumferential and radial strain and strain rate time curves. Time to peak shortening (TTP) was defined as the time from onset QRS to peak systolic shortening, averaged over all segments. Furthermore, global circumferential and radial strains (GCS and GRS, respectively) where obtained by averaging all segmental peak systolic strain values. 
Circumferential and radial peak systolic strain rate were defined as the maximum shortening and thickening velocity between onset QRS and time of peak systolic strain, respectively, averaged over all segments.

\section{RNA and RT-PCR}

Cardiac tissue was lysed with stainless steel beads (Qiagen, Venlo, the Netherlands) in lysis buffer with the TissueLyser LT (Qiagen, Venlo, the Netherlands). RNA was isolated from the lysate with mirVANA kit (Thermo Fisher Scientific, Waltham, MA) according to the manufacturer's instructions. DNAse treatment was performed with DNAfree kit (Thermo Fisher Scientific, Waltham, MA) according to the manufacturer's guidelines. Reverse transcription was performed with miScript kit (Qiagen, Venlo, the Netherlands) using equal RNA input according to the manufacturer's instructions. RT-PCR was performed with iQ SYBR $®$ Green Supermix (Bio-Rad, Hercules, CA) and iCycler iQ (Bio-Rad, Hercules, CA) according to the manufacturer's instructions with $10 \mathrm{ng}$ of cDNA as input. The primer sequences are:

mir-103, forward: agcagcattgtacagggctatga, reverse: gaatcgagcaccagttacg;

Pdk4, forward: gcatttctactcggatgctcatg, reverse: ccaatgtggcttgggtttcc;

Ldha, forward: ggaaggaggttcacaagcag, reverse: acccgcctaaggttcat;

Ndufb3, forward: acagacagtggaaaattgaaggg, reverse: gcccatgtatctccaagcct;

Cyc1, forward: gcattcggaggggtttccag, reverse: ccgcatgaacatctcccca;

Sdhb, forward: aatttgccatttaccgatggga, reverse: agcatccaacaccataggtcc;

Ucp3, forward: ggatttgtgccctcctttctg, reverse: cattaaggccctcttcagttgct.

MiR-103/107 qPCR data are shown as miR-103 alone since the primer set cannot distinguish between the two microRNA paralogs.

\section{Western blotting}

Protein lysates were prepared from snap frozen tissues in $500 \mu$ of RIPA SDS (50 mM Tris$\mathrm{HCl}, 150 \mathrm{mM}$ sodium chloride, $0.1 \%$ SDS, $0.5 \%$ sodium deoxycholate, $1 \%$ NP- 40 , proteinase inhibitor cocktail (Roche), and $0.5 \mathrm{mM}$ sodium orthovanadate) in the TissueLyser LT (Qiagen, Venlo, the Netherlands). Cell lysates from neonatal rat cardiac myocytes (nRCMs) were prepared in 2x sample buffer $(62.5 \mathrm{mM}$ Tris- $\mathrm{HCl}, 50 \mathrm{mM}$ dithiothreitol, $10 \%$ glycerol, $2 \%$ SDS, $0.01 \%$ bromophenol blue). Total protein content of cell and tissue lysates was determined using the microBCA protein assay kit (Thermo Fisher Scientific, Waltham, MA). $20 \mu \mathrm{g}$ of protein from tissue or cell lysate were resolved on SDS-PAGE polyacrylamide gel. The PageRuler ${ }^{\mathrm{TM}}$ protein ladder (Thermo Fisher Scientific, Waltham, MA) was used as a molecular weight reference. Electrophoresis was performed in a Mini-PROTEAN setup (Bio-Rad, Hercules, CA) for $1.5 \mathrm{~h}$ at $110 \mathrm{~V}$. Proteins were transferred to a $0.45 \mu \mathrm{M}$ PVDF membrane (Merck Millipore, Billerica, MA) at $110 \mathrm{~V} / 200 \mathrm{~mA}$ for $1 \mathrm{~h}$. The membrane was blocked in $5 \%$ milk or BSA in tris-buffered saline with $0,1 \%$ Tween for $1 \mathrm{~h}$ at room temperature and incubated 
with primary antibody overnight at $4^{\circ} \mathrm{C}$ with gentle shaking. The antibodies against PhosphoTroponin I (Ser23/24, \#4004, Cell Signaling Technology, Danvers, USA), total Troponin I (\#4002, Cell Signaling Technology, Danvers, USA), phospho-phospholamban (Ser16/Thr17, \#8496) and total-phospholamban were purchased from Cell Signaling Technology (\#14562, Danvers, USA); the antibody against GAPDH was purchased from Millipore (\#CB1001, Burlington, USA); the antibody against Phospho-CAMK II (Thr 177) was purchased from Santa Cruz Biotechnology (\#28438, Heidelberg, Germany). HRP-linked secondary antibodies anti-mouse IgG, HRP-linked (\#7076, Cell Signaling Technology, Danvers, USA) and antirabbit IgG, HRP-linked (\#7074, Cell Signaling Technology, Danvers, USA) were applied in TBS-T for 1 hour at RT. Immuno-reactivity was visualized by a homemade enhanced chemiluminescence reagent (enhancer: $11 \mathrm{mg} \mathrm{P}$-coumaric Acid, $10 \mathrm{~mL}$ DMSO; substrate: 10 $\mathrm{mL} 1 \mathrm{M}$ Tris- $\mathrm{HCl} \mathrm{pH}$ 8.6, $25 \mathrm{mg}$ sodium luminol, $21 \mu \mathrm{l} 30 \% \mathrm{H}_{2} \mathrm{O}_{2}, 90 \mathrm{~mL}$ distilled water) and immunoblot intensities were analyzed by densitometry with the software Image Studio Lite (Westburg, Leusden, Netherlands).

\section{Histology}

Paraffin-embedded $4 \mu \mathrm{m}$ left ventricular sections were stained with hematoxylin-eosin (HE) and Picro Sirius red (SR) as described before,${ }^{15}$ or GS lectin Biotinylated Griffonia Simplicifolia Lectin I (Burlingame, CA). Morphometric analyses were performed using a microscope (Leica DM2000; Leica, Wetzlar, Germany), camera (Leica DFC295 3Mpix CMOS color), and LAS Image Analysis software (Leica). Quantification of fibrosis via SR staining and of cardiomyocyte area via laminin staining were performed as previously described ${ }^{8}$. Capillary density was analyzed in 8 lectin stained sections per mouse at 40x magnification. Sections were analyzed with a capillary density assessment macro in ImageJ from which tissue area $\left(\mathrm{mm}^{2}\right)$, number of vessels and number of vessels per $\mathrm{mm}^{2}$ were calculated.

\section{Transmission electron microscopy}

Cardiac tissue was fixed with $3 \%$ glutaraldehyde in phosphate buffer and stored at $4^{\circ} \mathrm{C}$. Tissue was washed with phosphate buffer and fixed with $1 \%$ osmium tetroxide in phosphate buffer containing $0.8 \%$ potassium ferricyanide at $4^{\circ} \mathrm{C}$. Samples were dehydrated in acetone, infiltrated with Epon resin for forty-eight hours, embedded and polymerized at $60^{\circ} \mathrm{C}$ for fortyeight hours. Ultrathin sections were obtained using a Leica Ultracut UC6 ultramicrotome (Leica Microsystems, Vienna, Austria) and mounted on Formvar-coated copper grids. Staining was performed with $2 \%$ uranyl acetate in water and lead citrate. The sections were observed in a Tecnai G2 Spirit transmission electron microscope equipped with a CCD Eagle 4kx4k camera (FEl Company, Eindhoven, The Netherlands). Five tissue samples per experimental group were selected and three pictures per sample were analyzed. Mitochondrial volume density was calculated as the mitochondria-containing fraction of a 32-by-32 grid placed on pictures of $1900 x$ magnification. To estimate the number and size distribution of all mitochondria within the cardiac tissue, mitochondria were counted, and the longest mitochondrial diameter was measured with ImageJ ROI-Manager on three pictures per 
sample at 1900x magnification. The number of mitochondria in each size range was calculated as percentage of total mitochondria number for identical amounts of area in each sample. Mitochondrial ultrastructure was assessed at $6800 x$ magnification. Five tissue samples per experimental group were selected and three pictures per sample were analyzed.

\section{In vitro experiments}

HL-1 cells were cultured according to Dr. Claycomb (Louisiana State University, New Orleans, LA).${ }^{16} \mathrm{nRCMs}$ were isolated and cultured in 6 well and 8 well microscopy $\mu$-slides (\#80826, ibidi, Martinsried) as previously described. ${ }^{17} \mathrm{HL}-1$ or $\mathrm{nRCM}$ were transfected with $30 \mathrm{nM}$ miR103/107 inhibitors (miRCURY LNA microRNA inhibitor, Exiqon; sequence: CCCTGTACAATGCTGC) or respective controls in combination with transfection reagent Lipofectamine 2000 (Thermo Fisher Scientific, Waltham, MA) according to the manufacturer's instructions.

\section{HL-1 substrate uptake experiments}

Substrate uptake experiments were performed as previously described. ${ }^{18}$ Briefly, palmitate (coupled to BSA in a palmitate:BSA ratio of 1:3) and deoxy-D-glucose were added to final concentrations of 20 and $4 \mu \mathrm{M}$, respectively, with tracer amounts of $\left[{ }^{14} \mathrm{C}\right]$ palmitate and 2deoxy-D-[3H]glucose. After $10 \mathrm{~min}$, uptake was terminated and unbound substrate was removed by washing the cells with ice-cold depletion medium containing $0.2 \mathrm{mM}$ phloretin. Cells were lysed by the addition of $1 \mathrm{M} \mathrm{NaOH}$. Subsequently, incorporated glucose and palmitate were measured by scintillation counting of $\left[{ }^{14} \mathrm{C}\right]$ and $\left[{ }^{3} \mathrm{H}\right]$.

\section{Liquid Chromatography - Mass Spectrometry}

Tissue disruption and lysis was performed by use of Tissue Lyser II (Qiagen) in a buffer containing 5M Urea (GE Healthcare) in 50mM Ammonium bicarbonate (ABC) (Sigma-Aldrich). The lysate was then reduced with $20 \mathrm{mM}$ Dithiothreitol (DTT) for 45 minutes and alkylated with $40 \mathrm{mM}$ lodoacetamide (IAM) for 45 minutes in the dark. The alkylation was terminated by $20 \mathrm{mM}$ DDT to consume any excess IAM. Digestion was performed with a mixture of LysC and Trypsin (Promega), which was added at a ratio of 1:25 (enzyme to protein). After two hours of digestion at $37^{\circ} \mathrm{C}$ in a water bath, the lysate was diluted with $50 \mathrm{mM} \mathrm{ABC}$ to $1 \mathrm{M}$ Urea and further digested at $37^{\circ} \mathrm{C}$ overnight. The digestion was terminated by addition of formic acid (FA) to a total of $1 \%$. Biognosys (Biognosys, Schlieren, Switzerland) iRT's were added to each peptide sample according to manufacturer's instructions (required for the data-independent acquisition (DIA) analysis using Spectronaut). Peptide separation was performed on a Thermo Scientific (Dionex) Ultimate 3000 Rapid Separation UHPLC system equipped with an Acclaim PepMap C18 analytical column $(2 \mu \mathrm{M}, 100 \AA, 75 \mu \mathrm{M}$ x $150 \mathrm{~mm})$. Peptide samples were first desalted on an online installed C18 trapping column. After desalting peptides were separated on the analytical column with a 90 minute linear gradient from $5 \%$ to $35 \%$ Acetonitrile (Biosolve) with $0.1 \% \mathrm{FA}$ at $300 \mathrm{~nL} / \mathrm{min}$ flow rate. The UHPLC system was coupled to a $\mathrm{Q}$ 
Exactive HF mass spectrometer (Thermo Scientific). Data Dependent Acquisition (DDA) settings were as follows: full MS scan between $375-1,500 \mathrm{~m} / \mathrm{z}$ at resolution of 120,000 followed by MS/MS scans of the top 15 most intense ions at a resolution of 30,000. The HRM DIA method consisted of a survey full MS scan at 120,000 resolution at $350-1,650 \mathrm{~m} / \mathrm{z}$. Then 58 DIA windows were acquired at 30,000 resolution. For protein identification the DDA spectra were analyzed with Proteome Discoverer (PD) version 2.1.1.21. Within the PD software, the search engine Sequest was used with the SwissProt mouse database (Mus musculus; SwissProt TaxID=10090; v2017-01-18) and the Biognosys iRT peptide sequences. The database search was performed with the following settings: enzyme was trypsin, a maximum of 2 missed cleavages, minimum peptide length of 6 , precursor mass tolerance of $10 \mathrm{ppm}$, fragment mass tolerance of $0.02 \mathrm{Da}$, dynamic modifications of methionine oxidation and protein $\mathrm{N}$-terminus acetylation, static modification of cysteine carbamidomethylation. The DDA measurements were used to create a spectral library using spectral library generation in Spectronaut 9 (Biognosys, Schlieren, Switzerland). Only identifications with False Discovery Rate (FDR) of maximum $1 \%$ at peptide and protein level were taken into account for spectral library generation. For protein quantitation the DIA data were analyzed with Spectronaut 9 , with the manufacturer's recommended default settings. The DDA data were analyzed with Proteome Discoverer 2.2 (Thermo Scientific).

\section{Metabolic flux analysis}

Mitochondrial stress test and glycolytic stress test were performed on 4 days cultured primary nRCMs by real-time extracellular flux analyses using a seahorse XF96 flux analyzer (Seahorse Bioscience, North Billerica, MA). Oxygen consumption rate (OCR) and extracellular acidification rate (ECAR) were measured as previously described. ${ }^{19}$ For the mitochondrial stress OCR, an indicator of mitochondrial respiration was measured. ${ }^{19}$ Cells were seeded at a density of 50.000 cells per well in a XF96 cell culture microplate (Agilent). On the day of the measurement, cells were washed with XF Mitochondrial assay medium and placed in a $37^{\circ} \mathrm{C}$ incubator without $\mathrm{CO}_{2}$ for one hour. An automated Seahorse XF96 protocol consisted of $20 \mathrm{~min}$ calibration/equilibration, followed by synchronized injection of drugs/reagents at optimized concentrations in each of 3 ports (mixing 4 minutes followed by a measurement of 4 minutes). Injection ports were loaded with: Oligomycin (ATP synthase inhibitor) at $1 \mu \mathrm{M}$, Carbonyl cyanide p-trifluoromethoxyphenylhydrazone (FCCP, oxidative phosphorylation uncoupler) at $0.5 \mu \mathrm{M}$, a mixture of $1 \mu \mathrm{M}$ Rotenone (respiratory complex I inhibitor) and $1 \mu \mathrm{M}$ Antimycin A (respiratory complex III inhibitor) as described previously. ${ }^{19}$ OCR was recorded and averaged three times for each conditional cycle. For the glycolysis stress test, ECAR, a surrogate for anaerobic glycolysis, was measured using the Seahorse XF96 flux analyzer. Cells were seeded at a density of 70.000 cells per well in a XF96 cell culture microplate (Agilent). On the day of the measurement, cells were washed with XF Glycolytic assay medium and placed in a $37^{\circ} \mathrm{C}$ incubator without $\mathrm{CO}_{2}$ for one hour prior to the assay. Injection ports were loaded with: Glucose $(10 \mathrm{mM})$, Oligomycin $(2 \mu \mathrm{M})$ to stimulate anaerobic glycolysis for ATP production, 2-deoxyglucose (2-DG) (100 mM) to inhibit glycolysis 
as described previously. ${ }^{19}$ After assay completion, total protein content of cell lysates was determined using the microBCA protein assay kit (Thermo Fisher Scientific, Waltham, MA).

\section{Mitochondrial live cell imaging}

Live imaging of mitochondria was performed on primary $\mathrm{nRCMs}$ cultured and transfected in gelatin-coated 8 well microscopy $\mu$-slides (\#80826, ibidi, Martinsried). Prior to imaging, cells were incubated with $250 \mathrm{nM}$ Tetramethylrhodamine methyl ester (TMRM, T668, Thermo Fisher Scientific, Waltham, MA), $3 \mu \mathrm{g} / \mathrm{ml}$ Calcein AM (C1430, Thermo Fisher Scientific, Waltham, MA) and $2.5 \mu \mathrm{g} / \mathrm{ml}$ Hoechst (H21486, Thermo Fisher Scientific, Waltham, MA) in phenol-red free medium for 30 minutes at $37^{\circ} \mathrm{C}$ and $5 \% \mathrm{CO}_{2}$ to stain mitochondria, cytoplasm and nuclei, respectively. TMRM is utilized to monitor mitochondrial membrane potential and mitochondrial network structure. In healthy mitochondria, ETC and ATP synthesis are efficiently coupled, however defects in the OXPHOS system affect mitochondrial membrane potential. If membrane potential is compromised, the retention of TMRM within mitochondria is hindered and the detectable fluorescent signal decreases. Cells were washed 3 times with PBS and incubated in phenol-red free medium. Mitochondria were observed with a CorrSight fluorescence microscope using a Zeiss $63 x$ NA1.4 objective, an Andromeda spinning disc module and Hamamatsu ORCA-Flash4.0 V2 camera, resulting in a pixel size of $103 \mathrm{~nm}$ (FEI Company, Eindhoven, The Netherlands), in a chamber at $37^{\circ} \mathrm{C}$ and $5 \% \mathrm{CO}_{2}$. For each experimental condition, 10 fields of view were imaged. Excitation lasers with wavelengths of 405, 488 and $561 \mathrm{~nm}$, and emission filters with wavelengths of 446, 523 and 600 were used for visualizing the nuclei, cytosol and mitochondria, respectively. Z-stacks that contained 100 images each were placed at Nyquist Z-distance $(170 \mathrm{~nm})$ to image whole cardiomyocytes. The Z-stacks underwent deconvolution using the CLME algorithm of Huygens Professional (SVI Hilversum). Cells were segmented manually on top of maximum intensity projections of the channel-merged Z-stacks for the analysis of 3-6 cells per field of view. Image quantification was performed as described before, ${ }^{20}$ with the exception that our analysis was performed in 3-dimensions and was written in Matlab 2017 (Mathworks) complemented with the Diplmage toolbox (TU Delft). In short, all channels were first filtered both with a top-hat and a 3D median filter, masked using thresholding at a constant value and segmented automatically. The volume of the cytoplasm was calculated by extracting the hole-filled nuclear volume (as defined by the Hoechst staining) from the hole-filled cytosolic volume, which reflects the cell volume (as defined by the Calcein staining).

\section{Statistical Analyses}

Data are presented as mean \pm SEM unless specified otherwise. Comparisons between 2 groups were performed with the 2-tailed Student t-tests. For comparisons of more than 2 groups, 1-way ANOVA was used followed by post-hoc testing with Bonferroni correction for more groups. For comparisons between the same groups over time, repeated measures 
ANOVA was used followed by post-hoc testing with Bonferroni correction. Values of $\mathrm{P}<0.05$ were considered statistically significant. 


\section{Results}

\section{AntagomiR-103/107 treatment impairs cardiac function in healthy adult mice}

To study the effect of the inhibition of miR-103/107 on cardiac function and metabolism of unstressed hearts antagomiR-103/107 was injected in adult mice (Fig. 1A). After 6 weeks, the expression of both miRNAs was reduced by $\sim 70 \%$ in the heart and by $>95 \%$ in the liver following antagomiR-103/107 treatment, compared to scrambled oligo treated controls (Supplemental figure S1), demonstrating the effectiveness of the antagomiR-103/107 treatment. First, we explored the effect of the antagomiR-103/107 on systemic metabolism and monitored circulating free fatty acid, triglyceride and glucose levels over the course of 6 weeks. In line with a previous study, ${ }^{13}$ fasting glucose levels tended to decrease in the antagomiR-103/107 group compared to control after 3 weeks (Fig. 1B). At the same time, the levels of free fatty acids and triglycerides were unchanged between groups (Fig. 1B). Hematological analysis at sacrifice showed a significant decrease in total white blood cell counts and lymphocyte counts in the antagomiR-103/107 group as compared to scrambled controls (Supplemental table S1). Differences in neutrophil and monocyte counts were not observed (Supplemental table S1). Morphometric parameters did not show differences between experimental groups (Table 1). These data indicate that antagomiR-103/107 only had mild effects on systemic metabolism in healthy, non-obese mice.

Table 1. Morphometric parameters at sacrifice.

\begin{tabular}{lcc|cc} 
Morphometrics & \multicolumn{2}{c|}{ Scrambled } & \multicolumn{2}{c}{ AntagomiR-103/107 } \\
& Mean & \pm SD & Mean & \pm SD \\
\hline Heart weight/Tibia length $(\mathbf{m g} / \mathbf{m m})$ & 6.00 & 0.157 & 6.05 & 0.228 \\
Liver weight/Tibia length $(\mathbf{m g} / \mathbf{m m})$ & 65.13 & 1.533 & 64.00 & 1.460 \\
Kidney weight/Tibia length $(\mathbf{m g} / \mathbf{m m})$ & 8.90 & 0.188 & 8.87 & 0.351 \\
Lung weight/Tibia length $(\mathbf{m g} / \mathbf{m m})$ & 8.88 & 0.226 & 9.46 & 0.258 \\
Spleen weight/Tibia length $(\mathbf{m g} / \mathbf{m m})$ & 5.17 & 0.195 & 5.77 & 0.202 \\
Body weight (week 0$)$ & 22.00 & 0.415 & 22.42 & 0.513 \\
Body weight (week 6) & 26.00 & 0.388 & 25.98 & 0.348 \\
\hline
\end{tabular}

$\mathrm{N}=7$ per group; statistical differences were not observed. 
Table 2. Echocardiographic parameters.

\begin{tabular}{|c|c|c|c|c|c|c|c|c|c|c|c|c|}
\hline & \multicolumn{4}{|c|}{ Day 1} & \multicolumn{4}{|c|}{ Week 4} & \multicolumn{4}{|c|}{ Week 6} \\
\hline & \multicolumn{2}{|c|}{ Scr } & \multirow{2}{*}{\multicolumn{2}{|c|}{$\begin{array}{c}\text { Ant } \\
\text { Mean } \pm \text { SD }\end{array}$}} & \multirow{2}{*}{\multicolumn{2}{|c|}{$\begin{array}{c}\text { Scr } \\
\text { Mean } \pm \text { SD }\end{array}$}} & \multicolumn{2}{|c|}{ Ant } & \multirow{2}{*}{\multicolumn{2}{|c|}{$\begin{array}{c}\mathrm{Scr} \\
\text { Mean } \pm \mathrm{SD}\end{array}$}} & \multicolumn{2}{|c|}{ Ant } \\
\hline & Mean & $\pm S D$ & & & & & Mean & $\pm S D$ & & & Mean & $\pm \mathrm{SD}$ \\
\hline Wall thickness (mm) & 0.77 & 0.09 & $0.86^{*}$ & 0.06 & 0.83 & 0.06 & $0.77^{*}$ & 0.1 & 0.83 & 0.13 & 0.82 & 0.07 \\
\hline Heart rate (bpm) & 546.7 & 39 & 583 & 42 & 548.3 & 30 & 570 & 32 & 532 & 36 & $576.00^{*}$ & 29 \\
\hline LVd volume [uL] & 28.34 & 3.98 & 25.4 & 7.12 & 34.6 & 7.62 & 40.69 & 7.33 & 35.58 & 8.59 & 39.13 & 9.5 \\
\hline LVs volume [uL] & 63.78 & 7.68 & 63.52 & 14.48 & 80.19 & 10.25 & 88.08 & 13.45 & 80.68 & 12.82 & 80.67 & 18.78 \\
\hline Stroke volume (\%) & 35.44 & 4.66 & 38.12 & 7.78 & 45.59 & 4.25 & 47.39 & 7.5 & 45.1 & 5.98 & 41.54 & 10.52 \\
\hline Ejection fraction(\%) & 55.6 & 3.35 & 60.31 & 3.15 & 57.22 & 4.92 & 53.84 & 3.89 & 56.25 & 5.33 & $51.43^{*}$ & 4.62 \\
\hline FS (\%) & 28.5 & 2.23 & 31.66 & 2.13 & 29.85 & 3.23 & 27.67 & 2.47 & 29.23 & 3.49 & $26.06^{*}$ & 2.91 \\
\hline Ci TTP/cycle time (-) & 0.47 & 0.06 & 0.44 & 0.07 & 0.45 & 0.04 & $0.52 * \$$ & 0.05 & 0.45 & 0.03 & $0.52 * \$$ & 0.05 \\
\hline R TTP/cycle time (-) & 0.48 & 0.06 & 0.43 & 0.07 & 0.46 & 0.04 & 0.53 & 0.05 & 0.45 & 0.03 & $0.56 \$$ & 0.05 \\
\hline Global Ci Strain (\%) & -21.5 & 5.05 & -22.2 & 3.74 & -21.2 & 4.75 & -19.4 & 2.35 & -20.5 & 3.24 & $-17.62^{*}$ & 2.04 \\
\hline Global R strain (\%) & 24.54 & 10.08 & 26.91 & 3.95 & 25.68 & 4.19 & 26.67 & 6.24 & 22.84 & 8.22 & $21.76^{*}$ & 3.69 \\
\hline Ci SRd (1/s) & 10.18 & 1.54 & 9.5 & 1.34 & 10.38 & 1.96 & 10.79 & 1.35 & 8.81 & 1.49 & 9.53 & 0.64 \\
\hline Ci SRs (1/s) & -9.04 & 2.19 & -9.87 & 2.69 & -8.5 & 1.66 & $-7.24^{*}$ & 0.77 & -7.73 & 1.39 & $-7.14^{*}$ & 0.83 \\
\hline R SRd (1/s) & 9.27 & 2.35 & 9.13 & 2.35 & 9.95 & 1.83 & $12.03 * \$$ & 1.35 & 7.74 & 2.1 & 10.11 & 1.88 \\
\hline R SRs (1/s) & 7.98 & 2.45 & 8.89 & 1.5 & 7.92 & 0.67 & 8.23 & 1.99 & 7.82 & 0.99 & $6.86^{*}$ & 0.71 \\
\hline
\end{tabular}

LVd, left ventricular volume diastolic; LVs, left ventricular volume systolic; FS, fractional shortening; TTP, time to peak; Ci, circular; R, radial; SRd, strain rate diastolic; SRs, strain rate systolic. $\mathrm{N}=7$ per group; * $p<0.05$ vs scrambled, $\$ p<0.05$ vs same treatment at day 1

To monitor cardiac effects of the inhibition of the two microRNAs, LV systolic function was evaluated by echocardiographic analysis at 1 day, 4 weeks and 6 weeks after start of antagomiR-103/107 treatment. At day 1 and week 4, cardiac fractional shortening (FS) was comparable between groups (Fig. 1C). Remarkably, at week 6 the antagomiR-103/107 group presented a modest but significant reduction in FS compared to scrambled control. To gain more detailed information on the dynamics of myocardial contraction in the left ventricle (LV), we performed speckle tracking strain analysis and assessed global LV circumferential and radial strains as well as time to peak (TTP) systolic strain and peak systolic strain rate in both dimensions (Fig. 1D, E). In line with the decreased FS at 6 weeks, antagomiR-103/107 treatment led to a prolonged TTP in both radial and circumferential dimensions after 4 and 6 weeks compared to day 1 ; and for the circumferential dimension also compared to scrambled control (Fig. 1E). 

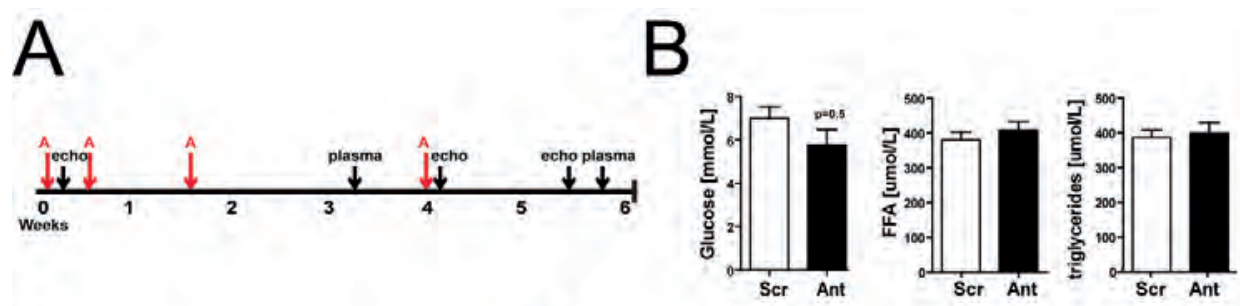

6

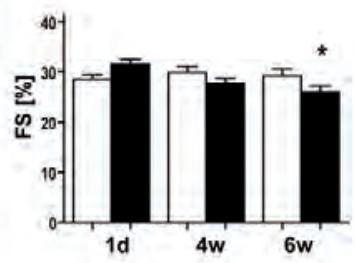

D

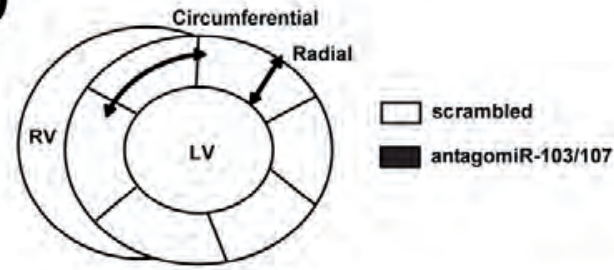

Radial
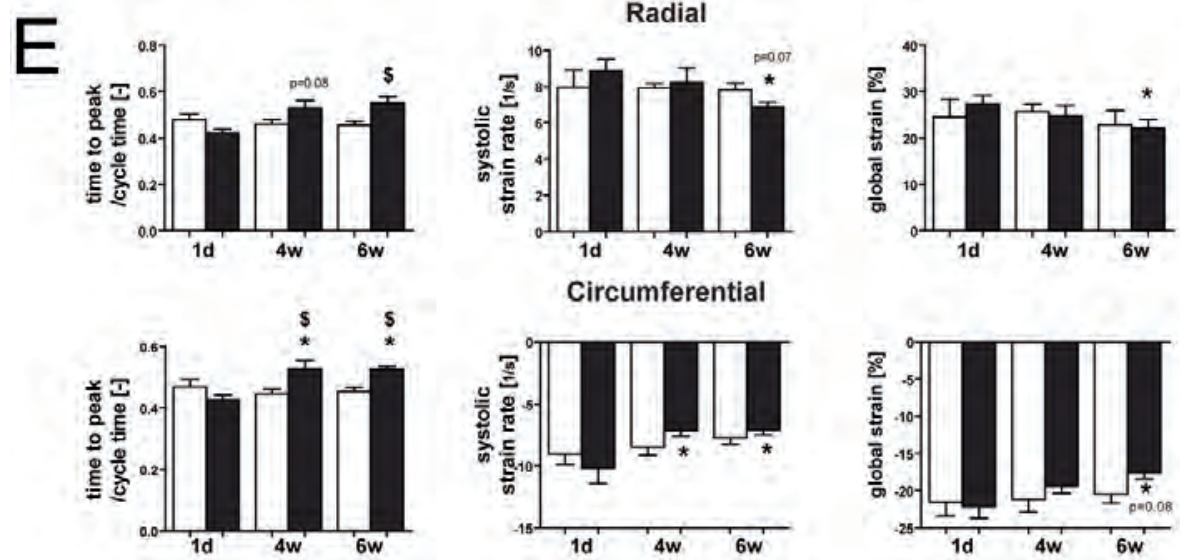

Circumferential
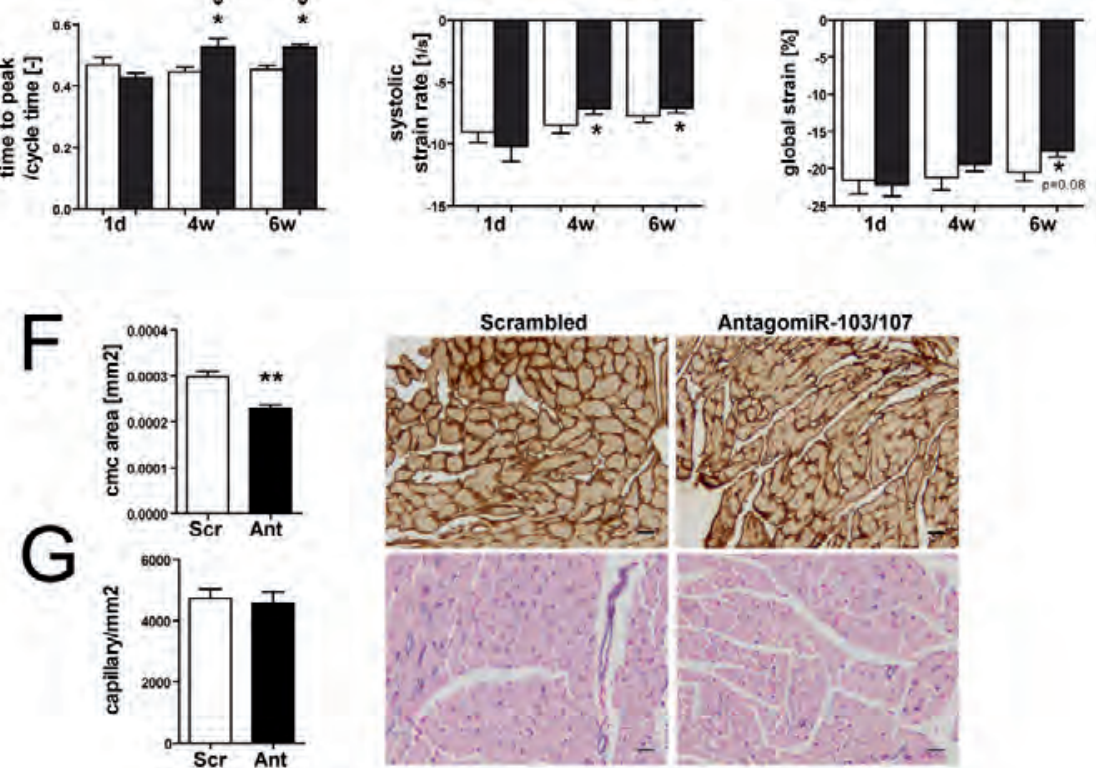

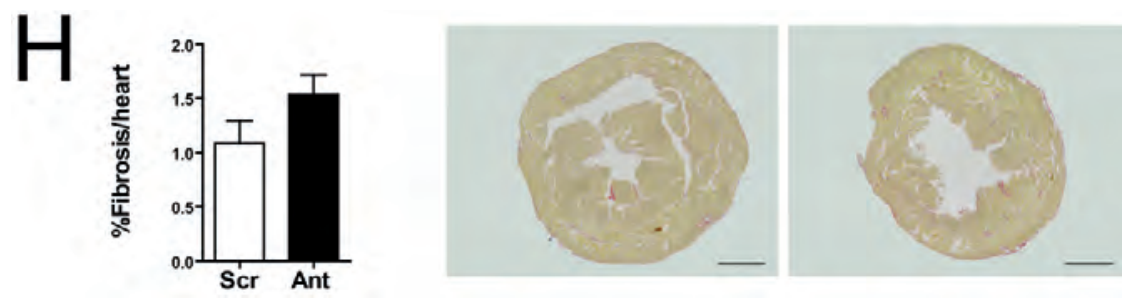

Figure 1: AntagomiRs-103/107 impair cardiac function and strain. A) timeline of the study A, antagomiR-103/107; B) Analysis of fasted plasma at week 3 of glucose, free fatty acids (FFA), triglycerides; C) echocardiographic fractional shortening (FS); D) schematic representation of the strain analysis depicting the short axis view of the left ventricle divided in the analyzed segments and indicating the radial and circumferential axes of motion; E) echocardiographic radial and circumferential strain and strain rate metrics; F), G), $\boldsymbol{H}$ ) quantification and representative pictures of $\boldsymbol{F}$ ) laminin staining indicating mean cardiomyocyte area, scale bar: $20 \mu \mathrm{m}$ G) lectin staining indicating capillary density, scale bar: 20 $\mu \mathrm{m}$ and $\boldsymbol{H}$ ) picrosirius red staining indicating fibrosis, scale bar: $1 \mathrm{~mm}$; Scr, scrambled (40 mg/kg/d); Ant, antagomiR (20 mg/kg/d antagomiR-103 and $20 \mathrm{mg} / \mathrm{kg} / \mathrm{d}$ antagomiR-107); data are presented as mean \pm SEM; $n=7$ per group; * $p<0.05$ vs scrambled.

However, the scrambled control group did not show a difference in TTP over the time of the study. Consistently with the decreased LV systolic function observed in terms of FS, ejection fraction (EF) and TTP (Fig. 1E, table 2), 6 weeks of antagomiR-103/107 treatment led to decreased global strain in both radial and circumferential planes compared to day 1 (Fig. 1E). AntagomiR-103/107 treatment also led to reduced peak systolic radial strain rate after 6 weeks and peak systolic circumferential strain rate after 4 and 6 weeks (Fig. 1E). Remarkably, inhibition of miR-103/107 led to decreased cardiomyocyte size without modifying the capillary density and cardiac fibrosis as assessed by histological analysis (Fig. 1F, G, H).

Taken together, chronic treatment with antagomiR-103/107 led to a significant decrease of LV systolic function paralleled by a prolonged time to peak LV contraction and a decreased systolic strain rate, in the absence of any (patho)physiological trigger.

\section{AntagomiR-103/107 do not affect the inotropic state}

The echocardiographic strain analysis, which showed prolonged TTP and decreased systolic strain rate upon miR-103/107 inhibition, may point toward a negative inotropic effect of antagomiR-103/107. Negative inotropic agents can decrease myocardial force and contractility by slowing cardiomyocyte $\mathrm{Ca}^{2+}$ flux, or by reducing $\mathrm{Ca}^{2+}$ sensitivity of sarcomeric proteins via phosphorylation/dephosphorylation. However, the phosphorylation status of phospholamban (PLB) and cardiac troponin I ( $\mathrm{p}-\mathrm{Tnl}$ ), key regulators of sarcoplasmic reticulum $\mathrm{Ca}^{2+}$ sequestration and myofilament $\mathrm{Ca}^{2+}$ sensitivity that become phosphorylated upon inotropic stimulation, was not significantly changed upon antagomiR-103/107 treatment (Fig. 2A, B). 


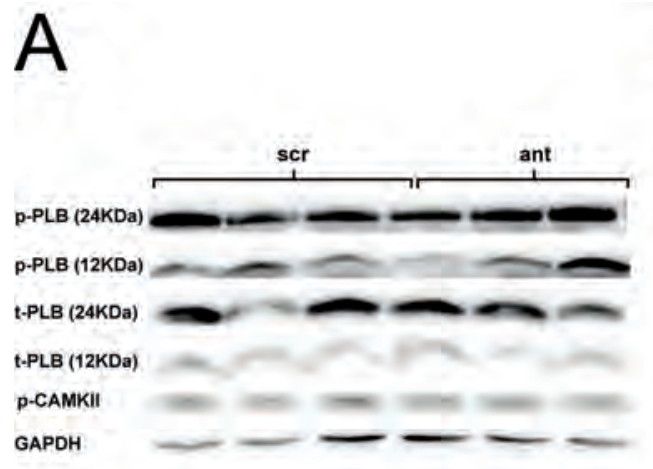

\section{B}
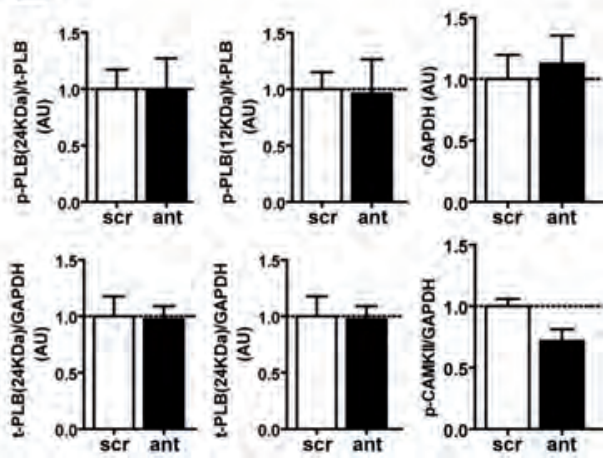

Figure 2. AntagomiR-103/107 do not affect phosphorylation of proteins involved in cardiac $\mathrm{Ca}^{2+}$ homeostasis. A) Representative western blot of the lysates of hearts treated with antagomiR-103/107 or scrambled, and B) quantification of western blot; Scr, scrambled; Ant, antagomiR; data are presented as mean \pm SEM; $n=3$ per group; * $p<0.05$ vs scrambled.

In addition, phosphorylation of $\mathrm{Ca}^{2+} /$ calmodulin-dependent protein kinase II (p-CAMKII), essential for $\mathrm{Ca}^{2+}$ homeostasis and for the regulation of the contraction-relaxation cycle, did not differ between antagomiR-103/107 treated and control mice (Fig. 2A, B). These results indicate that the observed effect of antamiR-103/107 treatment on myocardial strain is not likely to be due to alterations in inotropic state.

\section{AntagomiR-103/107 modifies the cardiac proteome}

To gain insight into underlying processes that could drive cardiac dysfunction and remodeling upon inhibition of miR-103/107, we performed a microRNA-103/107 target analysis. According to the online database TargetScan ${ }^{21}$ miR-103/107 have 838 predicted targets, which can be grouped according to their biological function using the PANTHER gene annotation database 22 (Supplemental Fig. S2).

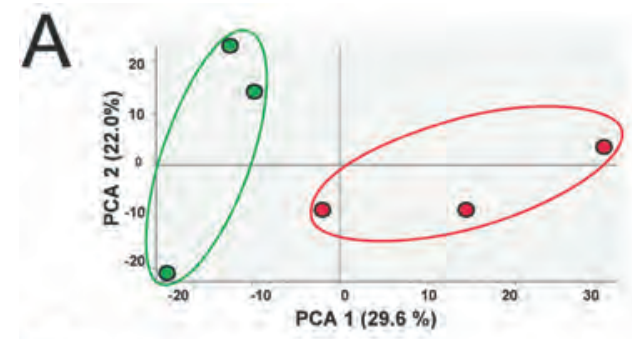


$\mathrm{B}$ Tillet Striasat Muscle Contraction
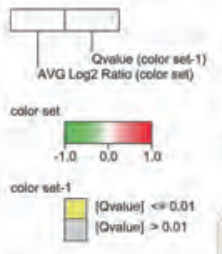

Colce rule net met No data found
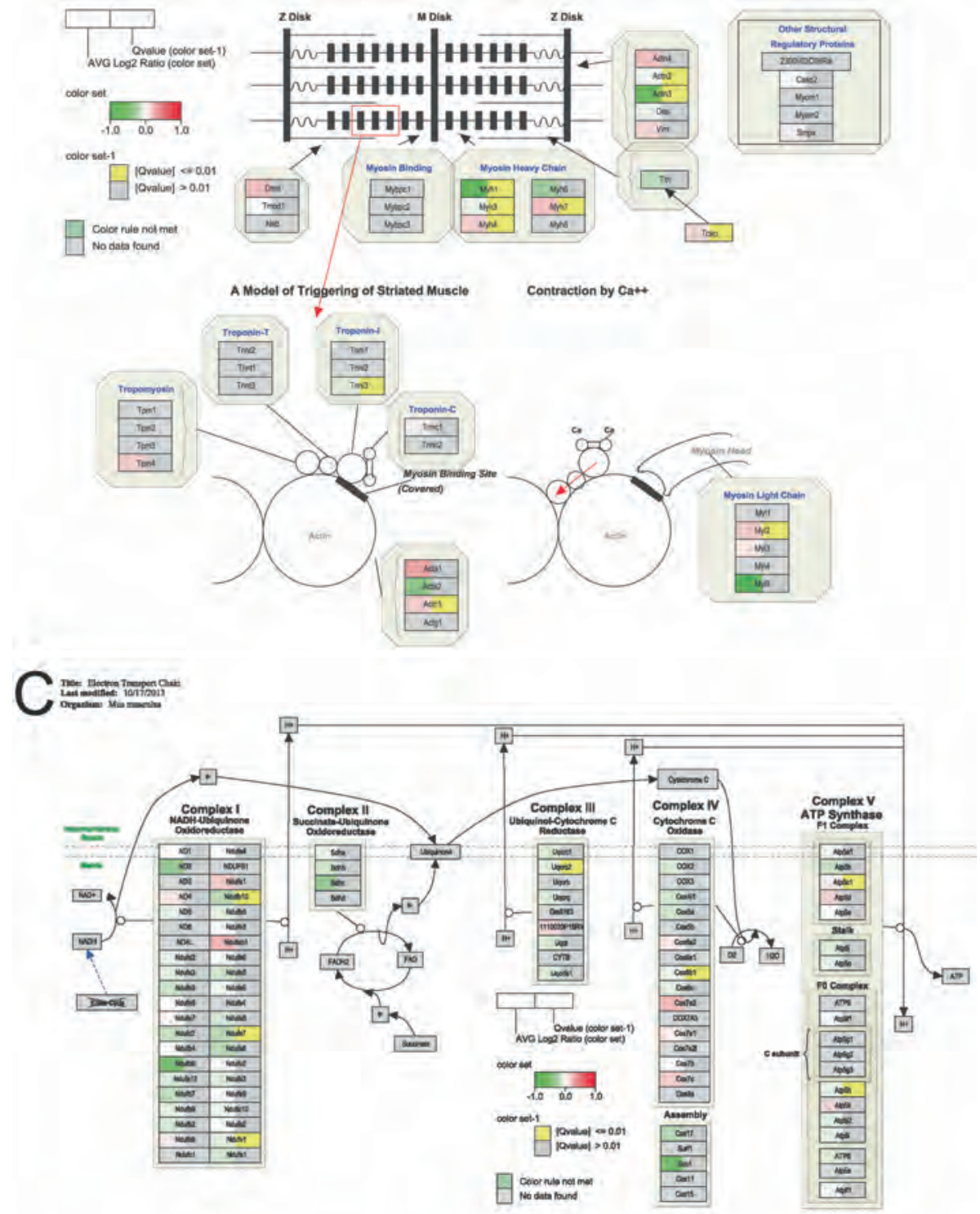

Figure 3. AntagomiR-103/107 modifies the cardiac proteome. A) unsupervised mass spectrometryprotein abundancies clustering resulting from the multivariate analysis (PCA) by the software Proteome Discoverer 2.2 (Thermo Scientific); green represents scrambled $(n=3)$ and red represents antagomiR103/107 (n=3); B), C) PathVisio visualization of B) striated muscle contraction and C) electron transport chain protein levels quantified by mass spectrometry of heart lysates; green coloring indicates less 
expression of protein in antagomiR-103/107 treated mice, red coloring indicates an increased expression, yellow coloring indicates a significant $q$-value $(q<0.01)$;

Interestingly, $\sim 29 \%$ of anticipated miR-103/107 targets are associated with metabolic processes, including carbohydrate as well as lipid metabolism. To further probe the mechanism underlying the antagomiR-103/107 induced alterations in cardiac function, we performed mass spectrometry (MS)-based label-free quantitative proteomics (MS) on LV tissue from scrambled and antagomiR-103/107 treated mice. Unsupervised clustering analysis of the MS data clearly separated the scrambled control and the antagomiR-103/107 group (Fig. 3A), underscoring the effect of antagomiR-103/107 on cardiac phenotype. Anticipated targets of miR-103/107, including mitochondrial proteins, were differentially expressed upon antagomiR-103/107 treatment (Supplemental table S2). The generated data were integrated into the pathway analysis application PathVisio for visualization of differentially regulated pathways related to sarcomere function and metabolism. Multiple proteins involved in striated muscle contraction as well as the mitochondrial electron transport chain (ETC) were found to be differentially expressed following antagomiR-103/107 treatment (Fig. 3B, C and supplemental table S2). Indeed, antagomiR-103/107 affected protein levels within the ETC complexes I, III, IV and V as compared to scrambled control (Fig. 3C).

\section{AntagomiR-103/107 decrease cardiomyocyte mitochondrial volume density}

In view of the reported role of miR-103/107 in regulating metabolism, ${ }^{23}$ the prominence of predicted targets related to metabolism (Supplemental figure S2), and our MS data on the ETC, we decided to focus on the effects of miR-103/107 inhibition on cardiac energy metabolism, as a possible explanation for the decline in cardiac function.

As a first general characterization of cardiac energy status, we investigated the number and size distribution of the mitochondria within the cardiomyocytes by means of transmission electron microscopy (Fig. 4A). Notably, mitochondrial volume density was significantly lower in antagomiR-103/107 treated group as compared to scrambled. The number of mitochondria was not changed significantly, but there was a general trend towards smaller-sized mitochondria in antagomiR-103/107 treated group compared to scrambled ( $p=0.1$, Fig. 4A). 

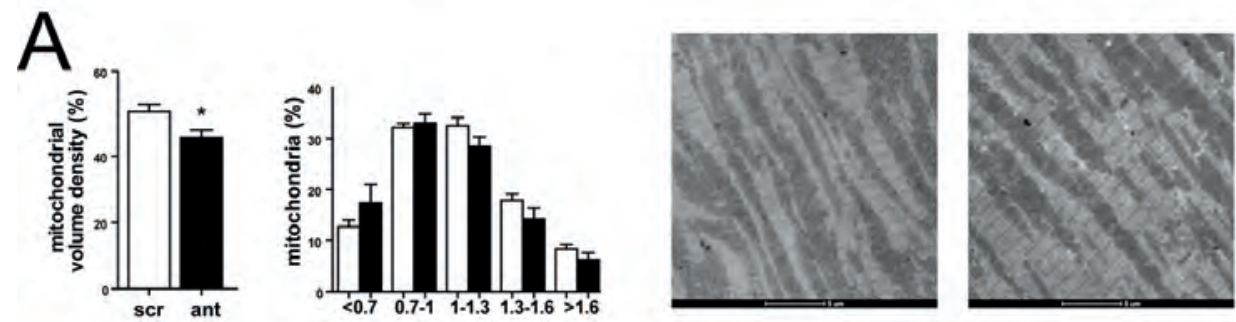

B

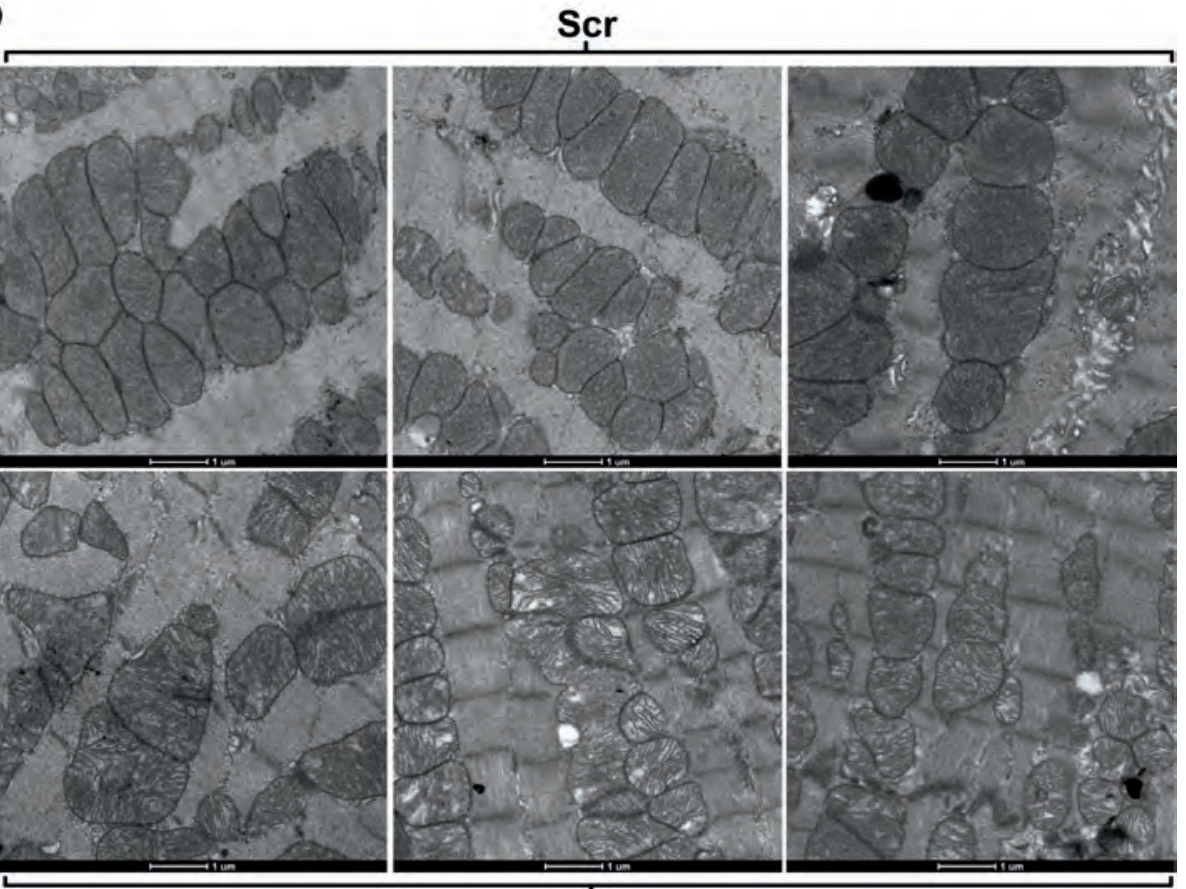

Ant

Figure 4. AntagomiR-103/107 decrease cardiac mitochondrial volume density. A) Mitochondrial volume density and size range quantification, TEM images of cardiac tissue of antagomiR-103/107 or scrambled treated hearts at $1900 \times$ magnification, $n=5$ per group; $\boldsymbol{B})$ TEM images visualizing mitochondrial morphology of antagomiR-103/107 or scrambled treated hearts at $6800 x$ magnification

In the high resolution images, mitochondrial morphology was visibly altered in the antagomiR103/107 treated group, as revealed by the mitochondrial cristae appearance (Fig. 4B). Together, the negative effects of antagomiR-103/107 on mitochondrial volume density and on ETC protein expression may point to a reduction in cardiac mitochondrial capacity following antagomiR-103/107 treatment. 


\section{MiR-103/107 inhibition in cardiomyocytes reduces mitochondrial respiration}

Given the effects of in vivo antagomiR-103/107 treatment on cardiac mitochondrial indices, we next investigated the effects of miR-103/107 inhibition on substrate uptake and energy metabolism in cardiomyocytes in vitro. First, we measured the degree of insulin-stimulated glucose and palmitate uptake in $\mathrm{HL}-1$ cardiomyocytes.

A

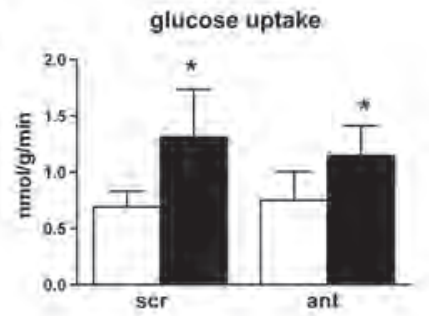

B

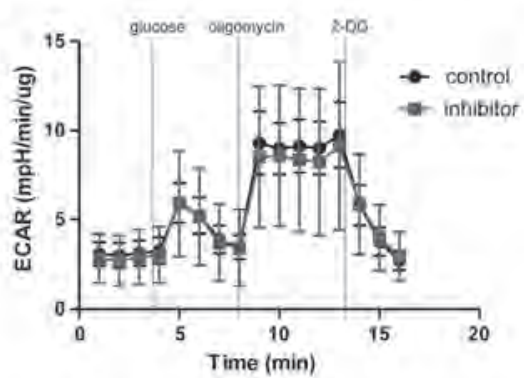

D

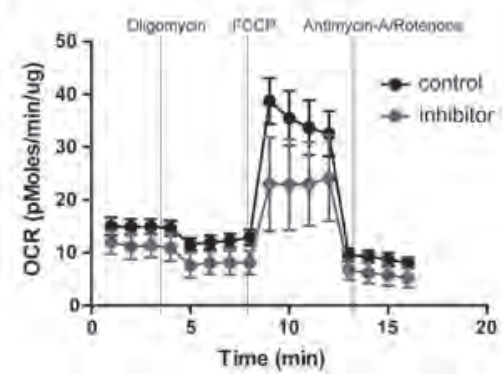

palmitate uptake

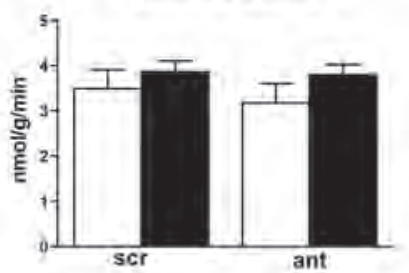

$\square$ unstimulated

- insulin-stimulated
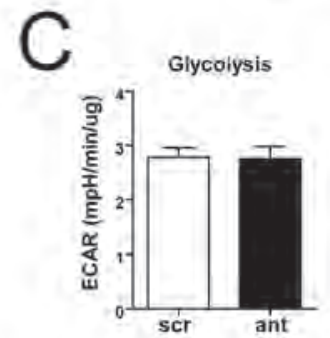

Glycolytic capacity

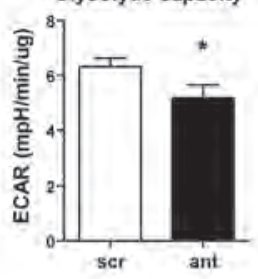

$E$
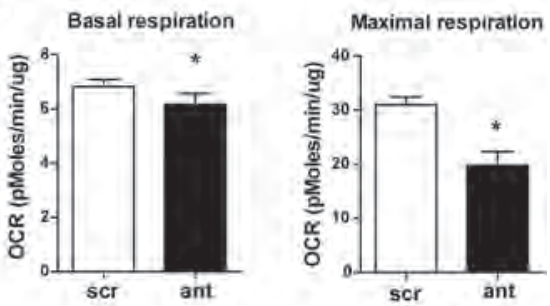

Figure 5. MiR-103/107 inhibition in cardiomyocytes decreases mitochondrial respiration. A) bar graphs of Insulin-stimulated glucose and palmitate uptake of HL1 cells transfected with scrambled control or inhibitors for miR-103/107; B) XF trace of the extracellular acidification rate (ECAR) of nRCM transfected with scrambled control or inhibitors for miR-103/107; C) glycolysis and glycolytic capacity quantification from $C ; D) X F$ trace of the oxygen consumption rate (OCR) of $n R C M$ transfected with scrambled control or inhibitors for miR-103/107; E) quantification of mitochondrial basal and maximal respiration from E; 2-DG, 2-deoxyglucose; FCCP, Carbonyl cyanide p-trifluoromethoxyphenylhydrazone; $s c r$, scrambled; ant, inhibitors; data are presented as mean \pm SEM of at least 4 replicates; ${ }^{*} p<0.05 \mathrm{vs} \mathrm{scr}$. 
In line with our previous results, ${ }^{24}$ insulin stimulation induced the uptake of glucose and tended to induce palmitate uptake in HL-1 cardiomyocytes (Fig. 5A). Importantly, miR-103/107 inhibition did not significantly change the level of glucose or palmitate uptake as compared to control, neither under basal, nor under insulin-stimulated conditions (Fig. 5A). These data indicate that inhibition of miR-103/107 in cardiomyocytes does not alter the substrate uptake rate in cardiomyocytes. To assess the effects of miR-103/107 on energy expenditure, substrate utilization and mitochondrial respiration, $\mathrm{nRCMs}$ were transfected with inhibitors for miR-103/107 or negative control and metabolic assessment was conducted by metabolic flux analysis (Seahorse $®$ ). MiR-103/107 inhibition did not affect the extracellular acidification rate (ECAR), an indirect measure for glycolysis, but decreased glycolytic capacity as compared to control (Fig. 5B, C).

MiR-103/107 inhibition significantly decreased the oxygen consumption rate (OCR), a measurement of mitochondrial respiration, at baseline and even more so after maximal stimulation by FCCP (Fig. 5D, E), as reflected by lower basal and maximal respiration (Fig. 5E). These data suggest that inhibition of miR-103/107 decrease mitochondrial respiration in cardiomyocytes.

Additionally, to investigate the effects of miR-103/107 inhibition on mitochondrial function and morphology, nRCMs were transfected with inhibitors for miR-103/107 or negative control and stained with TMRM to monitor mitochondrial membrane potential and mitochondrial network structure. We quantified TMRM signal intensity and assessed mitochondrial morphology three-dimensionally in live nRCMs with spinning-disc microscopy. MiR-103/107 inhibition did not significantly affect cell volume, mitochondrial volume or number of mitochondria (Fig. 6A, B). Reduced total mitochondria intensity as well as intensity per mitochondrion were indicative changes in mitochondrial membrane potential due to inhibition of miR-103/107 (Fig. 6B). In addition, mitochondrial networks were more fragmented after miR-103/107 inhibition, as reflected by significantly smaller largest mitochondrial fractions. Finally, individual mitochondria were smaller in nRCM following inhibition of miR-103/107 (Fig. 6B).

These results are in line with our in vivo data on decreased sarcomeric mitochondrial volume density as well as changes in mitochondrial morphology, ETC protein levels and the mild reduction in cardiac function. 


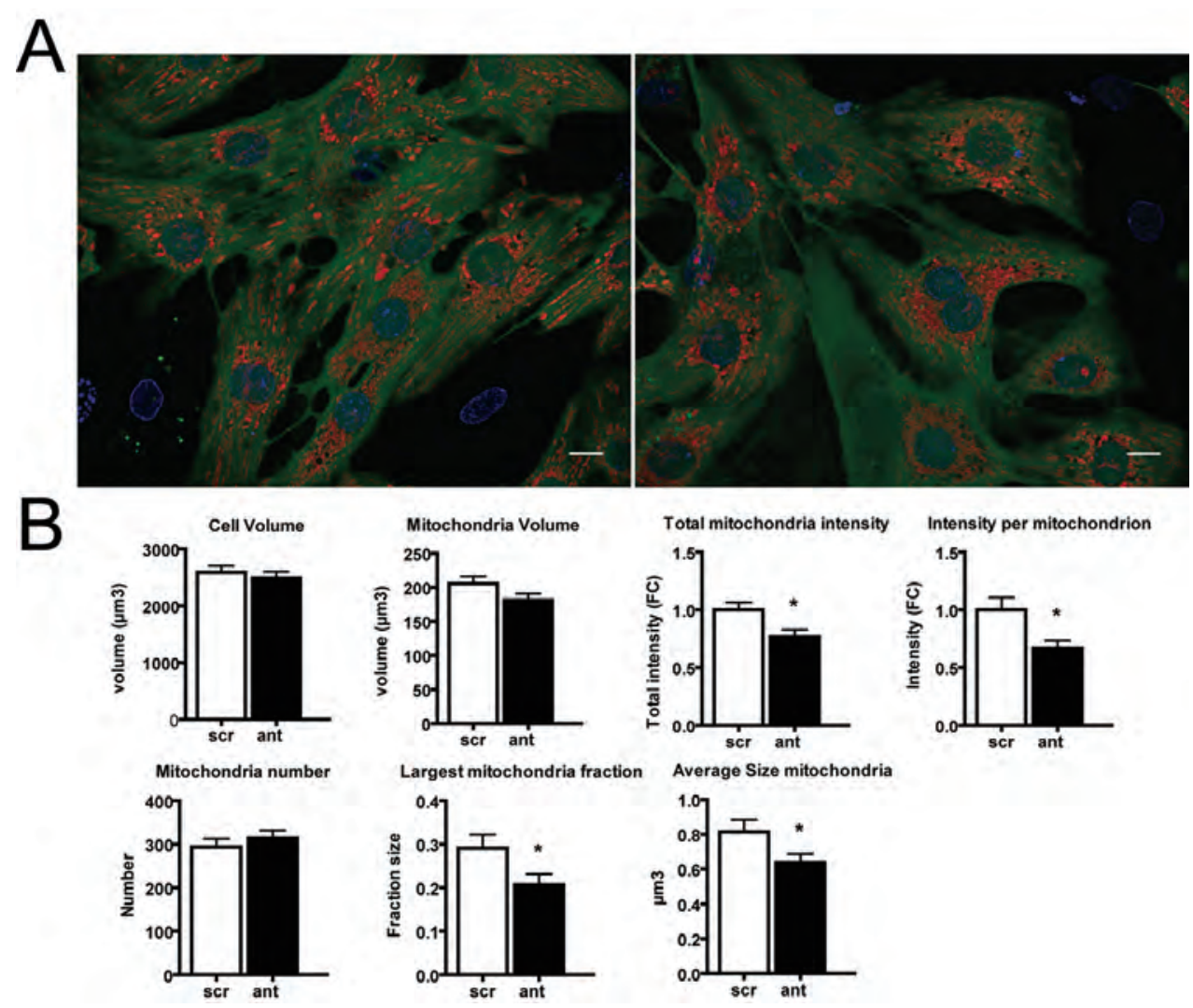

Figure 6. MiR-103/107 inhibition in cardiomyocytes affects mitochondrial morphology. A) Maximum intensity projections of nRCMs stained with calcein (green), Hoechst (blue) and TMRM (red) to visualize cytosol, nuclei and mitochondria, respectively. Scale bar: $10 \mu \mathrm{m}$; B) mitochondrial network analyses including cell and mitochondria volume, mitochondrial intensities (reflecting mitochondrial membrane potential) as measured by TMRM fluorescence, and quantification of mitochondrial number and size; scr, scrambled; ant, inhibitors; data are presented as mean \pm SEM of 40 individually analyzed cells per condition; * $p<0.05$ vs scr.

Taken together, our data show that chronic inhibition of miR-103/107 in healthy mice compromises mitochondrial function and leads to cardiac structural and functional remodeling. 


\section{Discussion}

The protective function of antagomiR-103/107 on systemic glucose metabolism and insulin sensitivity has been recently established for metabolic disease. ${ }^{13}$ In this study we applied antagomiR-103/107 and disclosed their effect on cardiac function and cardiomyocyte metabolism. We showed that systemic delivery of antagomiR-103/107 in healthy mice reduced cardiac LV function as indicated by decreased FS and strain rate in absence of pathological stimuli. In addition, antagomiR-103/107 treated mice presented with a diminished cardiac mitochondrial volume density as well as decreased protein levels of the striated muscle contraction and the electron transport chain complexes. The investigation of cardiomyocyte metabolism upon miR-103/107 inhibition showed a reduced mitochondrial respiratory capacity. Our results suggest that miR-103/107 inhibition affects cardiac systolic function via modulation of mitochondrial respiration without affecting the overall ATP availability for the cardiomyocytes. Which one(s) of the predicted targets of miR-103/107 is responsible for mediating the observed effect on cardiac function remains to be established.

MiR-103 and miR-107 are conserved in all known vertebrate species and are paralogs that differ only at a single nucleotide, and hence are thought to have overlapping targets. ${ }^{23} \mathrm{MiR}$ 103 and miR-107 are located within introns of genes coding for pantothenate kinases (PANKs). PANKs are enzymes that regulate cellular coenzyme-A levels, affecting multiple metabolic reactions including the synthesis of fatty acids, amino acids, cholesterol, pyruvate, glucose and tricarboxylic acid (TCA) cycle intermediates. ${ }^{23}$ Based on the fact that miRNA expression is often correlated with their host gene expression, it has been proposed that miR103/107 also play a significant role in PANK-associated metabolic reactions. ${ }^{23}$ Moreover, bioinformatics target prediction indicated that miR-103/107 target exceptionally more metabolic enzymes than usually seen from miRNAs. These predictions include fatty acid synthase, carnitine palmitoyl transferase I and pyruvate dehydrogenase. ${ }^{23}$ Accordingly, using TargetScan ${ }^{21}$ and PANTHER databases, ${ }^{22}$ we found that $~ 29 \%$ of anticipated miR-103/107 targets are associated with metabolic processes, including carbohydrate as well as lipid metabolism. In the current study, we were not able to detect significant changes in cardiac metabolic gene expression at the mRNA level following antagomiR-103/107 treatment. However, in line with a previous study, ${ }^{13}$ these regulatory effects could be detected in liver tissue (data not shown), the main tissue targeted by antagomiR nucleotides. Since miR$103 / 107$ were incompletely inhibited in the heart (about $70 \%$ ), it is conceivable that some residual regulation by miR-103/107 still took place. However, this remains to be further investigated.

Increased expression of miR-103/107 in liver has been associated with insulin resistance in patients with alcoholic liver disease, non-alcoholic fatty liver disease and nonalcoholic steatohepatitis, conditions often associated with diabetes. ${ }^{25}$ Moreover, previous studies of miRNA microarray analysis, aimed at selecting the most deregulated miRNAs in obesity and insulin resistance, found miR-103/107 to be among the most upregulated in the livers of two 
types of obese mice: ob/ob and diet-induced obese mice ${ }^{13}$ and the expression of these miRNAs was also reportedly increased in diabetic Goto-Kakizaki rats. ${ }^{26}$ These data indicated an association of miR-103/107 with insulin resistance which led to the idea of using antagomiRs against miR-103/107 as anti-diabetic drug. ${ }^{13}$ Liver-specific overexpression of miR-103/107 in mice induced hyperglycemia and hyperinsulinemia, and also impaired glucose tolerance, ${ }^{13}$ suggesting that increased miR-103/107 levels during liver disease associated with diabetes may contribute to disease progression. Conversely, antagomiR-103/107 treatment in obese mice improved glucose tolerance and insulin sensitivity in liver and adipose tissue and rescued $\beta$-oxidation pathway genes like $C p t 1 .{ }^{13}$ Currently, a clinical Phase $\mathrm{I} / \mathrm{ll}$ a trial is ongoing, which applies antagomiR-103/107 in patients suffering from steatohepatitis and type 2 diabetes. In line, in our study antagomiR-103/107 treatment led to a trend to decreased plasma glucose in healthy animals.

To study the myocardial deformation pattern, we performed speckle tracking echocardiography analysis. Speckle tracking echocardiography is widely used in the clinical setting for the assessment of global and regional systolic function in patients with heart failure and apparently normal ejection fraction. ${ }^{27}$ While EF and FS are parameters that describe the myocardial pump function, strain and strain rate quantify the contractility pattern of the myocardium. ${ }^{28,29}$ In the present study, while the systolic strain rate decreased at weeks 4 and 6 in the antagomiR-103/107 treated group, the diastolic strain rate was increased at week 4 in the radial plane. This suggests a possible partial compensation for the prolonged systolic phase as indicated by TTP. These measurements fit with a normal physiological range of LV function in which the heart is able to compensate for a prolonged systolic phase with a higher strain rate of relaxation. These findings are particularly important since antagomiR-103/107 are currently being investigated for clinical application in a phase I/lla clinical trial. Our results may be indicative of an effect on cardiac function within the patient population of the ongoing clinical trial, which had originally been enrolled for the presence of liver metabolic disease. In this context, it is noteworthy that the current findings are derived from studies with healthy, unstressed animals. It is well feasible that the observed depression of cardiac function may be even more pronounced in the challenged heart.

Among the physiological modifiers of cardiac contractile force and speed of contraction, we investigated the effect of antagomiR-103/107 on the cardiac inotropic state, by measuring the phosphorylation status of proteins involved in $\mathrm{Ca}^{2+}$ homeostasis. Phospholamban (PLB) modulates $\mathrm{SR} \mathrm{Ca}^{2+}$ uptake by inhibiting SERCA ${ }^{30}$ and becomes phosphorylated upon CAMP/PKA stimulation. We did not detect changes in PLB phosphorylation or t-PLB in antagomiR-103/107 treated mice as compared to controls. Moreover, CaMKII signaling is central in cardiac contractility and calcium handling. ${ }^{31}$ Activated and phosphorylated CaMKII, associated with the sarcoplasmic reticulum, regulates both calcium uptake and release functions with each cycle of contraction and relaxation. ${ }^{31}$ We analyzed cardiac protein levels of $\mathrm{t}-\mathrm{Tnl}$ and $\mathrm{p}-\mathrm{Tnl}$ and did not find a difference between antagomiR-103/107 treatment and 
control. Although no definitive proof, the absence of changes in phosphorylation of these proteins suggests that the observed decline in cardiac function is not secondary to alterations in inotropic state.

Interestingly, antagomiR-103/107 treatment led to changes in contractile protein expression, as assessed by mass spectrometry, and was associated with a reduction in cardiomyocyte size. Together, this points to an active cardiac remodeling process induced by the antagomiR103/107 treatment. Despite smaller cardiomyocytes following antagomiR-103/107 treatment, total heart weight and cardiac wall dimensions were not affected, which might imply an increased volume of the interstitial space and the presence of edema. It remains to be established if these observations are a reflection of atrophic or apoptotic processes ${ }^{32}$ and, importantly, if this contributes to the decline in cardiac function.

The impairment of bioenergetics is considered key in the development of HF. ${ }^{33}$ The ATP that the myocardium has to synthesize and transfer to sustain the excitation-contraction coupling must continuously support an optimal myocardial performance in both systolic and diastolic phase. ${ }^{33}$ ATP availability is crucial for $\mathrm{Ca}^{2+}$ homeostasis during the excitation-contraction cycle ${ }^{34}$ and most of the ATP derives from mitochondrial oxidative phosphorylation. In light of the current knowledge and of our in vivo data on the decreased cardiac levels of multiple proteins of the mitochondrial electron transport chain, one possible explanation for the observed contractile dysfunction in this study is that in antagomiR-103/107 treated hearts mitochondrial function, and thus ATP synthesis, gets compromised. The effects of miR103/107 inhibition on mitochondrial membrane potential, an indicator of mitochondrial health, as shown by the live cell imaging of the uptake of TMRM and the increased mitochondrial network fragmentation are in support of this reasoning. Since calcium is an important signaling molecule involved in the ATP-consuming cardiac muscle contraction and relaxation, ${ }^{28}$ future investigations should consider contractility readouts in cardiomyocytes of mice treated with antagomiR-103/107.

A validated target of miR-103/107 is caveolin-1 (Cav-1), ${ }^{13}$ the principal structural protein of caveolae, which are membrane domains that have been implicated in signal transduction. ${ }^{35}$, 36 Trajkovski and colleagues have shown that Cav-1 upregulation is paralleled by a concomitant stabilization of the insulin receptor. ${ }^{13}$ Moreover, Meshulam and colleagues have shown that the expression of Cav-1 in cells that normally do not express caveolin (HEK 293) facilitates the uptake of fatty acids. ${ }^{37}$ Indeed, caveolae have been suggested to participate in lipid transport and may serve as organizing centers for a variety of receptors and signaltransducing molecules. ${ }^{38}$ In light of this function of Cav-1, we have studied the substrate uptake of HL-1 cardiomyocytes upon inhibition of miR-103/107 and found that the substrate uptake was not affected upon inhibition of miR-103/107 at baseline. 


\section{Conclusion}

The current findings highlight the role of miR-103/107 in cardiac function. We show that systemic inhibition of miR-103/107 by means of antagomiRs decreases cardiac systolic function, as reflected by the reduced FS and systolic strain rate, in absence of pathological stimuli. In addition, antagomiR-103/107 led to decreased cardiac mitochondrial volume density, altered mitochondrial morphology, reduced mitochondrial OXPHOS protein content and membrane potential. The present findings raise concern on the possible cardiac implications for the use of antagomiR-103/107 as anti-diabetic drug, and careful cardiac phenotyping within ongoing clinical trials is highly recommended. 


\section{Acknowledgements}

This work was supported by the Netherlands Organization for Scientific Research (NWO) (grant no. 917.14.363 VIDI to B.S.; grant no. 016.176.340 VIDI to J.Lu.), the Netherlands Heart Foundation (Dekker grant no. 2014T105 to B.S.; grant no. 2015T082 to J.Lu.), Health Foundation Limburg (to B.S.), and an ERA-CVD Joint International Call grant (Netherlands Heart Foundation and NWO-ZonMw Grant no. 2016T091 to M.v.B.), Marie Curie action program CardiomiR FP7-MC-IAPP (grant no. 285991 to J.Le.). We acknowledge the support from Royal Netherlands Academy of Sciences (CVON 2011-11 ARENA to S.H.).

\section{Author Contributions}

Conceptualization, B.S., M.v.B., M.R.; Investigation, M.R., J.Lu, J.Le, P.C., R.V., A.R.K., R.v.L., W.V., Y.L., J.J.F.P.L., R.M., B.C.P.; Methodology, M.R., J.Lu., J.Le., P.C., R.V., A.R.K., R.v.L., V.W., B.C.P., R.M, K.K..; Software, J.Lu., R.M., B.C.P, K.K.; Formal analysis, B.S., M.v.B., M.R.; Writing - Original Draft, M. R; Writing - Review \& Editing, B.S., M. v. B., M. R., A.R.K.,; Funding Acquisition, B.S., M. v. B., S.H.; Supervision, B.S., M. v. B..

\section{Disclosures}

There is no conflict of interest to disclose. 


\section{References}

1. Huss JM, Kelly DP. Mitochondrial energy metabolism in heart failure: a question of balance. The Journal of Clinical Investigation 2005;115:547-555.

2. Doenst T, Nguyen TD, Abel ED. Cardiac Metabolism in Heart Failure - Implications beyond ATP production. Circulation research 2013;113:709-724.

3. Brown DA, Perry JB, Allen ME, Sabbah HN, Stauffer BL, Shaikh SR, Cleland JGF, Colucci WS, Butler J, Voors AA, Anker SD, Pitt B, Pieske B, Filippatos G, Greene SJ, Gheorghiade M. Expert consensus document: Mitochondrial function as a therapeutic target in heart failure. Nat Rev Cardiol 2017;14:238-250.

4. Wai T, Langer T. Mitochondrial Dynamics and Metabolic Regulation. Trends in endocrinology and metabolism: TEM 2016;27:105-117.

5. He L, Hannon GJ. MicroRNAs: small RNAs with a big role in gene regulation. Nat Rev Genet 2004;5:522-531.

6. Wong LL, Wang J, Liew OW, Richards AM, Chen YT. MicroRNA and Heart Failure. Int $J$ Mol Sci 2016;17:502.

7. Corsten MF, Papageorgiou A, Verhesen W, Carai P, Lindow M, Obad S, Summer G, Coort SL, Hazebroek M, van Leeuwen R, Gijbels MJ, Wijnands E, Biessen EA, De Winther MP, Stassen FR, Carmeliet P, Kauppinen S, Schroen B, Heymans S. MicroRNA profiling identifies microRNA-155 as an adverse mediator of cardiac injury and dysfunction during acute viral myocarditis. Circ Res 2012;111:415-425.

8. Heymans S, Corsten MF, Verhesen W, Carai $P$, van Leeuwen RE, Custers K, Peters T, Hazebroek M, Stoger L, Wijnands E, Janssen BJ, Creemers EE, Pinto YM, Grimm D, Schurmann N, Vigorito E, Thum T, Stassen F, Yin X, Mayr M, de Windt LJ, Lutgens E, Wouters K, de Winther MP, Zacchigna S, Giacca M, van Bilsen M, Papageorgiou AP, Schroen B. Macrophage microRNA-155 promotes cardiac hypertrophy and failure. Circulation 2013;128:1420-1432.

9. Melman YF, Shah R, Das S. MicroRNAs in heart failure: is the picture becoming less miRky? Circ Heart Fail 2014;7:203-214.

10. Pinti MV, Hathaway QA, Hollander JM. Role of microRNA in metabolic shift during heart failure. American Journal of Physiology Heart and Circulatory Physiology 2017;312:H33-H45.
11. Wang J, Song $Y$, Zhang $Y$, Xiao $H$, Sun $Q$, Hou N, Guo S, Wang Y, Fan K, Zhan D, Zha L, Cao Y, Li Z, Cheng X, Zhang Y, Yang X. Cardiomyocyte overexpression of miR-27b induces cardiac hypertrophy and dysfunction in mice. Cell Res 2012;22:516-527.

12. el Azzouzi H, Leptidis S, Dirkx E, Hoeks J, van Bree B, Brand K, McClellan EA, Poels E, Sluimer JC, van den Hoogenhof MM, Armand AS, Yin X, Langley S, Bourajjaj M, Olieslagers $\mathrm{S}$, Krishnan J, Vooijs M, Kurihara H, Stubbs A, Pinto YM, Krek W, Mayr M, da Costa Martins PA, Schrauwen P, De Windt LJ. The hypoxia-inducible microRNA cluster miR199a approximately 214 targets myocardial PPARdelta and impairs mitochondrial fatty acid oxidation. Cell Metab 2013;18:341-354.

13. Trajkovski M, Hausser J, Soutschek J, Bhat B, Akin A, Zavolan M, Heim MH, Stoffel M. MicroRNAs 103 and 107 regulate insulin sensitivity. Nature 2011;474:649-653.

14. Wang WX, Danaher RJ, Miller CS, Berger JR, Nubia VG, Wilfred BS, Neltner JH, Norris CM, Nelson PT. Expression of miR-15/107 family microRNAs in human tissues and cultured rat brain cells. Genomics Proteomics Bioinformatics 2014;12:19-30.

15. Junqueira LC, Bignolas G, Brentani RR. Picrosirius staining plus polarization microscopy, a specific method for collagen detection in tissue sections. Histochem $J$ 1979;11:447-455.

16. Claycomb WC, Lanson NA, Jr., Stallworth BS, Egeland DB, Delcarpio JB, Bahinski A, Izzo NJ, Jr. HL-1 cells: a cardiac muscle cell line that contracts and retains phenotypic characteristics of the adult cardiomyocyte. Proc Natl Acad Sci U S A 1998;95:2979-2984.

17. De Windt LJ, Willemsen PH, Popping S, Van der Vusse GJ, Reneman RS, Van Bilsen M. Cloning and cellular distribution of a group II phospholipase A2 expressed in the heart. $J$ Mol Cell Cardiol 1997;29:2095-2106.

18. Dirkx E, Schwenk RW, Coumans WA, Hoebers N, Angin Y, Viollet B, Bonen A, van Eys GJ, Glatz JF, Luiken JJ. Protein kinase D1 is essential for contraction-induced glucose uptake but is not involved in fatty acid uptake into cardiomyocytes. J Biol Chem 2012;287:5871-5881.

19. Mdaki KS, Larsen TD, Weaver LJ, Baack ML. Age Related Bioenergetics Profiles in Isolated Rat Cardiomyocytes Using Extracellular Flux Analyses. PLoS One 2016;11:e0149002. 
20. lannetti EF, Smeitink JA, Beyrath J, Willems $\mathrm{PH}$, Koopman WJ. Multiplexed high-content analysis of mitochondrial morphofunction using live-cell microscopy. Nat Protoc 2016;11:1693-1710.

21. Agarwal V, Bell GW, Nam J-W, Bartel DP. Predicting effective microRNA target sites in mammalian mRNAs. eLife 2015;4:e05005.

22. Mi $H$, Huang $X$, Muruganujan $A$, Tang $H$, Mills C, Kang D, Thomas PD. PANTHER version 11: expanded annotation data from Gene Ontology and Reactome pathways, and data analysis tool enhancements. Nucleic acids research 2017;45:D183-d189.

23. Wilfred BR, Wang WX, Nelson PT. Energizing miRNA research: a review of the role of miRNAs in lipid metabolism, with a prediction that miR-103/107 regulates human metabolic pathways. Mol Genet Metab 2007;91:209217.

24. Schwenk RW, Dirkx E, Coumans WA, Bonen A, Klip A, Glatz JF, Luiken JJ. Requirement for distinct vesicle-associated membrane proteins in insulin- and AMP-activated protein kinase (AMPK)-induced translocation of GLUT4 and CD36 in cultured cardiomyocytes. Diabetologia 2010;53:22092219.

25. Dajani A, AbuHammour A. Treatment of Nonalcoholic Fatty Liver Disease: Where do we Stand? An Overview. Saudi Journal of Gastroenterology : Official Journal of the Saudi Gastroenterology Association 2016;22:91-105.

26. Herrera BM, Lockstone HE, Taylor JM, Ria M, Barrett A, Collins S, Kaisaki P, Argoud K, Fernandez C, Travers ME, Grew JP, Randall JC, Gloyn AL, Gauguier D, McCarthy MI, Lindgren CM. Global microRNA expression profiles in insulin target tissues in a spontaneous rat model of type 2 diabetes. Diabetologia 2010;53:1099-1109.

27. Blessberger $\mathrm{H}$, Binder $\mathrm{T}$. NON-invasive imaging: Two dimensional speckle tracking echocardiography: basic principles. Heart 2010;96:716-722.

28. Ammar KA, Paterick TE, Khandheria BK, Jan MF, Kramer C, Umland MM, Tercius AJ,
Baratta L, Tajik AJ. Myocardial mechanics: understanding and applying threedimensional speckle tracking echocardiography in clinical practice. Echocardiography (Mount Kisco, NY) 2012;29:861-872.

29. Kraigher-Krainer E, Shah AM, Gupta DK, Santos A, Claggett B, Pieske B, Zile MR, Voors AA, Lefkowitz MP, Packer M, McMurray JJ, Solomon SD. Impaired systolic function by strain imaging in heart failure with preserved ejection fraction. J Am Coll Cardiol 2014;63:447-456.

30. Lohse MJ, Engelhardt S, Eschenhagen T. What is the role of beta-adrenergic signaling in heart failure? Circ Res 2003;93:896-906.

31. Frey N, McKinsey TA, Olson EN. Decoding calcium signals involved in cardiac growth and function. Nat Med 2000;6:1221-1227.

32. Goldspink DF, Burniston JG, Tan LB. Cardiomyocyte death and the ageing and failing heart. Exp Physiol 2003;88:447-458.

33. Rosca MG, Hoppel CL. Mitochondrial dysfunction in heart failure. Heart Fail Rev 2013;18:607-622.

34. Janssen PM. Myocardial contractionrelaxation coupling. Am J Physiol Heart Circ Physiol 2010;299:H1741-1749.

35. Han B, Copeland CA, Tiwari A, Kenworthy AK. Assembly and Turnover of Caveolae: What Do We Really Know? Front Cell Dev Biol 2016;4:68.

36. Patel HH, Murray F, Insel PA. Caveolae as organizers of pharmacologically relevant signal transduction molecules. Annu Rev Pharmacol Toxicol 2008;48:359-391.

37. Meshulam T, Simard JR, Wharton J, Hamilton JA, Pilch PF. Role of caveolin-1 and cholesterol in transmembrane fatty acid movement. Biochemistry 2006;45:2882 2893.

38. Smart EJ, Graf GA, McNiven MA, Sessa WC, Engelman JA, Scherer PE, Okamoto T, Lisanti MP. Caveolins, liquid-ordered domains, and signal transduction. Mol Cell Biol 1999;19:7289-7304. 


\section{Supplemental Materials}

\section{Supplemental figures}

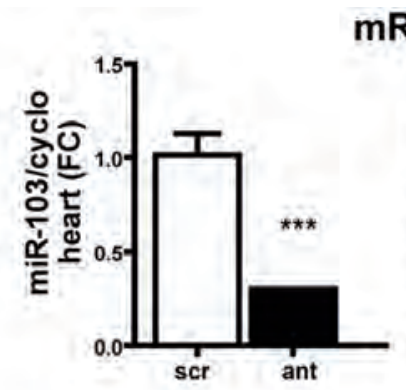

mRNA
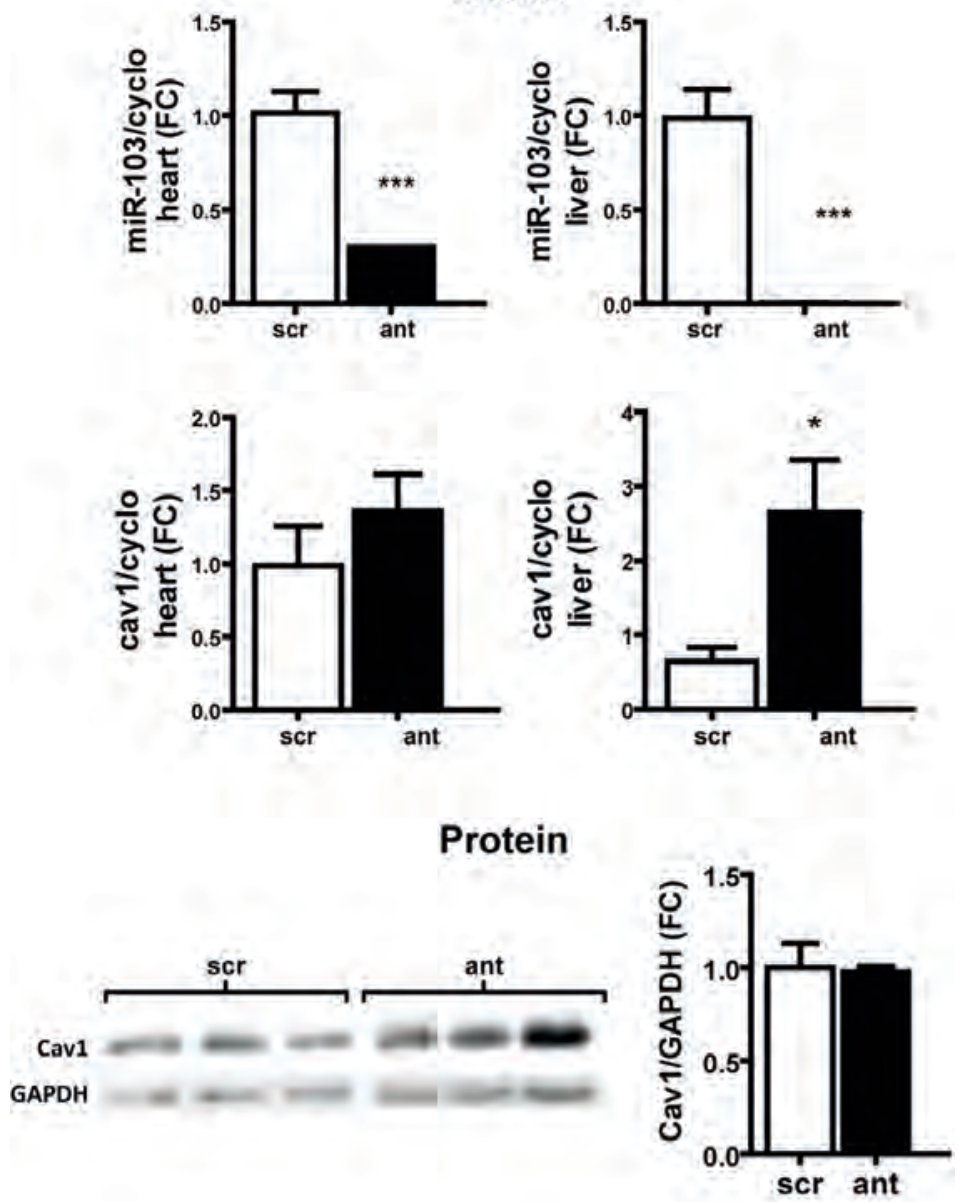

Figure S1: A) MiR-103 and Cav1 gene expression in heart and liver of animals treated with scrambled control or antagomiR-103/107, * $p<0.05$ vs scrambled, ${ }^{* * *} p<0.001$ vs scrambled, $n=7$ per group; B) representative western blot and quantification of Cav1 and GAPDH of the lysates of hearts treated with antagomiR-103/107 or scrambled, $n=3$ per group; data are shown as mean \pm SEM, scr, scrambled control, ant; antagomiR-103/107. 


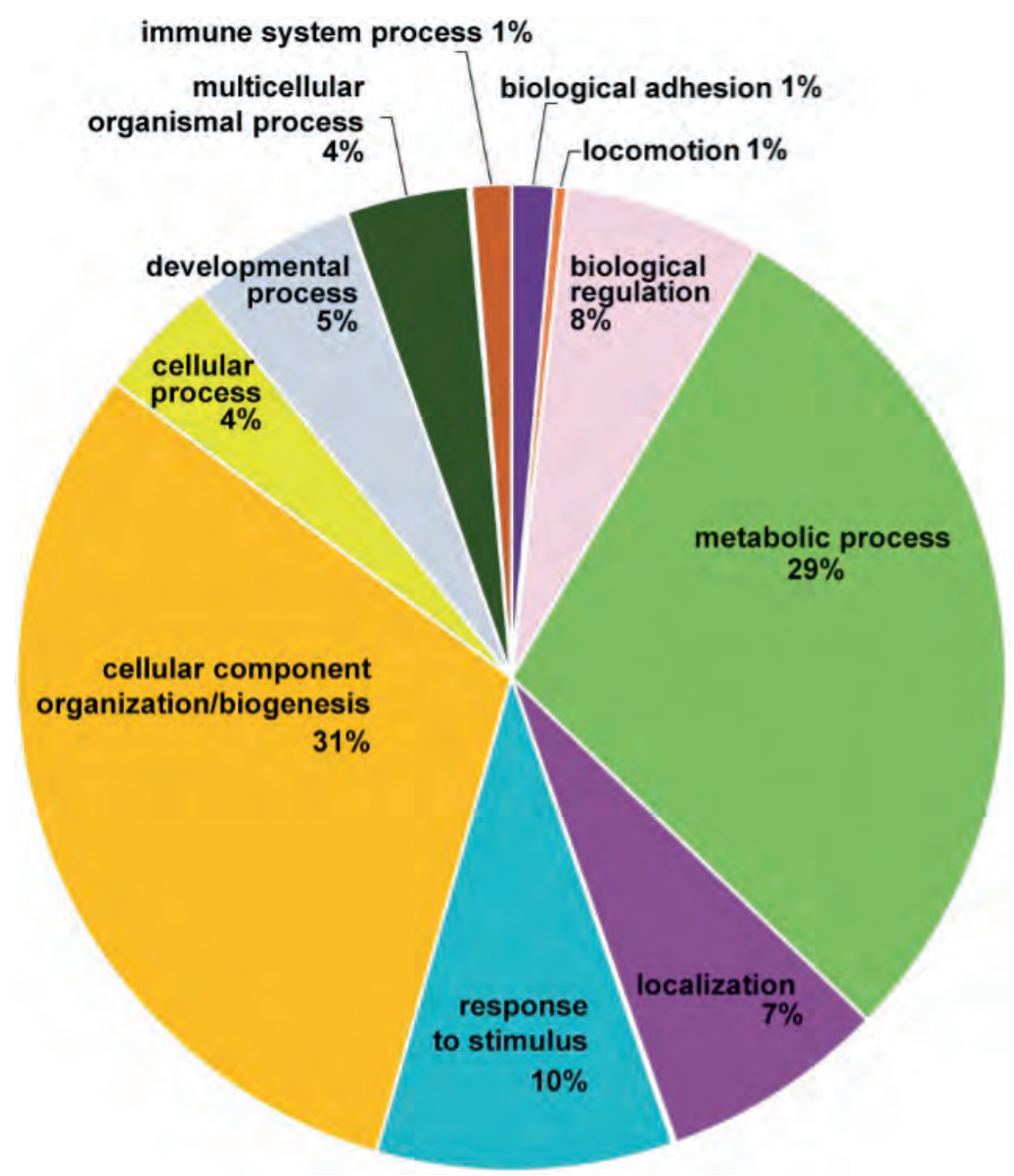

Figure S2: Panther GO-slim biological processes annotation chart for predicted targets of miR-103/107. Total predicted genes: 838; total number of process hits: 1397 


\section{Supplemental tables}

Table S1. Hematological and immunological analysis in plasma of scrambled or antagomiR103/107 treated mice at week 3.

\begin{tabular}{|c|c|c|c|c|}
\hline \multirow[t]{2}{*}{ Immune formula } & \multicolumn{2}{|c|}{ Scrambled } & \multicolumn{2}{|c|}{ AntagomiR } \\
\hline & Mean & \pm SEM & Mean & \pm SEM \\
\hline WBC $\left(10^{\wedge} 3 / \mu L\right)$ & 5.17 & 0.24 & $3.94^{*}$ & 0.33 \\
\hline Neutrophils $\left(10^{\wedge} 3 / \mu \mathrm{L}\right)$ & 0.33 & 0.03 & 0.27 & 0.04 \\
\hline$\%$ Neutrophils & 6.54 & 0.76 & 6.85 & 0.42 \\
\hline Lymphocytes $\left(10^{\wedge} 3 / \mu \mathrm{L}\right)$ & 4.64 & 0.27 & $3.48^{*}$ & 0.28 \\
\hline$\%$ Lymphocytes & 89.54 & 1.61 & 88.30 & 0.91 \\
\hline Monocytes $\left(10^{\wedge} 3 / \mu \mathrm{L}\right)$ & 0.04 & 0.01 & 0.04 & 0.01 \\
\hline$\%$ Monocytes & 0.78 & 0.31 & 0.90 & 0.19 \\
\hline Eosinophils $\left(10^{\wedge} 3 / \mu \mathrm{L}\right)$ & 0.01 & 0.00 & 0.03 & 0.03 \\
\hline$\%$ Eosinophils & 0.22 & 0.04 & 0.87 & 0.64 \\
\hline Basophils $\left(10^{\wedge} 3 / \mu L\right)$ & 0.15 & 0.03 & 0.12 & 0.02 \\
\hline$\%$ Basophils & 2.91 & 0.62 & 3.08 & 0.21 \\
\hline RBC (M/uL) & 6.10 & 0.18 & 6.58 & 0.11 \\
\hline HGB (g/dL) & 8.97 & 0.26 & 9.68 & 0.18 \\
\hline НСТ (\%) & 48.29 & 1.48 & 52.23 & 0.85 \\
\hline MCV (fL) & 79.11 & 0.47 & 79.38 & 0.35 \\
\hline $\mathrm{MCH}(\mathrm{pg})$ & 14.71 & 0.10 & 14.70 & 0.07 \\
\hline $\operatorname{MCHC}(\mathrm{g} / \mathrm{dL})$ & 18.59 & 0.06 & 18.53 & 0.06 \\
\hline RDW (\%) & 15.77 & 0.51 & 17.07 & 0.59 \\
\hline PLT (K/dL) & 853.29 & 20.48 & 823.17 & 32.20 \\
\hline MPV (fL) & 5.84 & 0.16 & 5.82 & 0.07 \\
\hline РСТ (\%) & 0.50 & 0.03 & 0.48 & 0.02 \\
\hline PDW (GSD) & 16.94 & 0.23 & 16.93 & 0.21 \\
\hline
\end{tabular}

$n=7$ per group; * $p<0.05$ vs scrambled 
Table S2. Mass spectrometry analysis of heart apex of scrambled or antagomiR-103/107 treated mice.

\begin{tabular}{|c|c|c|c|c|c|c|c|c|}
\hline Protein [OS=Mus musculus] & UniProt ID & UP & $\begin{array}{l}\text { Log2 } \\
\text { Ratio }\end{array}$ & Q-value & $\begin{array}{l}\text { Ant/ } \\
\text { Scr }\end{array}$ & Ant [-] & Scr [-] & $\begin{array}{l}\text { Data } \\
\text { Points }\end{array}$ \\
\hline $\begin{array}{l}26 \mathrm{~S} \text { proteasome non-ATPase } \\
\text { regulatory subunit } 7\end{array}$ & P26516 & 4 & 0.52 & $1.81 \mathrm{E}-02$ & 1.43 & 18129.9 & 12684.1 & 4 \\
\hline complement factor $\mathrm{H}$ & P06909 & 2 & 0.42 & $1.22 \mathrm{E}-02$ & 1.34 & 5832.5 & 4345.8 & 2 \\
\hline Hemopexin ${ }^{a}$ & Q91X72 & 18 & 0.38 & $6.04 \mathrm{E}-11$ & 1.30 & 248566.8 & 191392.4 & 23 \\
\hline $\begin{array}{l}\text { Peptidyl-prolyl cis-trans } \\
\text { isomerase } \mathrm{F} \text {, mitochondrial }\end{array}$ & Q99KR7 & 8 & 0.35 & $1.96 \mathrm{E}-02$ & 1.27 & 24018.7 & 18844.0 & 9 \\
\hline Complement C3 & P01027-1 & 11 & 0.28 & 1.10E-02 & 1.21 & 50356.1 & 41446.4 & 12 \\
\hline Actin, alpha skeletal muscle & P68134 & 3 & 0.28 & $1.84 \mathrm{E}-02$ & 1.21 & 167488.3 & 138069.6 & 6 \\
\hline Cytochrome c, somatic & P62897 & 24 & 0.27 & $9.73 \mathrm{E}-17$ & 1.20 & 2779866.3 & 2307895.8 & 41 \\
\hline Acylphosphatase-2 & P56375 & 7 & 0.27 & $9.64 \mathrm{E}-04$ & 1.20 & 122844.4 & 102199.0 & 8 \\
\hline $\begin{array}{l}\text { Aspartate aminotransferase, } \\
\text { mitochondrial }\end{array}$ & P05202 & 41 & 0.24 & $5.26 \mathrm{E}-14$ & 1.18 & 1101538.9 & 933398.8 & 62 \\
\hline Fibrinogen gamma chain & Q8VCM7 & 10 & 0.24 & $3.18 \mathrm{E}-03$ & 1.18 & 68054.0 & 57702.7 & 10 \\
\hline Myosin-7 & Q91Z83 & 65 & 0.20 & $6.88 \mathrm{E}-05$ & 1.15 & 1948494.3 & 1701126.8 & 96 \\
\hline $\begin{array}{l}\text { Fatty acid-binding protein, } \\
\text { heart }\end{array}$ & P11404 & 23 & 0.18 & 3.80E-05 & 1.13 & 5532021.5 & 4883083.0 & 50 \\
\hline Protein S100-A1 & P56565 & 5 & 0.18 & $1.71 \mathrm{E}-02$ & 1.13 & 183583.0 & 162465.1 & 8 \\
\hline $\begin{array}{l}\text { Actin, alpha cardiac muscle } 1 \\
\text { a }\end{array}$ & P68033 & 60 & 0.15 & $2.20 \mathrm{E}-03$ & 1.11 & 61439824.0 & 55271280.0 & 163 \\
\hline $\begin{array}{l}\text { myosin regulatory light chain } \\
2 \text {, ventricular/cardiac muscle } \\
\text { isoform }\end{array}$ & P51667 & 37 & 0.15 & $9.10 \mathrm{E}-03$ & 1.11 & 7096360.5 & 6411138.5 & 83 \\
\hline $\begin{array}{l}\text { Translationally-controlled } \\
\text { tumor protein }\end{array}$ & P63028 & 10 & 0.14 & $1.10 \mathrm{E}-02$ & 1.11 & 297646.4 & 269287.2 & 13 \\
\hline Myosin-4 & Q5SX39 & 14 & 0.14 & 3.85E-03 & 1.10 & 3429579.3 & 3111626.8 & 20 \\
\hline Pregnancy zone protein & Q61838 & 13 & 0.12 & $9.46 \mathrm{E}-03$ & 1.09 & 101444.3 & 93338.5 & 14 \\
\hline Myoglobin a & P04247 & 36 & 0.12 & $3.72 \mathrm{E}-03$ & 1.08 & 14948670.0 & 13778867.0 & 88 \\
\hline $\begin{array}{l}\text { Acyl-coenzyme A thioesterase } \\
13\end{array}$ & Q9CQR4 & 13 & 0.10 & $1.04 \mathrm{E}-02$ & 1.07 & 1336000.1 & 1245060.6 & 23 \\
\hline Telethonin & O70548 & 4 & 0.10 & $2.50 \mathrm{E}-03$ & 1.07 & 153428.2 & 143335.0 & 4 \\
\hline $\begin{array}{l}\text { electron transfer flavoprotein } \\
\text { subunit beta }\end{array}$ & Q9DCW4 & 35 & 0.06 & $2.78 \mathrm{E}-06$ & 1.04 & 3497220.5 & 3361798.3 & 57 \\
\hline $\begin{array}{l}\text { Cytochrome b-c1 complex } \\
\text { subunit } 7\end{array}$ & Q9D855 & 18 & 0.05 & $2.73 \mathrm{E}-05$ & 1.04 & 1626810.6 & 1571087.5 & 30 \\
\hline $\begin{array}{l}\text { ATP synthase subunit gamma, } \\
\text { mitochondrial }\end{array}$ & Q91VR2 & 28 & 0.04 & 7.14E-05 & 1.03 & 1369158.4 & 1327708.0 & 44 \\
\hline Laminin subunit alpha-2 & Q60675 & 60 & 0.03 & 7.67E-04 & 1.02 & 167368.0 & 164485.1 & 69 \\
\hline $\begin{array}{l}\text { glyceraldehyde-3-phosphate } \\
\text { dehydrogenase }\end{array}$ & P16858 & 38 & 0.02 & $4.55 \mathrm{E}-04$ & 1.01 & 6986970.0 & 6887551.5 & 79 \\
\hline Beta-enolase & P21550 & 52 & -0.01 & $3.02 E-04$ & 0.99 & 2640891.5 & 2665133.0 & 92 \\
\hline Adenylate kinase isoenzyme 1 & Q9R0Y5-1 & 25 & -0.02 & $2.39 E-04$ & 0.99 & 2043768.6 & 2069378.4 & 40 \\
\hline $\begin{array}{l}\text { Ornithine aminotransferase, } \\
\text { mitochondrial }\end{array}$ & P29758 & 17 & -0.03 & 1.64E-02 & 0.98 & 193450.4 & 197165.2 & 26 \\
\hline Alpha-actinin-2 & Q9JI91 & 120 & -0.03 & 8.73E-04 & 0.98 & 2255220.0 & 2309955.8 & 209 \\
\hline Cysteine-rich protein 2 & Q9DCT8 & 16 & -0.04 & $1.76 \mathrm{E}-02$ & 0.97 & 630263.5 & 648074.9 & 27 \\
\hline $\begin{array}{l}\text { NADH dehydrogenase } \\
\text { [ubiquinone] } 1 \text { alpha } \\
\text { subcomplex subunit } 2\end{array}$ & Q9CQ75 & 11 & -0.05 & 1.33E-02 & 0.97 & 795473.6 & 821258.3 & 16 \\
\hline Myosin-3 & $\mathrm{P} 13541$ & 9 & -0.05 & 4.03E-03 & 0.97 & 1769777.5 & 1828452.1 & 11 \\
\hline $\begin{array}{l}\text { Cytochrome c oxidase subunit } \\
6 \text { B1 }\end{array}$ & P56391 & 11 & -0.05 & $5.96 \mathrm{E}-04$ & 0.97 & 6591877.0 & 6821341.0 & 18 \\
\hline
\end{tabular}




\begin{tabular}{|c|c|c|c|c|c|c|c|c|}
\hline Protein [OS=Mus musculus] & UniProt ID & UP & $\begin{array}{l}\text { Log2 } \\
\text { Ratio }\end{array}$ & Q-value & $\begin{array}{l}\text { Ant/ } \\
\text { Scr }\end{array}$ & Ant [-] & Scr [-] & $\begin{array}{l}\text { Data } \\
\text { pints }\end{array}$ \\
\hline $\begin{array}{l}\text { Malate dehydrogenase, } \\
\text { cytoplasmic }\end{array}$ & P14152 & 37 & -0.05 & $8.40 \mathrm{E}-03$ & 0.97 & 4713308.0 & 4881656.0 & 59 \\
\hline Alpha-crystallin B chain & P23927 & 23 & -0.06 & $1.23 \mathrm{E}-02$ & 0.96 & 1099699.0 & 1147986.0 & 47 \\
\hline $\begin{array}{l}\text { ATP synthase subunit } d \text {, } \\
\text { mitochondrial }\end{array}$ & Q9DCX2 & 21 & -0.07 & $3.51 \mathrm{E}-03$ & 0.95 & 2873328.3 & 3010304.5 & 37 \\
\hline $\begin{array}{l}\text { Aspartate aminotransferase, } \\
\text { cytoplasmic }\end{array}$ & P05201 & 35 & -0.07 & $1.52 \mathrm{E}-03$ & 0.95 & 1689716.6 & 1777122.5 & 55 \\
\hline $\begin{array}{l}\text { Isocitrate dehydrogenase } \\
\text { [NAD] subunit alpha, } \\
\text { mitochondrial }\end{array}$ & Q9D6R2 & 34 & -0.08 & $6.38 \mathrm{E}-04$ & 0.95 & 1214956.3 & 1279973.0 & 57 \\
\hline $\begin{array}{l}\text { Malate dehydrogenase, } \\
\text { mitochondrial }\end{array}$ & P08249 & 39 & -0.08 & $3.74 \mathrm{E}-09$ & 0.95 & 15937558.0 & 16827072.0 & 74 \\
\hline $\begin{array}{l}\text { Cytochrome b-c1 complex } \\
\text { subunit } 2 \text {, mitochondrial }\end{array}$ & Q9DB77 & 34 & -0.08 & 7.17E-03 & 0.94 & 2317813.8 & 2453957.8 & 58 \\
\hline $\begin{array}{l}\text { EH domain-containing protein } \\
1 \mathrm{a}\end{array}$ & Q9WVK4 & 15 & -0.08 & $3.45 \mathrm{E}-03$ & 0.94 & 72112.0 & 76449.4 & 20 \\
\hline $\begin{array}{l}\text { Electron transfer flavoprotein } \\
\text { subunit alpha, mitochondrial }\end{array}$ & Q99LC5 & 32 & -0.09 & $1.52 \mathrm{E}-04$ & 0.94 & 4521429.5 & 4796793.5 & 58 \\
\hline $\begin{array}{l}\text { NADH dehydrogenase } \\
\text { [ubiquinone] flavoprotein 1, } \\
\text { mitochondrial }\end{array}$ & Q91YT0 & 37 & -0.09 & $3.95 \mathrm{E}-03$ & 0.94 & 1150154.4 & 1222285.6 & 67 \\
\hline Troponin I, cardiac muscle & P48787 & 31 & -0.10 & $3.99 \mathrm{E}-04$ & 0.93 & 5298699.0 & 5685937.0 & 49 \\
\hline $\begin{array}{l}\text { Cytochrome c oxidase subunit } \\
2\end{array}$ & P00405 & 8 & -0.10 & 1.64E-02 & 0.93 & 4445445.5 & 4772605.0 & 16 \\
\hline $\begin{array}{l}\text { Heterogeneous nuclear } \\
\text { ribonucleoproteins } \mathrm{C} 1 / \mathrm{C} 2\end{array}$ & $\begin{array}{l}\text { Q9Z204;- } \\
2 ;-3 ;-4 ;-5\end{array}$ & 5 & -0.11 & 1.99E-02 & 0.93 & 39069.5 & 42063.2 & 5 \\
\hline $\begin{array}{l}\text { Carnitine O- } \\
\text { palmitoyltransferase 2, } \\
\text { mitochondrial }\end{array}$ & P52825 & 43 & -0.11 & $1.84 \mathrm{E}-03$ & 0.93 & 349260.2 & 376413.4 & 54 \\
\hline $\begin{array}{l}\text { Very long-chain specific acyl- } \\
\text { CoA dehydrogenase, } \\
\text { mitochondrial }\end{array}$ & P50544 & 48 & -0.11 & 8.97E-03 & 0.93 & 1795736.5 & 1940154.9 & 69 \\
\hline Protein FAM136A a & Q9CR98 & 5 & -0.11 & $4.98 \mathrm{E}-03$ & 0.92 & 46795.8 & 50645.9 & 7 \\
\hline $\begin{array}{l}\text { O-acetyl-ADP-ribose } \\
\text { deacetylase MACROD1 }\end{array}$ & Q922B1 & 20 & -0.12 & $9.49 \mathrm{E}-06$ & 0.92 & 228717.3 & 247875.4 & 28 \\
\hline $\begin{array}{l}\text { EH domain-containing protein } \\
4 \mathrm{a}^{2}\end{array}$ & Q9EQP2 & 14 & -0.13 & $8.49 \mathrm{E}-06$ & 0.92 & 179074.2 & 195609.8 & 15 \\
\hline Dystroglycan & Q62165 & 5 & -0.14 & $1.51 \mathrm{E}-03$ & 0.91 & 17315.3 & 19054.6 & 6 \\
\hline Peroxiredoxin-5, mitochondrial & P99029;-2 & 15 & -0.14 & $3.71 \mathrm{E}-03$ & 0.91 & 2688488.0 & 2962060.0 & 26 \\
\hline $\begin{array}{l}\text { Mitochondrial import inner } \\
\text { membrane translocase } \\
\text { subunit TIM44 }\end{array}$ & O35857 & 10 & -0.14 & $2.32 \mathrm{E}-03$ & 0.91 & 36331.5 & 40140.4 & 11 \\
\hline $\begin{array}{l}\text { Methylcrotonoyl-CoA } \\
\text { carboxylase beta chain, } \\
\text { mitochondrial }\end{array}$ & Q3ULD5 & 25 & -0.15 & 1.07E-03 & 0.90 & 228112.0 & 252481.9 & 30 \\
\hline $\begin{array}{l}\text { Guanine nucleotide-binding } \\
\text { protein } G(I) / G(S) / G(T) \text { subunit } \\
\text { beta-2 }\end{array}$ & P62880 & 4 & -0.15 & $1.83 \mathrm{E}-02$ & 0.90 & 40107.8 & 44575.5 & 5 \\
\hline $\begin{array}{l}\text { Heterogeneous nuclear } \\
\text { ribonucleoprotein } U\end{array}$ & Q8VEK3 & 7 & -0.16 & $2.96 \mathrm{E}-03$ & 0.90 & 24624.8 & 27453.8 & 11 \\
\hline $\begin{array}{l}\text { medium-chain specific acyl- } \\
\text { CoA dehydrogenase, } \\
\text { mitochondrial }\end{array}$ & P45952 & 38 & -0.16 & 4.07E-03 & 0.90 & 3404054.5 & 3796175.8 & 65 \\
\hline $\begin{array}{l}\text { haloacid dehalogenase-like } \\
\text { hydrolase domain-containing } \\
\text { protein } 2\end{array}$ & Q3UGR5-1 & 4 & -0.16 & $1.18 \mathrm{E}-02$ & 0.90 & 49349.2 & 55088.4 & 4 \\
\hline $\begin{array}{l}\text { Long-chain-fatty-acid--CoA } \\
\text { ligase } 1 \text { a }\end{array}$ & P41216 & 55 & -0.16 & $2.96 \mathrm{E}-08$ & 0.89 & 849570.8 & 950392.8 & 73 \\
\hline Hemoglobin subunit beta-2 & P02089 & 6 & -0.16 & $1.58 \mathrm{E}-04$ & 0.89 & 16437964.0 & 18395956.0 & 13 \\
\hline
\end{tabular}




\begin{tabular}{|c|c|c|c|c|c|c|c|c|}
\hline Protein [OS=Mus musculus] & UniProt ID & UP & $\begin{array}{l}\text { Log2 } \\
\text { Ratio }\end{array}$ & Q-value & $\begin{array}{l}\text { Ant/ } \\
\text { Scr }\end{array}$ & Ant $[-]$ & Scr [-] & $\begin{array}{l}\text { Data } \\
\text { Points }\end{array}$ \\
\hline $\begin{array}{l}\text { Long-chain specific acyl-CoA } \\
\text { dehydrogenase, mitochondrial } \\
\text { a }\end{array}$ & P51174 & 36 & -0.16 & 1.65E-02 & 0.89 & 4784476.5 & 5356746.5 & 58 \\
\hline $\begin{array}{l}\text { Heterogeneous nuclear } \\
\text { ribonucleoprotein } M\end{array}$ & Q9D0E1;-2 & 8 & -0.16 & $1.38 \mathrm{E}-03$ & 0.89 & 41784.1 & 46842.8 & 8 \\
\hline $\begin{array}{l}\text { Bifunctional glutamate/proline- } \\
\text {-tRNA ligase }\end{array}$ & Q8CGC7 & 14 & -0.17 & $5.65 \mathrm{E}-03$ & 0.89 & 61504.2 & 69178.1 & 14 \\
\hline $\begin{array}{l}\text { Branched-chain-amino-acid } \\
\text { aminotransferase, } \\
\text { mitochondrial a }\end{array}$ & O35855 & 15 & -0.19 & 4.74E-05 & 0.88 & 217851.4 & 248441.3 & 19 \\
\hline $\begin{array}{l}\text { Delta(3,5)-Delta(2,4)-dienoyl- } \\
\text { CoA isomerase, mitochondrial }\end{array}$ & O35459 & 29 & -0.19 & $5.16 \mathrm{E}-03$ & 0.87 & 727510.5 & 831638.0 & 44 \\
\hline $\begin{array}{l}\text { Dihydrolipoyllysine-residue } \\
\text { succinyltransferase comp of 2- } \\
\text { oxoglutarate dehydrogenase } \\
\text { complex, }\end{array}$ & Q9D2G2-1 & 28 & -0.19 & 3.66E-03 & 0.87 & 2201266.3 & 2518189.5 & 38 \\
\hline $\begin{array}{l}\text { T-complex protein } 1 \text { subunit } \\
\text { delta }\end{array}$ & P80315 & 4 & -0.20 & $4.20 \mathrm{E}-03$ & 0.87 & 13949.2 & 16061.8 & 4 \\
\hline $\begin{array}{l}\text { NADH dehydrogenase } \\
\text { [ubiquinone] iron-sulfur } \\
\text { protein } 7, \text { mitochondrial }\end{array}$ & Q9DC70 & 13 & -0.22 & $6.39 \mathrm{E}-03$ & 0.86 & 353860.3 & 411094.7 & 17 \\
\hline $40 S$ ribosomal protein $\mathrm{S} 11$ & P62281 & 2 & -0.22 & $7.82 \mathrm{E}-04$ & 0.86 & 13002.6 & 15128.0 & 3 \\
\hline $\begin{array}{l}\text { NADH dehydrogenase } \\
\text { [ubiquinone] } 1 \text { beta } \\
\text { subcomplex subunit } 10 \text { a }\end{array}$ & Q9DCS9 & 21 & -0.22 & $3.54 \mathrm{E}-03$ & 0.86 & 734613.3 & 856187.3 & 32 \\
\hline $\begin{array}{l}\text { sorting and assembly } \\
\text { machinery component } 50 \\
\text { homolog }\end{array}$ & Q8BGH2 & 10 & -0.22 & $1.68 \mathrm{E}-02$ & 0.86 & 96777.8 & 112939.0 & 11 \\
\hline $\begin{array}{l}\text { Acyl-coenzyme A thioesterase } \\
2 \text {, mitochondrial a }\end{array}$ & Q9QYR9 & 26 & -0.23 & 1.49E-03 & 0.85 & 567183.2 & 663567.3 & 35 \\
\hline Laminin subunit beta-1 & P02469 & 14 & -0.23 & 2.37E-03 & 0.85 & 171563.8 & 200856.8 & 16 \\
\hline fructosamine-3-kinase & Q9ER35 & 2 & -0.23 & 4.66E-03 & 0.85 & 26484.9 & 31151.6 & 2 \\
\hline $\begin{array}{l}\text { EH domain-containing protein } \\
2\end{array}$ & Q8BH64 & 18 & -0.23 & $1.02 \mathrm{E}-03$ & 0.85 & 133321.6 & 156871.3 & 25 \\
\hline 60S ribosomal protein L10-like & $\begin{array}{l}\text { P86048;Q6 } \\
\text { ZWV3 }\end{array}$ & 5 & -0.27 & 1.63E-05 & 0.83 & 65484.8 & 78754.8 & 5 \\
\hline adiponectin & Q60994 & 3 & -0.28 & 7.19E-03 & 0.82 & 22722.7 & 27560.4 & 3 \\
\hline $\begin{array}{l}\text { Lon protease homolog, } \\
\text { mitochondrial }\end{array}$ & Q8CGK3 & 19 & -0.28 & $2.78 \mathrm{E}-03$ & 0.82 & 175859.7 & 213585.7 & 23 \\
\hline 40 S ribosomal protein $S 2$ & P25444 & 4 & -0.29 & $3.19 \mathrm{E}-03$ & 0.82 & 34421.7 & 41953.7 & 4 \\
\hline Selenium-binding protein 1 & P17563 & 9 & -0.29 & $5.88 \mathrm{E}-06$ & 0.82 & 72690.8 & 88882.3 & 10 \\
\hline NAD kinase 2, mitochondrial & $\begin{array}{l}\text { Q8C5H8- } \\
1 ;-2 ;-3 ;-4\end{array}$ & 2 & -0.30 & $7.84 \mathrm{E}-03$ & 0.81 & 4520.9 & 5569.2 & 2 \\
\hline Transketolase & P40142 & 9 & -0.31 & $6.82 \mathrm{E}-03$ & 0.81 & 20513.9 & 25462.9 & 9 \\
\hline $\begin{array}{l}\text { C-1-tetrahydrofolate synthase, } \\
\text { cytoplasmic }\end{array}$ & Q922D8 & 3 & -0.36 & 1.64E-02 & 0.78 & 5013.7 & 6419.4 & 3 \\
\hline $\begin{array}{l}\text { Heat shock protein HSP } 90- \\
\text { alpha }\end{array}$ & P07901 & 8 & -0.36 & 1.77E-02 & 0.78 & 180191.6 & 231620.6 & 11 \\
\hline histone $\mathrm{H} 3.2$ & P84228 & 1 & -0.36 & $8.62 \mathrm{E}-05$ & 0.78 & 88267.4 & 113576.8 & 3 \\
\hline $40 S$ ribosomal protein $S 8$ & P62242 & 5 & -0.38 & $1.73 \mathrm{E}-07$ & 0.77 & 25016.8 & 32583.1 & 6 \\
\hline $60 S$ ribosomal protein $\mathrm{L7a}$ & P12970 & 8 & -0.41 & $1.73 \mathrm{E}-02$ & 0.76 & 16516.1 & 21871.5 & 8 \\
\hline $60 S$ ribosomal protein L32 a & P62911 & 4 & -0.42 & 1.97E-02 & 0.75 & 8644.8 & 11577.0 & 5 \\
\hline Catenin beta-1 & Q02248 & 5 & -0.45 & $3.71 \mathrm{E}-03$ & 0.73 & 9466.7 & 12930.9 & 5 \\
\hline Histone H1.0 & P10922 & 5 & -0.47 & $1.44 \mathrm{E}-05$ & 0.72 & 23809.3 & 33064.0 & 5 \\
\hline $60 S$ ribosomal protein L27a & P14115 & 5 & -0.48 & $1.50 \mathrm{E}-02$ & 0.72 & 37959.2 & 52889.9 & 5 \\
\hline Aspartyl aminopeptidase & Q9Z2W0 & 3 & -0.48 & $9.84 \mathrm{E}-04$ & 0.72 & 28783.8 & 40217.2 & 3 \\
\hline
\end{tabular}




\begin{tabular}{|c|c|c|c|c|c|c|c|c|}
\hline Protein [OS=Mus musculus] & UniProt ID & UP & $\begin{array}{l}\text { Log2 } \\
\text { Ratio }\end{array}$ & Q-value & $\begin{array}{l}\text { Ant } / \\
\text { Scr }\end{array}$ & Ant [-] & Scr [-] & $\begin{array}{l}\text { Data } \\
\text { Points }\end{array}$ \\
\hline Histone H1.3 & P43277 & 11 & -0.55 & $8.45 \mathrm{E}-05$ & 0.68 & 74064.0 & 108330.6 & 16 \\
\hline $60 S$ ribosomal protein $L 7$ & P14148 & 6 & -0.56 & 1.81E-02 & 0.68 & 9013.1 & 13247.8 & 6 \\
\hline histone $\mathrm{H} 4$ a & P62806 & 11 & -0.57 & 1.65E-09 & 0.67 & 1654453.1 & 2456581.3 & 316 \\
\hline Alpha-actinin-3 & O88990 & 2 & -0.61 & $1.82 \mathrm{E}-03$ & 0.66 & 18781.9 & 28585.9 & 3 \\
\hline $60 S$ ribosomal protein L14 & Q9CR57 & 3 & -0.65 & $1.88 \mathrm{E}-03$ & 0.64 & 10302.6 & 16135.4 & 4 \\
\hline $40 S$ ribosomal protein $S 25$ & P62852 & 3 & -0.69 & $1.90 \mathrm{E}-03$ & 0.62 & 37913.7 & 60990.8 & 3 \\
\hline Histone H3.1 & P68433 & 14 & -0.69 & $1.02 \mathrm{E}-19$ & 0.62 & 1074207.0 & 1730754.3 & 318 \\
\hline Histone $\mathrm{H} 3.3 \mathrm{C}$; histone $\mathrm{H} 3.3$ & $\begin{array}{l}\mathrm{P} 02301 ; \mathrm{P} 8 \\
4244\end{array}$ & 2 & -0.72 & $1.21 \mathrm{E}-03$ & 0.61 & 39108.6 & 64587.5 & 3 \\
\hline $\begin{array}{l}\text { Glutathione reductase, } \\
\text { mitochondrial a }\end{array}$ & $\begin{array}{l}\mathrm{P} 47791 ; \mathrm{P} 4 \\
7791-2\end{array}$ & 2 & -0.81 & $6.20 \mathrm{E}-03$ & 0.57 & 8223.1 & 14383.9 & 2 \\
\hline Myosin-1 & Q5SX40 & 1 & -0.83 & $3.74 \mathrm{E}-06$ & 0.56 & 262413.5 & 465269.9 & 2 \\
\hline $\begin{array}{l}\text { Eukaryotic translation } \\
\text { initiation factor } 3 \text { subunit I }\end{array}$ & Q9QZD9 & 3 & -0.94 & 1.96E-02 & 0.52 & 3608.7 & 6943.2 & 4 \\
\hline
\end{tabular}

Ant [-], average of antagomiR-103/107; Scr [-], average of scrambled control; Log2 ratio represents the average of the Log2 ratio; $n=3$ per group analyzed in triplicates; ${ }^{a}$, target of miR-103/107 based on TargetScan prediction. 

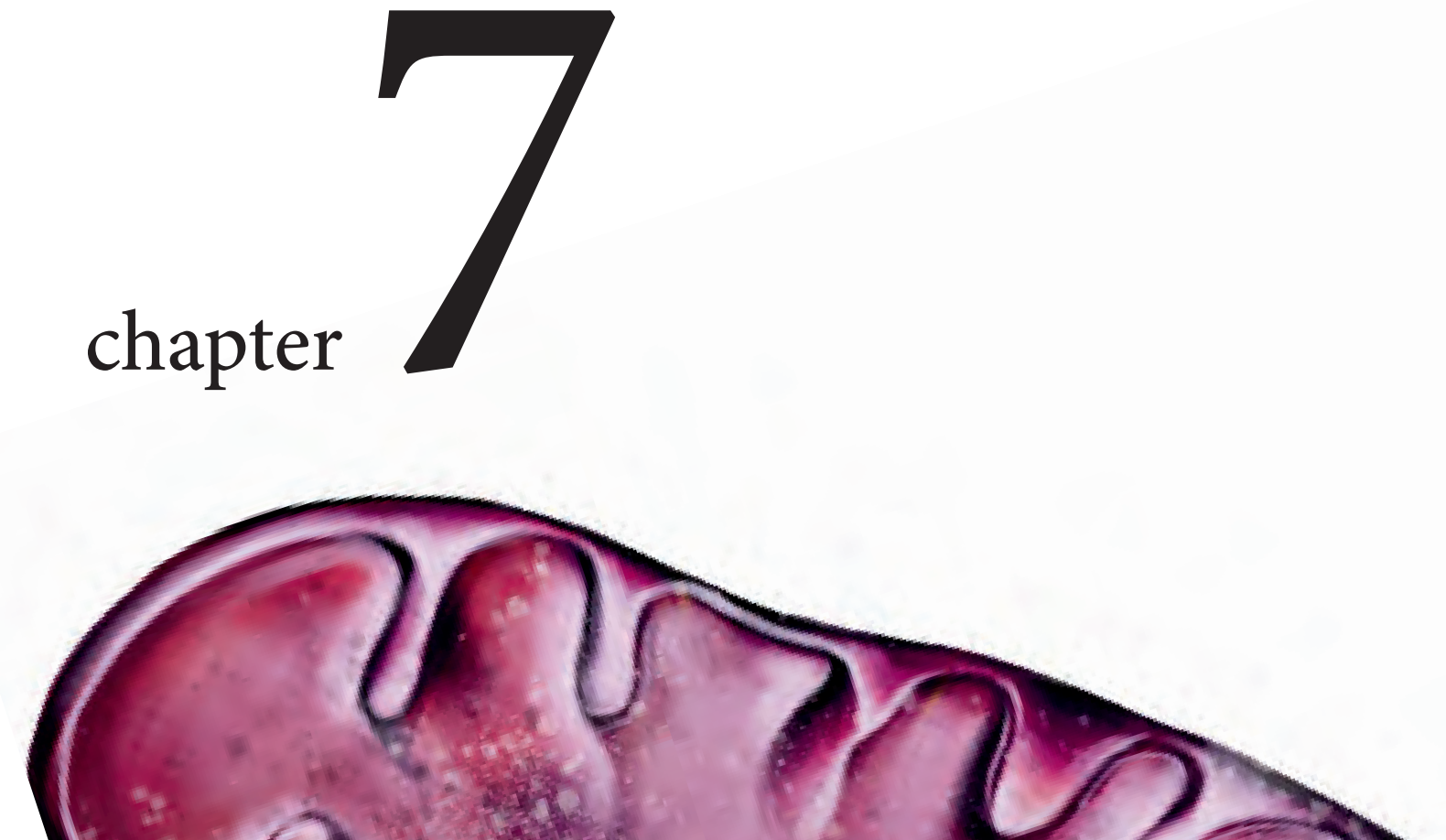


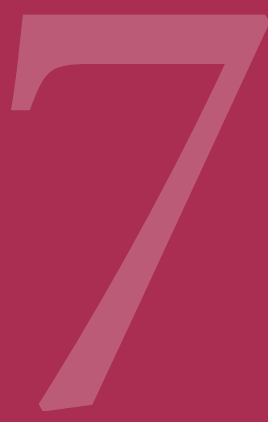

General Discussion 
The principal aim of this thesis was to advance our understanding of the nature and relevance of alterations in cardiac metabolism in the pathophysiology of cardiac disease, with special emphasis on HFpEF. Thereto, we first presented our views on the significance of changes in cardiac metabolism in a review (chapter 2) and postulate, similar to what has become known about 'metabolic rewiring' of cancer cells, that changes in cardiac metabolism primarily serve to enable cells to adjust to a new situation, rather than ensuring an adequate supply of ATP to the cardiomyocyte's contractile machinery. In chapter $\mathbf{3}$ and $\mathbf{4}$ we explored the nature of cardiac metabolic changes associated with MetS-induced HFpEF, making use of various 'omics-techniques' and network-biology approaches to get a more holistic view on pathophysiological processes at play (chapter 3) and of the nature of the metabolic rewiring in HFpEF (chapter 4). To that purpose we also made use of mass spectrometry imaging (MSI), a relatively novel technique allowing 'molecular histology' of metabolites. In chapter 5 we used cardiac fibroblasts to test the relation between cellular metabolism and cellular phenotype, showing that some of the ideas postulated in chapter 2 indeed apply to this cardiac cell type. We further detected metabolite variations in the fibroblast-rich zone of infarct areas in different phases post-myocardial infarction via MSI. In chapter 6, given that noncoding RNAs modulate many cellular processes ${ }^{1}$ including metabolism, we tested if inhibition of miR103/107, a microRNA previously implicated in the regulation of glucose metabolism and insulin sensitivity ${ }^{2}$, also proves to be beneficial for the heart.

The main conclusions of the combined studies presented in this thesis are that mitochondrial metabolism is affected in HFpEF and that cellular metabolism and phenotypical remodeling are bidirectional processes impacting each other. These conclusions will be discussed in more detail below, alongside opportunities for therapeutic strategies and future research.

\section{Mitochondrial metabolism is affected in HFpEF}

By employing a novel network biology approach, specifically designed for cardiome data sets, we identified specific processes that underly HFpEF in ZSF1-Obese rats (chapter 3). In line with the HFpEF paradigm of Paulus et al. ${ }^{3}$, this network analysis identified inflammation, endothelial dysfunction and ECM remodeling, alongside autophagy/apoptosis, as important disease processes in the ZSF1-Obese model of HFpEF. Moreover, indicative of an additional, important layer at play, substrate metabolism and mitochondrial oxidation were found to be even more affected, displaying the highest number of differentially regulated genes. Fatty acid beta-oxidation, ETC function, as well as oxidation-reduction and ATP metabolic processes were all documented to be highly affected processes (chapter 3 ). These metabolic pathways appeared to not be as extensively connected to the other processes, save for a small number of genes acting as bottlenecks, including the transcription factor PPARa. Previous studies have shown that these nuclear hormone receptor-type of transcription factors act as a transcriptional activator of fatty acid metabolism, and at the same time interfere with inflammatory signaling via NFkB, thereby providing a molecular link between metabolic and inflammatory processes. ${ }^{4,5}$ 
The findings presented in Chapter $\mathbf{4}$ indicate that several aspects of mitochondrial function are affected in HFpEF hearts. Mitochondrial dysfunction and oxidative stress have been documented in multiple comorbidities of HFpEF, such as obesity and type 2 diabetes, and have been detected in several tissues, including skeletal muscle, liver and adipose tissue.6, 7 Moreover, mitochondrial dysfunction and production of reactive oxygen species (ROS) are thought to play a role in HFpEF progression as well. ${ }^{8,9}$ However, the extent to which this dysfunction contributes to HFpEF development is still unclear. ${ }^{8}$ Cardiolipin, a common phospholipid species of the inner mitochondrial membrane, supports ETC supercomplex formation for optimal electron transfer. ${ }^{10}$ In chapter 4, we documented a prominent reduction of the most common cardiolipin species (cardiolipin 72:8) in the ZSF1-Obese HFpEF heart. The mitochondrial complex I is one of the main sites of ROS production and its dysfunction leads to enhanced oxidative stress. ${ }^{11}$ Due to the co-localization of cardiolipin and ETC complexes, ROS production and peroxidation of cardiolipin might be closely connected: both loss of cardiolipin and its peroxidation lead to instable complex formation, reducing ETC activity and efficiency, and in turn enhance ROS production. ${ }^{12,13}$ It is well conceivable that in HFpEF the decline in cardiac cardiolipin content, as detected by MSI in chapter 4, possibly caused by enzymatic degradation or via the peroxidation of the poly-unsaturated fatty-acyl chains, negatively affects ATP production and enhances mitochondrial ROS production. Enhanced ROS production can also damage other mitochondrial metabolic enzymes, including the TCA cycle enzyme ACO2 that contains four iron-sulfur clusters, making it highly vulnerable to oxidative stress. Impaired ACO2 activity will lead to the accumulation of upstream intermediates due to impaired TCA cycle function at the level of this enzyme. This putative TCA cycle block in turn possibly impairs the entry of fatty acid-derived acetyl-units into the TCA cycle and, in combination with increased plasma FFA levels, may lead to the observed accumulation of triglycerides in the ZSF1-Obese HFpEF heart (chapter 4). Taken together, these studies reveal a possible mismatch between the prominently affected fatty acid metabolism and mitochondrial oxidative metabolism upon HFpEF.

\section{MSI as a tool for cardiometabolic research}

Mass spectrometry imaging (MSI) measures the spatial distribution of molecules across a sample via sample ionization, sorting of ions according to their mass $(\mathrm{m} / \mathrm{z})$ and abundance detection for each location within a sample. Thereby, a mass spectrum is created for each location, containing the range of detected molecules. Through this, the spatial location of molecules can be preserved, and images can be created to visualize the distribution of each ion of interest across the entire sample. The analysis of biological tissue samples by MALDIMSI was first described in $1997^{14}$ and the first identification of metabolites within tissue was published in 2009, identifying 13 primary metabolites in rat brain. ${ }^{15}$ Improvements in technical and software workflows have made MSI techniques more user-friendly and are increasingly embraced by preclinical and clinical researchers alike. MSI applications are now quite established in cancer research and diagnostics ${ }^{16}$, toxicology and drug distribution analyses 17 , but are also applied in cardiovascular research in increased frequency. ${ }^{18}$ Cardiovascular- 
related MSI most often focuses on lipid analyses, with less studies assessing protein and metabolite content. ${ }^{18}$ An important consideration in all MALDI-MSI applications is the choice of matrix. In chapters $\mathbf{4}$ and $\mathbf{5}$, we utilized $\mathrm{N}$-(1-naphthyl) ethylenediamine dihydrochloride (NEDC), one of the most frequently used matrices for negative ion mode metabolite analyses next to 9AA. Both 9AA and NEDC confer different advantages and allow the detection of different subsets of metabolites. ${ }^{19}$ Utilization of multiple matrices might therefore uncover additional metabolites. In this respect, for our studies it would be interesting to also test matrices, like 2,5-dihydroxybenzoic acid (DHB), that would provide additional information about lipid-metabolites, such as long-chain acyl-carnitines.

Although $\mathrm{m} / \mathrm{z}$ values unveil the nature of metabolites to some extent, in many cases the $\mathrm{m} / \mathrm{z}$ value itself is insufficient to disclose the full identity of a metabolite, especially in TOF-based MSI with comparatively lower mass accuracy. In many cases one $\mathrm{m} / \mathrm{z}$ value can point to several metabolites. Future studies are needed to disclose the identity of the metabolites that appeared as discriminating $\mathrm{m} / \mathrm{z}$ values in our MSI studies of Chapter $\mathbf{4}$ and $\mathbf{5}$. For this, tandem MS (MS/MS) of selected $\mathrm{m} / \mathrm{z}$ peaks is required. In this respect, the observed reduction in the major cardiolipin species and concurrent alterations in other possible cardiolipin-like species in chapter 4 ask for additional MS/MS identification and verification. This would allow us to assess, for instance, if the $\mathrm{m} / \mathrm{z}$ peak that is increased in HFpEF hearts can be identified as a peroxidated cardiolipin species.

Another point of interest is spatial resolution. In the current studies we used a pixel size of 50 $\mu \mathrm{m}$. However, currently with MALDI-MSI resolutions of less than $5 \mu \mathrm{m}$ can be reached 20 . Higher resolutions, however, go hand in hand with increased data acquisition time, lower sensitivity and increased data sizes and require optimal sample preparation to avoid delocalization of analytes. ${ }^{21}$ With the resolution and sample prep utilized in this thesis we were able to disclose the heterogenous nature of myocardial infarcts, as far as regional metabolite variations are concerned. In chapter $\mathbf{5}$ we further demonstrated that early timepoints of myocardial infarction, before the development of overt fibrosis and thus suggestive of changes in cardiomyocytes themselves, present with distinct metabolite profiles. In chapter 4 , however, we saw a rather homogenous distribution of metabolites across ventricular sections of HFpEF hearts. It would be interesting to test if spatial heterogeneity in metabolite content would become detectable at a higher resolution. Given that cardiomyocyte hypertrophy, interstitial fibrosis, and a reduced capillary density lead to increased diffusion distances ${ }^{22}$, it is well conceivable that tissue areas of local hypoxia may arise that will become visible when higher imaging resolutions are applied.

\section{Intervening in cardiac metabolism to prevent and treat HFpEF}

HFpEF patients generally exhibit one or more comorbidities: hypertension is present in 50$90 \%$, diabetes in $25-49 \%$ and obesity in $33-56 \%$ of all patients, depending on clinical trial and cohort. ${ }^{23}$ Since these comorbidities generally precede the development of HFpEF, their treatment can aid in the prevention of HFpEF development as well as progression after HFpEF 
onset. However, it is important to note that drugs that are good at preventing HF in patients at risk, do not necessarily also serve well to treat HF upon disease establishment.

Anti-diabetic drugs for the treatment of HF: Medications used to treat type 2 diabetes, primarily aimed at reducing glucose load throughout the body or enhance insulin levels and sensitivity, have also been tested in HFpEF patients. Sodium-glucose cotransporter inhibitors (SGLT2i) lead to a reduced risk of HF hospitalization in patients suffering from type 2 diabetes at risk for HF. ${ }^{24}$ The Dipeptyl-dipeptidase-4 inhibitors (DPP-4ls, also referred to as Gliptins) are another class of anti-diabetic drugs. Circulatory levels of DPP-4 have been shown to correlate with heart failure severity ${ }^{25}$, generating interest in possible cardioprotective effects of DPP4Is. However, up to now clinical trials showed mixed results. ${ }^{26}$ The anti-diabetic drug metformin has been documented to also attenuate TGFb mediated fibrotic signalling in pressure-overloaded hearts, at least partially independent of its glucose lowering effects. ${ }^{27}$ Lifestyle interventions: In addition to drug treatments, lifestyle interventions are likely to be effective in the prevention of common HFpEF risk factors, but possibly in the treatment of $\mathrm{HFpEF}$ itself as well. Increased BMI and reduced physical activity increase the risk for HF in a dose-dependent manner. ${ }^{28}$ Regular physical exercise and maintenance of a normal BMI can thereby aid in risk reduction of HFpEF. Even after HFpEF diagnosis, lifestyle modifications could still prove beneficial. Although studies specifically focusing on lifestyle interventions like regular exercise or caloric restriction are few, their results indicate a promising, possibly complementary approach in the treatment of HFpEF. ${ }^{29-31}$

Interventions in mitochondrial metabolism: In chapter $\mathbf{3}$ and $\mathbf{4}$ we identified mitochondrial function and oxidative metabolism as important contributors in the pathophysiology of HFpEF. The functional consequences of the presently observed mitochondrial alterations will need to be further explored, but two main possibilities come to mind: impaired oxidative mitochondrial metabolism compromises cardiac contraction via a direct effect on ATP generation, and/or enhances ROS and thereby affects cardiac contractility. Studies have also implicated impairments in mitochondrial biogenesis in $\mathrm{HF}^{32}$ and medications for the improvement of biogenesis are being considered in HFpEF treatment: The GRAPEVINE-HF trial (NCT01185067) investigates grape seed extract, containing relatively large amounts of proanthocyanidins, for the AMPK- and SIRT1-mediated activation of PGC1a-induced mitochondrial biogenesis and nitric oxide synthase in HFpEF patients. Ubiquinol, the active form of Coenzyme Q10 is currently being tested in HFpEF patients ${ }^{33}$ due to its function as a ETC co-factor and electron transporter between ETC complexes. ${ }^{34}$ The antioxidant EUK-8, a manganese-superoxide dismutase mimetic, exerted protective effects against $L V$ remodelling in a pressure overload induced HF. ${ }^{35}$ Elamipeptride (SS-31) trials investigating potential ROS reduction are pending (NCT02814097, NCT02914665). Its association with and reduction of peroxidation of cardiolipin stabilizes ETC supercomplex formation and can improve mitochondrial function. ${ }^{36}$ Metformin has also been described to enhance mitochondrial respiration and increase ETC complex activity through AMPK activation ${ }^{37,38}$. 
MicroRNA modulation as metabolic intervention: MicroRNAs (miRNAs) provide another avenue by which cardiac metabolism can be altered. As post-transcriptional modulators, they have been regarded favorably for their potential as therapeutics. MiRNA modulation is being investigated in different clinical trials for the treatment of cardiovascular as well as metabolic diseases. ${ }^{39}$ Recently, a miR-132 inhibitor has been successfully utilized in a $1 \mathrm{~b}$ clinical trial of heart failure patients. ${ }^{40}$ This miRNA was identified to be a driver of pathological growth of cardiomyocytes in mice, and its inhibition was found to improve heart failure in a pig model of myocardial infarction. In addition, inhibitors against miR-378 have been suggested for the treatment of cardiometabolic disease. ${ }^{41}$ However, miRNA utilization as therapeutics could also induce unintended, possibly detrimental effects. Due to their ability to target a multitude of mRNAs at the same time ${ }^{42}$, miRNAs offer a multi-pronged approach to regulate various deregulated genes simultaneously, but at the same time not all effects can easily be predicted beforehand. ${ }^{43}$ MiRNA-103/107 has more than 800 predicted targets, $29 \%$ of which are connected to metabolic processes thereby offering substantial potential for metabolic modulation. Accordingly, our original plan was to test the impact of a miR-103/107 antagomiR in a mouse model of hypertension-induced cardiac remodeling. However, echocardiography revealed effects of the antagomiR on cardiac function already at baseline. We documented this in chapter 6, in which mice treated with miR-103/107 antagomiRs showed reduced systolic function, in combination with a reduced mitochondrial ETC content and a disturbed mitochondrial structure. In response to miR-103/107 inhibition in vitro, the mitochondrial membrane potential and respiratory capacity of cardiomyocytes were reduced as well, pointing to significant cardiac metabolic side-effects of this antagomiR. Although the therapeutic potential of miRNA-based applications for the treatment of cardiac diseases has been considered since the $2000 \mathrm{~s}^{44}$, no miRNA based therapy has reached the clinic yet. ${ }^{45}$ Also the Phase II clinical trial of antagomiR-103/107 in patients suffering from type 2 diabetes and liver disease has been discontinued.

Intervening in glycolysis: In chapter $\mathbf{5}$ we demonstrated that interventions at the level of glycolysis can be utilized to modulate fibroblast phenotype and function. Although interesting as a proof of concept, similar to antagomiRs, drugs that target metabolic enzymes by interfering with their activity or abundance, are likely to affect the metabolism of other cell types and organs as well, holding great risk of unwanted side-effects in vivo. One possible way to overcome this is to improve their specificity by designing drugs that target isoforms of enzymes, which are more abundant in the anticipated target cell than other cells.

Metabolic interventions and patient heterogeneity: Lastly, it should be mentioned that the abovementioned considerations specifically focus on a certain HFpEF patient phenotype, namely MetS-induced HFpEF. Due to its heterogenous nature, attempts have been made to divide HFpEF patients into different sub-phenotypes with distinct characteristics and comorbidities, whereby the MetS-associated HFpEF subgroup accounted for close to one third of investigated HFpEF cases. ${ }^{46}$ Thus, there are subsets of patients which develop HFpEF 
without MetS-associated comorbidities and consequently do not present with a cardiac metabolism affected by insulin resistance and obesity. Accordingly, the individual contributions of the underlying pathophysiological mechanisms we assessed in this thesis may differ substantially between different HFpEF patient subtypes and consequently impact therapeutic and research strategies.

\section{Impact of COVID-19 on thesis content}

The studies described in this thesis were executed in part during the period when restrictions associated with the COVID-19 pandemic were in place. Especially, experiments which needed to be performed outside of our own laboratories, were unfortunately more affected because of this. We originally intended to expand MSI-based experiments by adding MS/MS analyses for the identification of metabolites as well as lipid focused MALDI-MSI in chapters 4 and 5. Metabolic flux experiments were planned for in vitro experiments in chapter 5 to assess glycolysis and mitochondrial oxidation in cardiac fibroblasts under glycolytic modulation. These experiments would have helped in further substantiating the findings presented in this thesis. 


\section{References}

1. Rech $M$, Barandiarán Aizpurua $A$, van Empel V, van Bilsen M, Schroen B. Pathophysiological understanding of HFpEF: microRNAs as part of the puzzle. Cardiovascular Research 2018;114:782793.

2. Trajkovski M, Hausser J, Soutschek J, Bhat B, Akin A, Zavolan M, Heim MH, Stoffel M. MicroRNAs 103 and 107 regulate insulin sensitivity. Nature 2011;474:649-653.

3. Paulus WJ, Tschope C. A Novel Paradigm for Heart Failure With Preserved Ejection Fraction Comorbidities Drive Myocardial Dysfunction and Remodeling Through Coronary Microvascular Endothelial Inflammation. Journal of the American College of Cardiology 2013;62:263-271.

4. Smeets PJ, de Vogel-van den Bosch HM, Willemsen $\mathrm{PH}$, Stassen AP, Ayoubi T, van der Vusse GJ, van Bilsen $M$. Transcriptomic analysis of PPARalphadependent alterations during cardiac hypertrophy. Physiol Genomics 2008;36:15-23.

5. Alvarez-Guardia D, Palomer $\mathrm{X}$, Coll $\mathrm{T}$, Serrano L, Rodriguez-Calvo R, Davidson MM, Merlos M, El Kochairi I, Michalik L, Wahli W, Vazquez-Carrera M. PPARbeta/delta activation blocks lipidinduced inflammatory pathways in mouse heart and human cardiac cells. Biochim Biophys Acta 2011;1811:59-67.

6. Pinti MV, Fink GK, Hathaway QA, Durr AJ, Kunovac A, Hollander JM. Mitochondrial dysfunction in type 2 diabetes mellitus: an organ-based analysis. Am J Physiol Endocrinol Metab 2019;316:E268-E285.

7. Heinonen S, Jokinen R, Rissanen A, Pietilainen $\mathrm{KH}$. White adipose tissue mitochondrial metabolism in health and in obesity. Obes Rev 2020;21:e12958.

8. Zhou B, Tian R. Mitochondrial dysfunction in pathophysiology of heart failure. J Clin Invest 2018;128:37163726.

9. Miranda-Silva D, Lima T, Rodrigues $P$, Leite-Moreira A, Falcão-Pires I. Mechanisms underlying the pathophysiology of heart failure with preserved ejection fraction: the tip of the iceberg. Heart Fail Rev 2021.
10. Paradies G, Paradies V, De Benedictis V, Ruggiero FM, Petrosillo G. Functional role of cardiolipin in mitochondrial bioenergetics. Biochim Biophys Acta 2014;1837:408-417.

11. Kussmaul L, Hirst J. The mechanism of superoxide production by NADH:ubiquinone oxidoreductase (complex I) from bovine heart mitochondria. Proc Natl Acad Sci U S A 2006;103:7607-7612.

12. Maranzana E, Barbero G, Falasca Al, Lenaz G, Genova ML. Mitochondrial respiratory supercomplex association limits production of reactive oxygen species from complex I. Antioxid Redox Signal 2013;19:1469-1480.

13. Schwall CT, Greenwood VL, Alder NN. The stability and activity of respiratory Complex II is cardiolipin-dependent. Biochim Biophys Acta 2012;1817:15881596.

14. Caprioli RM, Farmer TB, Gile J. Molecular imaging of biological samples: localization of peptides and proteins using MALDI-TOF MS. Anal Chem 1997;69:4751-4760.

15. Benabdellah F, Touboul D, Brunelle A, Laprevote O. In situ primary metabolites localization on a rat brain section by chemical mass spectrometry imaging. Anal Chem 2009;81:5557-5560.

16. Housaindokht MR, Moosavi-Movahedi AA, Moghadasi J, Jones MN. Interaction of glucose oxidase with ionic surfactants: a microcalorimetric study. Int $\mathrm{J}$ Biol Macromol 1993;15:337-341.

17. Nishidate $M$, Hayashi $M$, Aikawa $H$, Tanaka K, Nakada N, Miura SI, Ryu S, Higashi T, Ikarashi Y, Fujiwara Y, Hamada A. Applications of MALDI mass spectrometry imaging for pharmacokinetic studies during drug development. Drug Metab Pharmacokinet 2019;34:209-216.

18. Mezger STP, Mingels AMA, Bekers $O$, Cillero-Pastor B, Heeren RMA. Trends in mass spectrometry imaging for cardiovascular diseases. Analytical and Bioanalytical Chemistry 2019;411:37093720.

19. Wang J, Qiu S, Chen S, Xiong C, Liu H, Wang J, Zhang N, Hou J, He Q, Nie Z. 
MALDI-TOF MS Imaging of Metabolites with a $\mathrm{N}$-(1-Naphthyl) Ethylenediamine Dihydrochloride Matrix and Its Application to Colorectal Cancer Liver Metastasis. Analytical Chemistry 2015;87:422-430.

20. Kompauer M, Heiles S, Spengler B. Atmospheric pressure MALDI mass spectrometry imaging of tissues and cells at $1.4-\mu \mathrm{m}$ lateral resolution. Nature Methods 2017;14:90-96.

21. Scupakova K, Balluff B, Tressler C, Adelaja T, Heeren RMA, Glunde K, Ertaylan G. Cellular resolution in clinical MALDI mass spectrometry imaging: the latest advancements and current challenges. Clin Chem Lab Med 2020;58:914-929.

22. Des Tombe AL, Van Beek-Harmsen BJ, Lee-De Groot MB, Van Der Laarse WJ. Calibrated histochemistry applied to oxygen supply and demand in hypertrophied rat myocardium. Microsc Res Tech 2002;58:412-420.

23. Triposkiadis F, Giamouzis G, Parissis J, Starling RC, Boudoulas H, Skoularigis J, Butler J, Filippatos G. Reframing the association and significance of comorbidities in heart failure. Eur $J$ Heart Fail 2016;18:744-758.

24. Fitchett D, Inzucchi SE, Cannon CP, McGuire DK, Scirica BM, Johansen OE, Sambevski S, Kaspers S, Pfarr E, George JT, Zinman B. Empagliflozin Reduced Mortality and Hospitalization for Heart Failure Across the Spectrum of Cardiovascular Risk in the EMPA-REG OUTCOME Trial. Circulation 2019;139:1384-1395.

25. dos Santos L, Salles TA, Arruda-Junior DF, Campos LC, Pereira AC, Barreto AL, Antonio EL, Mansur AJ, Tucci PJ, Krieger JE, Girardi AC. Circulating dipeptidyl peptidase IV activity correlates with cardiac dysfunction in human and experimental heart failure. Circ Heart Fail 2013;6:1029-1038.

26. Gopal K, Chahade JJ, Kim R, Ussher JR. The Impact of Antidiabetic Therapies on Diastolic Dysfunction and Diabetic Cardiomyopathy. Front Physiol 2020;11:603247.

27. Xiao H, Ma X, Feng W, Fu Y, Lu Z, Xu M, Shen Q, Zhu Y, Zhang Y. Metformin attenuates cardiac fibrosis by inhibiting the TGFbeta1-Smad3 signalling pathway. Cardiovasc Res 2010;87:504513.

28. Shah RV, Murthy VL, Abbasi SA, Eng J, Wu C, Ouyang P, Kwong RY, Goldfine A, Bluemke DA, Lima J, Jerosch-Herold M. Weight loss and progressive left ventricular remodelling: The Multi-Ethnic Study of Atherosclerosis (MESA). Eur J Prev Cardiol 2015;22:1408-1418.

29. Fu TC, Yang NI, Wang $\mathrm{CH}$, Cherng WJ, Chou SL, Pan TL, Wang JS. Aerobic Interval Training Elicits Different Hemodynamic Adaptations Between Heart Failure Patients with Preserved and Reduced Ejection Fraction. Am J Phys Med Rehabil 2016;95:15-27.

30. Edelmann F, Gelbrich G, Dungen HD, Frohling S, Wachter R, Stahrenberg R, Binder L, Topper A, Lashki DJ, Schwarz $S$, Herrmann-Lingen C, Loffler $M$, Hasenfuss G, Halle M, Pieske B. Exercise training improves exercise capacity and diastolic function in patients with heart failure with preserved ejection fraction: results of the Ex-DHF (Exercise training in Diastolic Heart Failure) pilot study. J Am Coll Cardiol 2011;58:17801791

31. Kitzman DW, Brubaker $\mathrm{P}$, Morgan $\mathrm{T}$, Haykowsky M, Hundley G, Kraus WE, Eggebeen J, Nicklas BJ. Effect of Caloric Restriction or Aerobic Exercise Training on Peak Oxygen Consumption and Quality of Life in Obese Older Patients With Heart Failure With Preserved Ejection Fraction: A Randomized Clinical Trial. JAMA 2016;315:36-46.

32. Karamanlidis G, Nascimben L, Couper GS, Shekar PS, del Monte F, Tian R. Defective DNA replication impairs mitochondrial biogenesis in human failing hearts. Circ Res 2010;106:1541-1548.

33. Pierce JD, Mahoney DE, Hiebert JB, Thimmesch AR, Diaz FJ, Smith C, Shen Q, Mudaranthakam DP, Clancy RL. Study protocol, randomized controlled trial: reducing symptom burden in patients with heart failure with preserved ejection fraction using ubiquinol and/or Dribose. BMC Cardiovasc Disord 2018;18:57.

34. Bentinger $M$, Tekle $M$, Dallner $G$. Coenzyme Q--biosynthesis and functions. Biochem Biophys Res Commun 2010;396:74-79. 
35. van Empel VP, Bertrand AT, van Oort RJ, van der Nagel R, Engelen M, van Rijen $\mathrm{HV}$, Doevendans PA, Crijns HJ, Ackerman SL, Sluiter W, De Windt LJ. EUK-8, a superoxide dismutase and catalase mimetic, reduces cardiac oxidative stress and ameliorates pressure overload-induced heart failure in the harlequin mouse mutant. J Am Coll Cardiol 2006;48:824-832.

36. Szeto HH, Birk AV. Serendipity and the discovery of novel compounds that restore mitochondrial plasticity. Clin Pharmacol Ther 2014;96:672-683.

37. Owen MR, Doran E, Halestrap AP. Evidence that metformin exerts its antidiabetic effects through inhibition of complex 1 of the mitochondrial respiratory chain. Biochem J 2000;348 Pt 3:607-614.

38. Wang Y, An H, Liu T, Qin C, Sesaki H, Guo S, Radovick S, Hussain M, Maheshwari A, Wondisford FE, O'Rourke $\mathrm{B}, \mathrm{He}$ L. Metformin Improves Mitochondrial Respiratory Activity through Activation of AMPK. Cell Rep 2019;29:1511-1523.e1515.

39. Chakraborty C, Sharma AR, Sharma G, Lee SS. Therapeutic advances of miRNAs: A preclinical and clinical update. $J$ Adv Res 2021;28:127-138.

40. Taubel J, Hauke W, Rump S, Viereck J, Batkai S, Poetzsch J, Rode L, Weigt H, Genschel C, Lorch U, Theek C, Levin AA, Bauersachs J, Solomon SD, Thum T. Novel antisense therapy targeting microRNA-132 in patients with heart failure: results of a first-in-human Phase $1 \mathrm{~b}$ randomized, double-blind, placebocontrolled study. Eur Heart $J$ 2021;42:178-188.

41. Carrer M, Liu N, Grueter CE, Williams $\mathrm{AH}$, Frisard MI, Hulver MW, Bassel-Duby $\mathrm{R}$, Olson EN. Control of mitochondrial metabolism and systemic energy homeostasis by microRNAs 378 and 378*. Proc Natl Acad Sci $U$ S A 2012;109:15330-15335.

42. Lim LP, Lau NC, Garrett-Engele $P$, Grimson A, Schelter JM, Castle J, Bartel DP, Linsley PS, Johnson JM. Microarray analysis shows that some microRNAs downregulate large numbers of target mRNAs. Nature 2005;433:769-773.

43. Chen $\mathrm{Y}$, Zhao H, Tan Z, Zhang C, Fu X. Bottleneck limitations for microRNA- based therapeutics from bench to the bedside. Pharmazie 2015;70:147-154.

44. van Rooij E, Olson EN. MicroRNAs: powerful new regulators of heart disease and provocative therapeutic targets. $J$ Clin Invest 2007;117:2369-2376.

45. Bajan S, Hutvagner G. RNA-Based Therapeutics: From Antisense Oligonucleotides to miRNAs. Cells-Basel 2020;9.

46. Shah SJ, Katz DH, Selvaraj S, Burke MA, Yancy CW, Gheorghiade M, Bonow RO, Huang CC, Deo RC. Phenomapping for novel classification of heart failure with preserved ejection fraction. Circulation 2015;131:269-279. 

Addendum

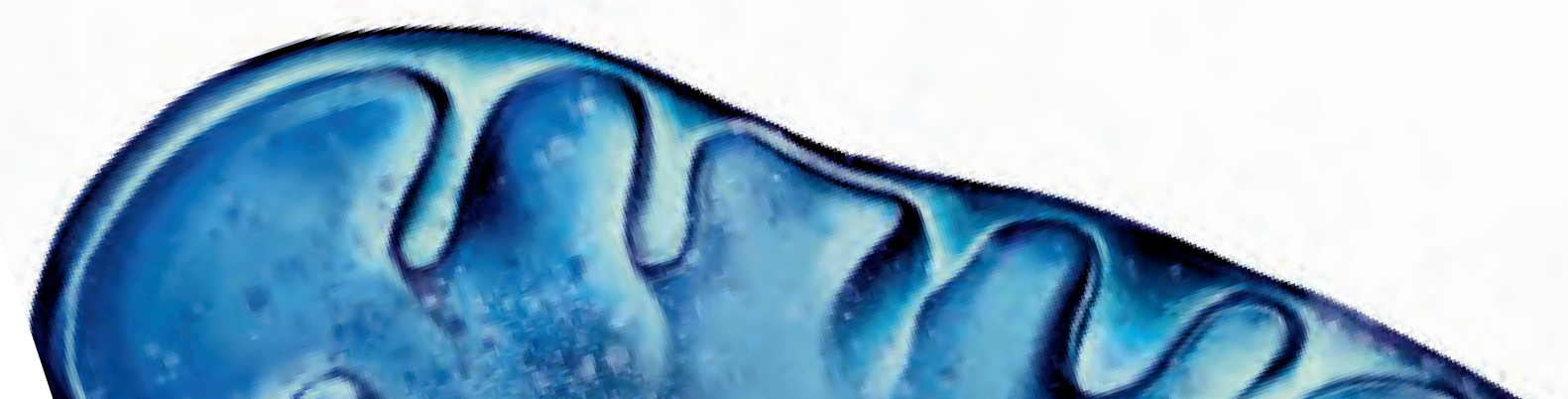




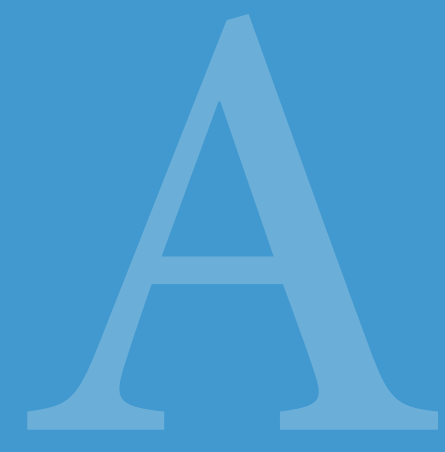

\section{Addendum}

Summary I Samenvatting I Zusammenfassung Impact

Acknowledgements About the author 



\section{Summary}

Heart failure (HF) is a global health problem of epidemic proportions currently affecting more than 37 million people and rising in prevalence. Although strides have been made to both decipher the mechanisms driving HF progression and improve treatment options, our pathophysiological understanding of this disease is still incomplete. Alterations in cardiac substrate metabolism are increasingly recognized as important contributors to cardiac disease, including heart failure with preserved ejection fraction (HFpEF), but the exact implication of metabolism in the individual cardiac cell types remains elusive and successful treatment strategies are lacking. Therefore, the main aim of this thesis is to address this knowledge gap by exploring if alterations in cardiac metabolism are involved in the pathogenesis of heart failure.

In chapter 2 we examine cardiac metabolic pathways past their role as suppliers of ATP for contraction and relaxation of the heart. To this end, we review the influence of cardiac metabolic changes on phenotype and function of different cardiac cell types and of the diseased heart and discuss how this may contribute to heart failure development.

Through network analyses, mass spectrometry imaging (MSI) and 'omics-techniques' we delve into cardiometabolic changes in MetS-induced HFpEF in the ZSF1-Obese rat. Chapter 3 describes a novel RNA-Seq based cardiome-directed network analysis approach, allowing insights into the global pathophysiological processes at play in HFpEF and highlighting mitochondrial metabolism as highly relevant and prominently altered. In chapter $\mathbf{4}$ we observe overall cardiometabolic rewiring upon HFpEF, including fatty acid-associated metabolism. Most notably, we document that MetS-associated HFpEF is strongly associated with a dysfunctional mitochondrial oxidative metabolism involving reductions in the mitochondrial phospholipid species cardiolipin, and derangements at the level of both the tricarboxylic acid cycle and the electron transport chain.

We study the influence of metabolic modulation on fibroblast activation and transdifferentiation in chapter 5. First, it is shown that the transdifferentiation of fibroblasts to myofibroblasts is associated with an increased glycolysis. Next, through drug-mediated glycolytic modulation, we document that metabolic interventions can effectively alter fibroblast phenotype and functions and also impact cytokine production by these cells. Additionally, we document distinct metabolite patterns in the fibroblast-rich infarct zone of rat hearts in acute and subacute phases of infarct healing with MSI.

The cardiac impact of inhibition of miR-103/107, regulating insulin sensitivity and glucose metabolism, is assessed in chapter 6. Our data indicate that antagomiR-103/107 affect cardiac metabolism and decrease cardiac function in otherwise healthy mice. On the cellular level, cardiomyocyte size as well as mitochondrial morphology are affected. Moreover, mitochondrial respiratory capacity and membrane potential decrease in response to miR- 
$103 / 107$ inhibition in vitro, indicating that this antagomiR has adverse effects of cardiac metabolism and function.

Chapter 7 provides a more detailed discussion of our experimental findings and expands on opportunities for further research.

In conclusion, the findings in this thesis expand the current knowledge of heart failure pathophysiology, in particular the contribution of cardiometabolic alterations in HFpEF development. We demonstrate that mitochondrial metabolism is a highly affected process in HFpEF and that cellular metabolism and phenotypical remodeling can be regarded as bidirectional processes impacting each other. These findings may aid in the development of therapeutic strategies in the future. 


\section{Samenvatting}

Hartfalen (HF) betreft meer dan 37 miljoen mensen wereldwijd en door de stijgende prevalentie is deze ziekte een ernstig volksgezondheidsprobleem. Hoewel veel onderzoek gedaan wordt om de oorzaken van hartfalenontwikkeling te ontcijferen, is onze kennis van de onderliggende pathofysiologische mechanismen niet compleet. Veranderingen in stofwisselingsprocessen van het hart worden meer en meer als belangrijke bijdragers in het ontwikkelen van hartziektes gezien, onder andere ook van hartfalen met behouden ejectiefractie (HFpEF). Het belang van het metabolisme in de individuele cel types van het hart blijft moeilijk te definiëren en beperkt daardoor behandelingsstrategieën. Het hoofddoel van deze thesis was daarom het kennisgebrek te verkleinen door veranderingen in cardiale metabolisme in de pathogenese van hartfalen te onderzoeken.

In hoofdstuk 2 bestuderen wij de belangrijke stofwisselingsroutes van het hart naast hun rol als voorzieners van ATP voor hartcontractie en relaxatie. Hierbij bediscussiëren wij de invloed van metabole veranderingen in verschillende hartceltypes op hun fenotype en functie en hoe dit tot de ontwikkeling van hartfalen zou kunnen bijdragen.

Wij onderzoeken cardiometabole veranderingen in het hart van de ZSF1-obees rat, een model van HFpEF geïnduceerd door het metabool syndroom (MetS), via beeld gevende massaspectrometrie (MSI), cardiome-gebaseerde netwerkanalyse en "omics-technieken". In hoofdstuk 3 wordt een nieuwe op RNA-Sequencing data gebaseerde netwerkanalyse beschreven die het mogelijk maakt inzicht in de belangrijke globale pathofysiologische processen in HFpEF te krijgen. Hierbij wordt mitochondriële metabolisme als belangrijke proces benadrukt. In hoofdstuk 4 herkennen wij globale metabolische veranderingen in HFpEF, onder andere lipide metabolisme. Meest opvallend lijkt MetS-geïnduceerd HFpEF geassocieerd te zijn met een verstoorde mitochondrieel oxidatieve stofwisseling met onder andere gereduceerd mitochondrieel fosfolipide cardiolipin en stoornissen in de citroenzuurcyclus en elektronen transportketen.

In hoofdstuk 5 wordt de invloed van metabole modulatie op de activatie en transdifferentiatie van hart fibroblasten bestudeerd. Wij laten zien dat fibroblast transdifferentiatie gepaard is met een verhoogde glycolyse en stellen vast dat metabole modificaties fibroblast functie en fenotype kunnen beïnvloeden. Verder documenteren wij met MSI dat de acuut en subacuut fases van infarct herstel geassocieerd zijn met duidelijk verschillende metabolieten patronen in het hart.

De invloed van miR-103/107 inhibitie in het hart wordt in hoofdstuk 6 beschreven. MiR$103 / 107$ speelt een belangrijke rol in de regulatie van insuline sensitiviteit en glucosemetabolisme. Wij documenteren dat antagomiR-103/107 in muizen het hart metabolisme verandert en tot een verminderde hartfunctie leidt. Verder wordt in vitro de 
celgrootte, mitochondriële morfologie en functie van hartspiercellen door antagomiR-103/107 beïnvloedt.

Tot slot biedt hoofdstuk 7 een uitgebreide discussie van de experimentele bevindingen en mogelijkheden voor toekomstig onderzoek.

De uitkomsten van deze thesis bouwen onze kennis over hartfalen verder uit, in het bijzonder de bijdrage van veranderingen in hart metabolisme tijdens de ontwikkeling van hartfalen. Wij laten zien dat mitochondrieel metabolisme een belangrijke rol speelt en verandert in HFpEF. Verder wijzen wij aan dat zowel cellulair metabolisme als ook fenotypische veranderingen als bidirectionele processen kunnen worden gezien die elkaar beïnvloeden. Deze vindingen kunnen als ondersteuning dienen in de ontwikkeling van toekomstige therapeutische strategieën. 


\section{Zusammenfassung}

Weltweit gibt es mehr als 37 Millionen Menschen, die mit einer Herzinsuffizienz leben. Durch unsere alternde Bevölkerung und einen suboptimalen Lebensstil wird erwartet, dass die Prävalenz von Herzinsuffizienz in Zukunft auch global weiter steigt. Trotz ausgiebiger Forschung, die Beiträge verschiedener Ursachen zur Entwicklung dieser Krankheit zu entziffern, ist unser Verständnis der zu Grunde liegenden Pathophysiologie unvollständig.

Stoffwechselveränderungen im Herzen wurden zwar schon vor einiger Zeit in Betrachtung gezogen, haben aber in den letzten Jahren mehr und mehr an Beachtung gewonnen. Sie werden als immer wichtigere Komponenten in der Pathogenese van kardiovaskulären Krankheiten angesehen, unter anderem auch in der Entwicklung von Herzinsuffizienz mit erhaltener Ejektionsfraktion (auch HFpEF genannt). Da das Herz aus verschiedenen Zelltypen besteht, bleibt es schwierig, deren individuellen Einfluss zu definieren und ebenso passende Therapien zu entwickeln. Dadurch war das Hauptziel dieser Dissertation, Veränderungen im kardiometabolen Stoffwechsel während der Entwicklung von Herzinsuffizienz zu untersuchen und dadurch Wissenslücken zu schließen.

Im Anschluss an die allgemeine Einleitung behandelt Kapitel 2 die verschiedenen kardialen Stoffwechselrouten über ihre Rolle als Quellen von ATP für die kontinuierliche Kontraktion des Herzens hinaus. Dabei wird der Einfluss von kardiometabolen Veränderungen auf Phänotyp und Funktion der einzelnen Zelltypen des Herzens untersucht und daraufhin diskutiert, inwiefern diese Veränderung zur Herzinsuffizienzentwicklung beitragen könnten.

In den beiden nachfolgenden Kapiteln werden kardiometabole Veränderungen im Herzen mithilfe von bildgebender Massenspektrometrie (MSI), cardiome-basierter und bioinformatischer Netzwerkanalyse, sowie verschiedenen „Omics-Techniken“ erforscht. Die ZSF1-adipöse Ratte dient dabei als ein Modell für HFpEF, hervorgerufen durch das metabole Syndrom (MetS). In Kapitel 3 wird eine neuartige Netzwerkanalyse für kardiovaskuläre RNASequenzierungsdaten beschrieben, welche es möglich macht, die wichtigsten pathophysiologischen Prozesse der HFpEF Entwicklung zu begutachten. Hierbei werden vor allem mitochondriale Stoffwechselprozesse als relevant und verändert hervorgehoben. In Kapitel 4 liegt der Fokus auf der Beobachtung von zentralen Veränderungen im Stoffwechsel der ZSF1-adipösen Ratte, unter anderem im Bereich des Fettstoffwechsels. Besonders bemerkenswert ist es, dass MetS-induzierte HFpEF stark mit dysfunktionalem oxidativem Stoffwechsel in den Mitochondrien verbunden zu sein scheint. Einschließlich fallen die geringere Anwesenheit des Phospholipids Cardiolipin sowie Störungen im Citratzyklus und der Elektronentransportkette auf.

Kapitel $\mathbf{5}$ beschäftigt sich mit dem Einfluss von Stoffwechselmodifikationen auf die Aktivierung und Transdifferenzierung von kardialen Fibroblasten. Zunächst wird gezeigt, dass Transdifferenzierung vom Fibroblasten zum Myofibroblasten mit verstärkter Glykolyse 
verbunden ist. Außerdem lässt sich erkennen, dass metabolische Interventionen effektiv in den Phänotyp und die Funktion von Fibroblasten eingreifen und diese anpassen können, beispielsweise in Form von veränderter Zytokinproduktion. Mithilfe von MSI wird die fibroblastreiche Infarktzone in einem Herzinfarkt-Rattenmodell in den akuten und subakuten Infarktphasen untersucht und herausgestellt, dass diese Bereiche in den verschiedenen Infarktphasen distinkte metabolische Profile aufweisen.

Im Rahmen von Kapitel 6 wird der Einfluss von miRNA-103/107-Inhibition auf das Herz beschrieben. MiRNA-103/107 reguliert Insulinsensitivität und den Stoffwechsel von Glukose. Die Resultate weisen auf, dass die Inhibition von miRNA-103/107 den Stoffwechsel des Herzens nachhaltig beeinflusst und die Herzfunktion von anderweitig gesunden Mäusen reduzieren kann. Auf Zellebene sind die Größe von Herzmuskelzellen sowie deren mitochondriale Morphologie verändert. Außerdem machen in vitro Zellexperimente deutlich, dass die Atemkapazität und das Membranpotential von Mitochondrien in Herzmuskelzellen reduziert sind, wenn miRNA-103/107 blockiert wird. Diese Ergebnisse deuten an, dass die Inhibition der miRNA mithilfe von antagomiRs negative Effekte auf den Stoffwechsel und die Funktion des Herzens hat.

Abschließend bietet Kapitel 7 eine detaillierte Diskussion der experimentellen Erkenntnisse und führt Möglichkeiten zukünftiger Forschung weiter aus.

Zusammenfassend lässt sich sagen, dass die Erkenntnisse dieser Dissertation unseren aktuellen Wissenstand von der Pathophysiologie der Herzinsuffizienz erweitern, vor allem im Bereich des Anteils von kardiometabolischen Änderungen während der HFpEF Entwicklung. Dabei wird deutlich, dass der mitochondriale Stoffwechsel in HFpEF stark beeinflusst wird und dass Zellstoffwechsel und phänotypische Umgestaltung als einander modulierende, bidirektionale Prozesse gesehen werden können. Diese Feststellungen können dazu beitragen, zukünftig adäquate therapeutische Strategien zu entwickeln. 




\section{Impact}

\section{Research}

Cardiovascular disease (CVD) represents a major cause of mortality, accounting for $45 \%$ of all deaths within Europe in 2019. ${ }^{1}$ Costs associated with CVD for the European Union are estimated to sum up to more than $200 €$ billion per year, constituting a considerable socioeconomic burden, which is only expected to increase in the future. ${ }^{1}$ In a similar fashion, due to increased ageing of the population, the prevalence of heart failure is expected to increase as well. ${ }^{2}$ Around $50 \%$ of all heart failure patients suffer from heart failure with preserved ejection fraction (HFpEF), which is characterized by impaired relaxation or filling of the left ventricle, leading to diastolic dysfunction. The prognosis of HFpEF is poor and HFpEF patients suffer from a variety of symptoms, such as exercise intolerance, dyspnoea and fatigue, leading to frequent hospital (re)admissions and a significantly reduced quality of life. HFpEF patients and people at risk for HFpEF often also have comorbidities such as chronic kidney disease, hypertension, hyperlipidaemia, type 2 diabetes, and obesity. ${ }^{3}$ These metabolic comorbidities compile the metabolic syndrome and are accompanied by chronic low-grade inflammation and an altered systemic metabolism. ${ }^{4}$ Cardiometabolic alterations are increasingly recognized as contributing factors in HFpEF development, but the details of this process are not quite clear yet. Fundamental research is therefore needed to unravel the exact nature of both the intra- and extracardiac metabolic disturbances and to design adequate treatment strategies for HFpEF.

Our main objective for this thesis was to strengthen our understanding of cardiometabolic alterations in cardiac pathophysiology with an emphasis on HFpEF. We successfully added to the current knowledge and demonstrated that mitochondrial oxidative metabolism and fatty acid metabolism are highly affected and possibly mismatched processes in HFpEF. Additionally, as evidenced by metabolic modulation of cardiac fibroblasts, we documented that cellular metabolism and phenotypical remodeling can be regarded as bidirectional processes impacting each other, providing new avenues of investigation for treatment strategies.

\section{Relevance}

In this thesis, we used both novel and underutilized analytical techniques to investigate the underlying processes in the pathophysiology of cardiac diseases, which can be of interest to other researchers separately from the results and conclusions we derived.

In chapter 3, we presented a novel approach for cardiome-directed network analysis of RNASequencing datasets. This methodology can be directly utilized for the analysis of other cardiac disease-based datasets but can also be modified and used for other pathologies or tissues to identify relevant processes and transcripts.

A rather underutilized technique in cardiovascular research is mass spectrometry imaging (MSI), which we applied in chapter 4 and $\mathbf{5}$. We demonstrated that MALDI-MSI can reveal distinct metabolite patterns both in preclinical models of HFpEF and myocardial infarction, and 
can therefore aid in the detection of different classes of biomolecules in other cardiac disease models as well. It will be interesting to explore if MSI can also be applied to cardiac biopsies from patients suffering from cardiac disease.

Furthermore, as we demonstrated in chapter $\mathbf{5}$, it can be worthwhile to take results from other research specialties into consideration. The principle of metabolic rewiring as a determinant of cellular function and phenotype is more commonly considered in cancer and immunology research. We demonstrated, as a proof of principle, that this mechanism is also relevant in cardiac research and appears applicable in cardiac fibroblasts.

\section{Target groups and activities}

To make our results accessible to the wider scientific and medical community, parts of this thesis have been submitted and published online in international, peer-reviewed journals, some of which in open-access format. The yet unpublished chapters will be submitted similarly in the upcoming time. The conducted research has also been presented at (inter)national meetings and conferences.

Although at this stage the results of this thesis are not directly translatable into new treatment strategies, they are essential as steppingstones, providing new mechanistic concepts and opportunities to investigate and devise therapies for HFpEF treatment and prevention. Our results substantiate the assumption that "lifestyle diseases" such as diabetes and obesity, directly impact the heart and contribute to the development of HFpEF. Metabolic interventions should therefore be considered as complementary therapy for HFpEF treatment and prevention. The altered substrate availability in obesity and diabetes also invites considerations into possible effects of nutrition, in general, and specific dietary supplements, in particular, on cardiac disease development. The HFpEF-afflicted heart is commonly regarded as metabolically inflexible, partially due to insulin resistance, and thereby likely unable to deal with excess fuel availability. This will result in cardiac lipotoxicity, oxidative stress and local inflammation, all mechanisms that will impact cardiac function. ${ }^{5}$ Close collaboration between preclinical and clinical researchers, including cardiologists and endocrinologists, can contribute towards the development of successful treatments which will reduce HFpEF morbidity and mortality and benefit patients, ultimately the most important target group.

Improving scientific communication to generate interest for cardiovascular research in the general public, is increasingly recognized as an important endeavour and can benefit researchers as well, generating visibility and public support. In an effort to connect with the public and communicate our research, aspects of heart failure research from our group have been presented to heart failure patients, their relatives, as well as people generally interested in heart failure research during a hospital experience day among others. 


\section{References}

1. Timmis A, Townsend N, Gale CP, Torbica A, Lettino M, Petersen SE, Mossialos EA, Maggioni AP, Kazakiewicz D, May HT, De Smedt D, Flather M, Zuhlke L, Beltrame JF, Huculeci R, Tavazzi L, Hindricks G, Bax J, Casadei B, Achenbach S, Wright L, Vardas P, European Society of C. European Society of Cardiology: Cardiovascular Disease Statistics 2019. Eur Heart J 2020;41:12-85.

2. Ponikowski $\mathrm{P}$, Anker SD, AlHabib KF, Cowie MR, Force TL, Hu S, Jaarsma T, Krum H, Rastogi V, Rohde LE, Samal UC, Shimokawa H, Budi Siswanto B, Sliwa K, Filippatos G. Heart failure: preventing disease and death worldwide. ESC Heart Fail 2014;1:4-25.

3. Savji N, Meijers WC, Bartz TM, Bhambhani V, Cushman M, Nayor M, Kizer JR, Sarma A, Blaha MJ, Gansevoort RT, Gardin JM, Hillege HL, Ji F, Kop WJ, Lau ES, Lee DS, Sadreyev R, van Gilst WH, Wang TJ, Zanni MV, Vasan RS, Allen NB, Psaty $B M$, van der Harst $P$, Levy D, Larson M, Shah SJ, de Boer RA, Gottdiener JS, Ho JE. The Association of Obesity and Cardiometabolic Traits With Incident HFpEF and HFrEF. JACC: Heart Failure 2018;6:701-709.

4. Grundy SM. Metabolic syndrome pandemic. Arterioscler Thromb Vasc Biol 2008;28:629-636.

5. Mishra S, Kass DA. Cellular and molecular pathobiology of heart failure with preserved ejection fraction. Nat Rev Cardiol 2021;18:400-423. 

First and foremost, I would like to thank Prof. Dr. Blanche Schroen and Dr. Marc van Bilsen, my promotion team. Blanche, ik leerde je tijdens het sollicitatiegesprek voor mijn masterstage kennen en was meteen onder de indruk van je vriendelijke, open manier en je enorme kennis. Bedankt voor al je hulp bij het bediscussiëren van resultaten, plannen en schrijven van het boekje! Marc, tijdens de afgelopen jaren stond je deur altijd voor mij open. De leerzame kritiek en je rust en geduld in de dagelijkse begeleiding droegen altijd bij om kritisch te blijven en mezelf verder als onderzoeker te ontwikkelen. Heel erg bedankt voor jullie constante ondersteuning.

I would also like to sincerely thank my assessment committee for taking the time to read and evaluate my thesis: Prof. dr. Leon Schurgers, Dr. Ebba Brakenhielm, Prof. dr. Christoph Maack, Prof. dr. Judith Sluimer and Dr. Sander Verheule.

The work of these last years would not have been nearly as successful, efficient or enjoyable, if not for my colleagues.

Rick en Wouter, jullie zijn de ruggengraat van het lab en hebben me vaak geholpen om nieuwe ideeën uit te testen. Wouter, wij waren vanaf het begin van mijn $\mathrm{PhD}$ kamergenoten en het was altijd erg gezellig. Hoewel veel van onze ideeën over diverse projecten later toch niet tot staat kwamen, heb ik veel geleerd en blijf altijd geïnspireerd van jouw creativiteit binnen en buiten het lab. Rick, niemand kan westerns en ELISAs beter uitvoeren en niemand kan zo goed iedereen motiveren om op tijd te gaan lunchen! Of het nu over "but does it bring you joy?", edelstenen, Italiaanse wijn en vakanties, bitcoins of gamestop aandelen ging - met jullie was er altijd iets nieuws te bespreken.

Monika, you taught me a lot about efficient lab work and always staying motivated. I am glad I got the opportunity to join in finishing up the 103/107 project first as a student and later during the PhD. I'm sure you'll stay just as successful in your industry career, and I wish you all the best! Steffie, je was mijn tweede kamergenoot en partner voor de veel benodigde koffiepauzes. Met jou was er altijd veel te praten en lachen. Bedankt voor alle hulp en heel veel geluk met je gezin en carrière! Robin, door je Postdoc was je de laatste van de "oude PhDs" op het lab en hebt mij veel geholpen. Je bent enorm gemotiveerd in alles waar je je focus op legt, heel veel succes voor je toekomst!

Ilona, of in Leuven, Maastricht, Pamplona of bij Bayer in Wuppertal was het altijd zo gezellig om met je samen te werken, cursussen bij te wonen of gewoon buiten de zon te genieten en even een beetje over koffie te praten. Je was altijd in om te helpen en je hebt zelfs stalen via trein in James Bond style aan mij geleverd - bedankt ervoor. Ik ben erg blij dat je als paranimf aan mijn zijde gaat staan en ben zo benieuwd wat je nog alles gaat bereiken met je nieuwe industrie carrière!

Georg, I always enjoyed your relaxed attitude and working with you on the network analysis project was a great experience. Quentin, although we haven't seen each other that often it was always nice seeing you again. Best of luck with your new job! Emma, it was great working with you. Best of luck in the States! 
Many thanks to the clinical colleagues of the cardio lab led by Stephane - your office is always the liveliest on the whole floor: Mark, Jort, Job, Arantxa, Michiel, Anne, Jerremy, Sophie and Maurits, thanks for great conversations and good luck with your future careers and time left for your PhDs.

I would also like to acknowledge the colleagues from the "extended" cardio lab: Paul, Leon, Paula and Martina, as well as Mora, Nicole, Christina, Andrea, Lara, Beatrice, Federica, Indira, Nicolo, Zenab, Claudia, Raquel, Vasco, Jana, Robin, Jordy and the newer members. Roel, Serve and Sandrine thanks for offering great advice.

Iram, it was great having you here in Maastricht, working together and talking about our lives during the quieter periods. I wish you all the best with the remainder of your PhD and your future career. I'd like to thank my interns Horia, Demi and Pip for your interest and effort, be it in the lab or remote during COVID times. l've thoroughly enjoyed working with you and wish you the best for your future careers.

Miranda and Yilin, thank you for the inspiring discussions about the Seahorse assays and cellular metabolism.

Barbara, Lilian en Ingrid, erg bedankt voor jullie hulp bij alle dingen de afgelopen jaren. Het was altijd gezellig bij jullie op kantoor. Lilian, speciaal bedankt voor alle advies in de laatste maanden rondom mijn $\mathrm{PhD}$.

I would also like to thank all my colleagues from the Physiology department. Bianca, Vivian en Jolanda, ook bij jullie kon ik altijd langskomen met allerlei vragen en probleempjes. Of diner, dagje-uit of kerstborrels - het was heerlijk om erbij te zijn. Chantal, van jou heb ik veel over de hartfibroblasten mogen leren en zonder jou inzet zou nooit zo veel experimenteel data in het fibroblast hoofdstuk zitten. Bedankt ervoor!

Frans, hartelijk bedankt voor je waardevolle opmerkingen bij het fibroblast project. Meike, veel dank voor je hulp rondom de fibroblasten isolaties. Het was altijd leuk om met je samen op lab te werken. Ook dank aan alle PhD Studenten en andere medewerkers voor de gezellige uitjes en diners met de groep.

During my PhD I have gotten the opportunity to work with and learn from many different collaborators.

Thanks to all the members of the ERA-CVD team for their help. Elizabeth, Paolo and Steven, thank you for your help and always making me feel welcome when visiting Leuven. I would also like to thank the collaborators from Porto, Inês Falcão-Pires and colleagues for their work for the network analysis project. Paul Mulder, thank you for all your help with the myocardial infarct model and it would have been great to visit Rouen and eat some Camembert! I'd like to thank the M4I Mass Spectrometry department. Berta, thank you for always organizing help and training for me at the M4I. Benjamin and Ronny thanks for your guidance. Stephanie, het was heel mooi om samen te werken en tips en tricks van jou te leren - bedankt ervoor! Klara, Maxime, Florian and Britt, thank you for taking time during your $\mathrm{PhD}$ to show me how to work with all the different machines. Many thanks to the M4I 
Microscopy core lab for the electron microscopy and live cell imaging support. Kevin, you taught me all about live cell imaging experiments and even got me introduced to Matlab thanks a lot for that!

Meine Gruppe aus Düren: Esa, Anna und Gina - ich bin so froh, dass wir immer noch die Zeit finden, uns zu sehen. Die gemeinsamen Spaziergänge, Yoga-Challenges und Abende in der Stadt haben mir immer viel Spaß gemacht. Vielen Dank dafür!

Als letztes möchte ich meiner Familie danken. Ohne eure Unterstützung wäre die Promotion überhaupt nicht möglich gewesen. Mama und Papa, ihr habt mich schon immer darin unterstützt, meine Träume zu erfüllen und bei allen Problemen eine Lösung finden. Durch euch weiß ich, dass es sich lohnt, Ziele vor Augen zu haben und immer am Ball zu bleiben. Mama, bei dir und Jochen kann ich immer auf ein offenes Ohr zählen. Ich möchte die Sonntage mit leckerem Essen und viel Gequatsche der letzten Jahre wirklich nicht missen. Dank euch konnte ich den Großteil der Doktorarbeit fast wunschlos glücklich schreiben. Csilla - mau - vielen Dank für die Hilfe beim Layout und Cover - ich hätte mir kein schöneres Design wünschen können. Wenn mal wieder was nicht so läuft wie geplant und ich „meine Bakterien“ umsonst gefüttert habe, kann ich mich immer wunderbar bei dir beschweren. Vielen Dank an Uwe und Ingrid, euer Interesse an meiner Promotion hat mich immer motiviert. Oma Marianne, vielen Dank für alle Unterstützung. Regula, meine zweite Paranymphe, ich könnte mir keine wundervollere Schwester wünschen. Ich bin so froh, dass du auch in Maastricht gelandet bist (und hier erstmal bleibst) und wir uns immer noch so häufig sehen.

Daniel, du hast die letzten Jahre immer an meiner Seite gestanden. Du hast mir zugehört, mich motiviert und auch mal beruhigt, wenn alles frustrierend war. Egal wo wir sind, bei dir fühle ich mich immer zu Hause und mit niemandem kann ich mehr lachen als mit dir. Danke für all die wundervollen Zeiten über die letzten Jahre. Ich freue mich schon auf die nächsten!

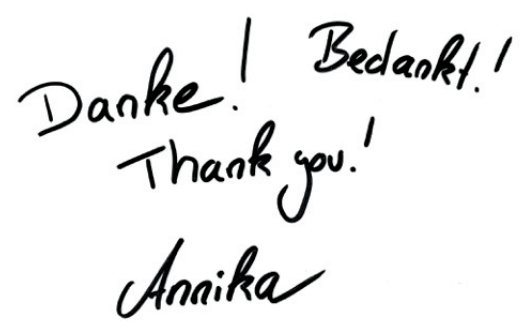





\begin{abstract}
About the author
Annika-Ricarda Kuhn was born on the $30^{\text {th }}$ of March 1993 in Lutherstadt-Wittenberg, Germany. In 2012, she started studying Biomedical Sciences at Maastricht University. She obtained her Biomedical Sciences BSc degree with a specialization in molecular life sciences in 2015, after interning in the orthopedic research department of the RWTH Aachen University Hospital, where she also worked as a student research assistant, studying the role of microenvironmental stimuli on BMSC differentiation and obtained a co-authorship publication from this work. She continued her studies at Maastricht University from 2015 onwards. During this time, she interned at the Bionanotechnology research group of the BIOMED institute at Hasselt University in Belgium, where she first came into closer contact with cardiovascular research and investigated microRNAs in a cell model of endothelial dysfunction. Subsequently, she joined the group of Prof Blanche Schroen in 2016 for her senior internship and further focused on microRNAs and their roles in cardiac metabolism. She obtained her MSc degree in Biomedical Sciences from Maastricht University in 2017. Afterwards she rejoined the group in August 2017 as a PhD student under supervision of Dr Marc van Bilsen and Prof Blanche Schroen, to investigate alterations in cardiac metabolism in the pathogenesis of heart failure. She presented her work at multiple conferences, such as the Dutch heart foundation training course on cardiac function and adaptation in 2017, as well as the HFA Winter Meeting on Translational Heart Failure Research in 2019.
\end{abstract}


